\title{
Semivolatile Organic (GC-MS) and Inorganic Analyses of Groundwater Samples During the Hydrous Pyrolysis/Oxidation (HPO) Field Test in Visalia, California, 1997
}

\author{
Roald N. Leif, Marina Chiarappa, Gene Kumamoto, Roger D. Aines, \\ Robin L. Newmark, and Kevin G. Knauss
}

February 5, 1998

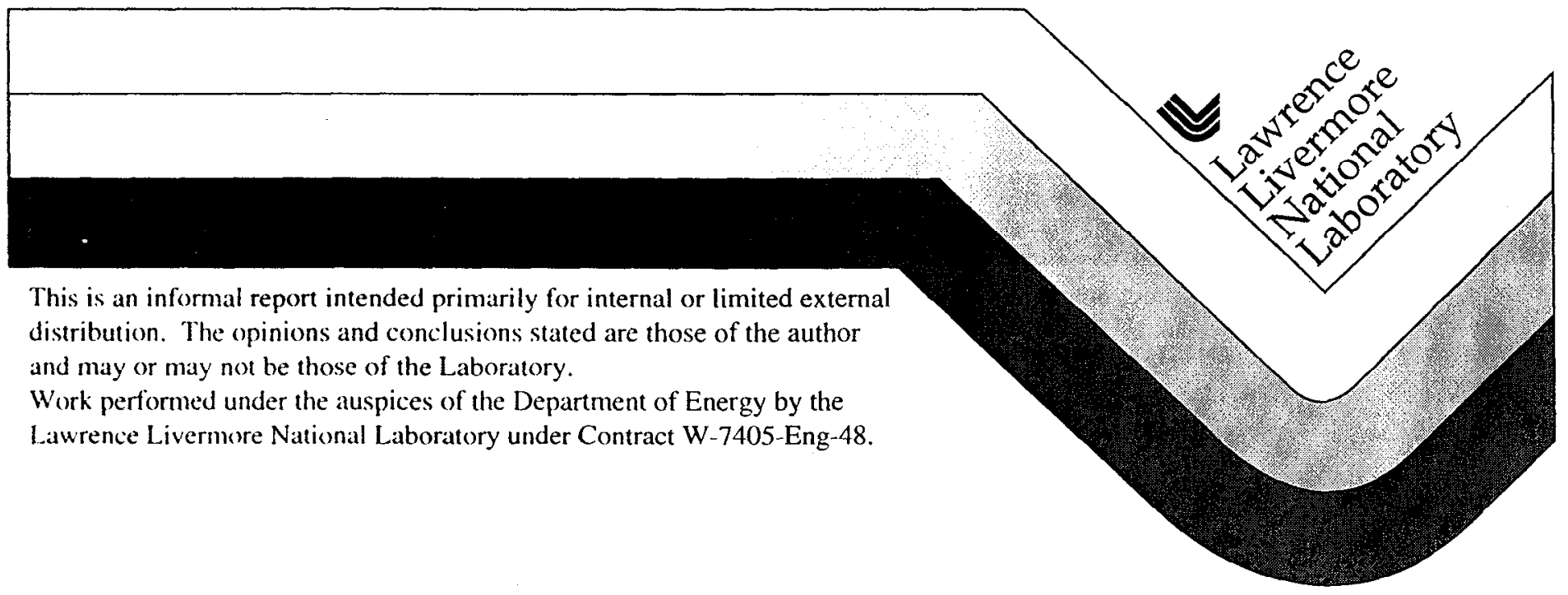


This document was prepared as an account of work sponsored by an agency of the United States Government. Neither the United States Government nor the University of California nor any of their employees, makes any warranty, express or implied, or assumes any legal liability or rosponsibility for the accuracy, completeness, or usefulness of any information, apparatus, product, or process disclosed, or represents that its use would not infringe privately owned rights. Reference herein to any specific commercial product, process, or service by trade name, trademark, manufacturer, or otherwise, does not necessarily constitute or imply its endorsement, recommendation, or favoring by the United States Government or the University of California. The views and opinions of authors expressed herein do not necessarily state or reflect those of the United States Government or the University of California, and shall not be used for advertising or product endorsement purposes. 
Semivolatile Organic (GC-MS) and Inorganic Analyses of Groundwater Samples

During the Hydrous Pyrolysis/Oxidation (HPO)

Field Test in Visalia, California, 1997

\author{
Roald N. Leif \\ Marina Chiarappa \\ Gene Kumamoto \\ Roger D. Aines \\ Robin L. Newmark \\ Kevin G. Knauss
}

February 5, 1998

v 2.1

Lawrence Livermore National Laboratory

Livermore, California 


\section{Contents}

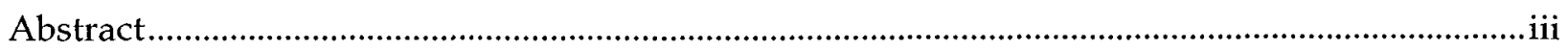

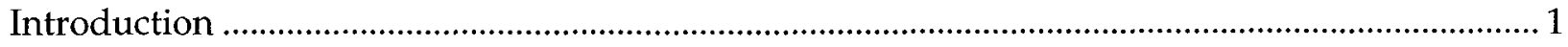

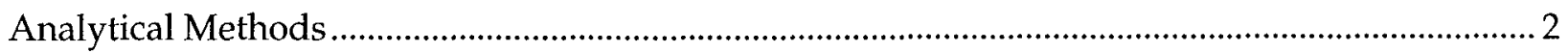

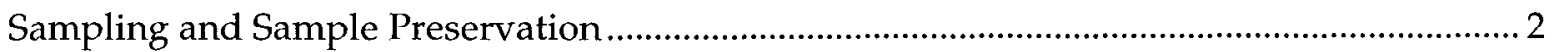

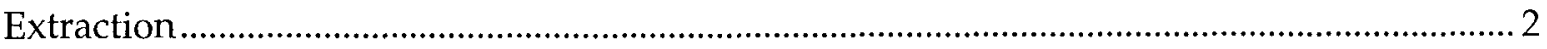

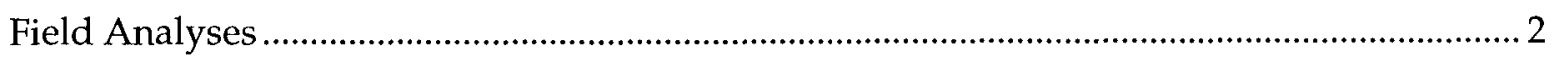

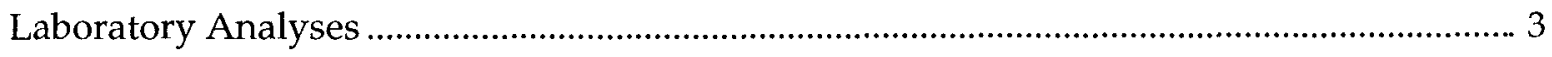

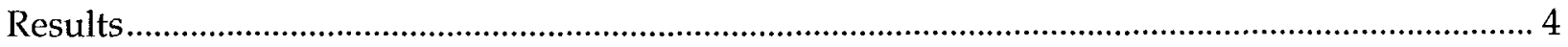

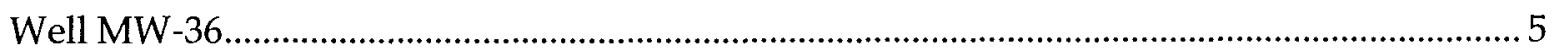

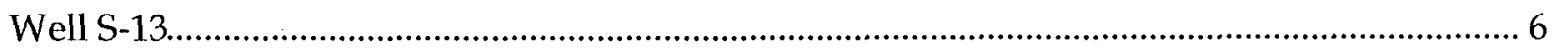

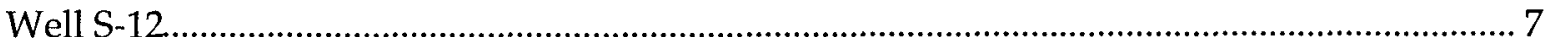

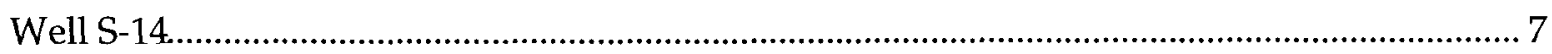

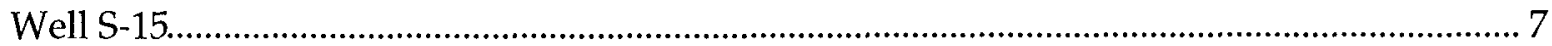

Miscellaneous Wells (MW-41, MW-44, EW-1, EW-2, EW-3, EW-5) ........................................ 8

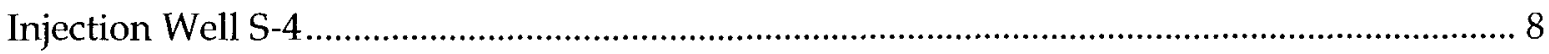

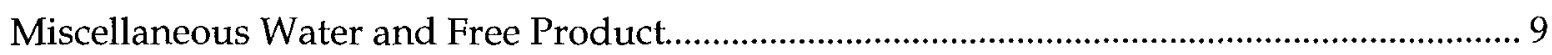

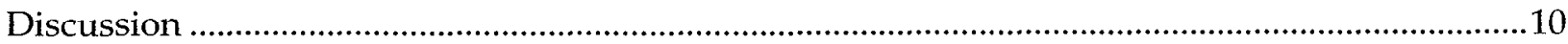

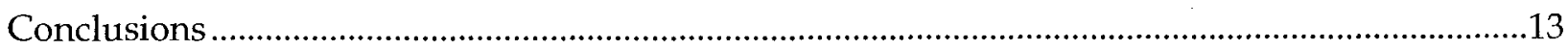

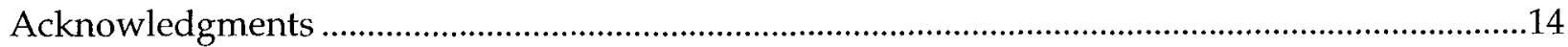

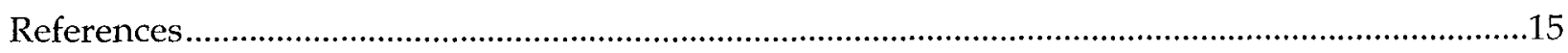

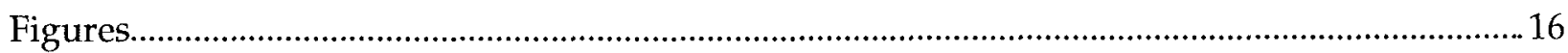

Appendix A: Chemical Structure Diagrams for the Semivolatile Organic Compounds

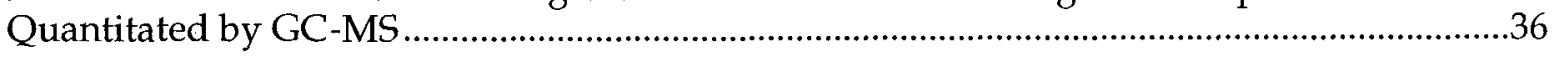

Appendix B: Tables of Analytical Results of Samples ......................................................................4 40 


\section{Acronyms and Abbreviations}

$\begin{array}{ll}\text { DAFT } & \text { dissolved-air flotation tank } \\ \text { DIC } & \text { dissolved inorganic carbon } \\ \text { DNAPL } & \text { dense, nonaqueous-phase liquid } \\ \text { DUS } & \text { dynamic underground stripping } \\ \text { EPA } & \text { U.S. Environmental Protection Agency } \\ \text { EW } & \text { extraction well } \\ \text { FID } & \text { flame ionization detector } \\ \text { GC-MS } & \text { gas chromatography-mass spectrometry } \\ \text { HPO } & \text { hydrous pyrolosis/oxidation } \\ \text { i.d. } & \text { internal diameter } \\ \text { LLNL } & \text { Lawrence Livermore National Laboratory } \\ \text { LNAPL } & \text { light, nonaqueous-phase liquid } \\ \text { MW } & \text { monitoring well } \\ \text { PAH } & \text { polycyclic aromatic hydrocarbons } \\ \text { RIC } & \text { reconstructed ion chromatogram } \\ \text { SPE } & \text { solid-phase extraction } \\ \text { TIC } & \text { total inorganic carbon } \\ \text { UCM } & \text { unresolved complex mixture }\end{array}$




\begin{abstract}
Hydrous pyrolysis/oxidation (HPO) is a novel, in situ, thermal-remediation technology that uses hot, oxygenated groundwater to completely oxidize a wide range of organic pollutants. A field demonstration of HPO was performed during the summer of 1997 at the Southern California Edison Pole Yard in Visalia, California, a site contaminated with creosote. The goal of the field experiment was to confirm the success of HPO under field remediation conditions. The groundwater was heated by steam injections, and oxygen was added by co-injection of compressed air. The progress of the HPO remediation process was evaluated by monitoring groundwater from multiple wells for dissolved oxygen, dissolved inorganic carbon, and dissolved organic contaminant levels.

Analyses of groundwater chemistry allowed us to measure the concentrations of creosole components and to identify oxygenated intermediates produced by the HPO treatment. Dissolved organic carbon levels increased in response to steam injections because of the enhanced dissolution and mobilization of the creosote into the heated groundwater. Elevated concentrations of phenols and benzoic acid were measured in wells affected by the steam injections. Concentrations of other oxygenated compounds (i.e., fluorenone, anthrone, and 9,10-anthracenedione) increased in response to the steam injections. The production of these partially oxidized compounds is consistent with the aqueous-phase HPO reactions of creosote.

Additional changes in the groundwater in response to steam injection were also consistent with the groundwater HPO chemistry. A drop in dissolved oxygen was observed in the aquifer targeted for the steam injections, and isotope shifts in the dissolved inorganic pool reflected the input of oxidized carbon derived from the creosote carbon.
\end{abstract}




\section{Introduction}

The 4.3-acre Southern California Edison Pole Yard in Visalia, California, operated for 80 years as a wood preservation treatment facility. Because of this operation, this site is contaminated with a dense, nonaqueous-phase liquid (DNAPL) mixture composed of pole-treating creosote and an oil-based carrier fluid containing pentachlorophenol. After the site was placed on the EPA Superfund list in 1977, pump and treat technology was deployed to reduce and contain the contaminant plume. Over nearly 20 years, an estimated $10,000 \mathrm{lb}$ of contaminant were removed from the soil and groundwater.

In the summer of 1997 Southern California Edison began the application of two thermally cnhanced remediation technologies to accelerate the clean-up. The first method, dynamic underground stripping (DUS), involves steam injection coupled with vacuum extraction to enhance the mobilization and removal of free product (Newmark and Aines, 1995). The second method, hydrous pyrolysis/oxidation (HPO), is a novel, in situ, thermal-remediation technology that uses hot, oxygenated groundwater to destroy organic contaminants by completely oxidizing the organic pollutants to carbon dioxide. The supplemental oxygen is delivered in the form of injected air. HPO is needed to destroy the residual DNAPL components not readily removed by the DUS process.

Initial laboratory-based feasibility experiments have been conducted to investigate the HPO of actual DNAPL material with excess dissolved $\mathrm{O}_{2}$ under conditions similar to those achievable during thermal-remediation (Knauss et al., 1998a; Leif et al., 1998). These experiments demonstrated that dissolved $\mathrm{O}_{2}$ readily reacts with the compounds present in the DNAPL creosote mixture to form products ranging from partially oxidized intermediates, such as phenols and benzoic acid (Figure 1), to the fully oxidized product $\mathrm{CO}_{2}$ (Figure 2 ).

Field implementation of HPO remediation at the Southern California Edison Pole Yard site was initiated in May 1997 using 11 steam injection wells encircling the creosote DNAPL pool (Figure 3). The lithology is shown in Figure 4 and consists of three aquifers. The shallow aquifer (approx. 35-70 ft below ground surface) and the intermediate aquifer (approx. 75-102 ft below ground surface) are bolh contaminated with DNAPL. The intermediate aquifer was targeted for the HPO field demonstration.

The focus of the Lawrence Livermore National Laboratory (LLNL) field demonstration effort was steam-injection Well S-4. This well was used for the HPO demonstration, and groundwater chemistry ( $\mathrm{pH}$, total inorganic carbon, dissolved oxygen, anions, cations, and organic semivolatile compounds) was monitored at Wells MW-36 (approximately $80 \mathrm{ft}$ away) and S-13 (approximately $95 \mathrm{ft}$ away). Several additional wells were also monitored periodically for groundwater chemistry. This report concentrates on the results of the semivolatile organic compounds extracted from the groundwater by solid-phase extraction (SPE) and identified and quantitated by gas chromatography-mass spectrometry (GC-MS). 

$-$ 


\section{Analytical Methods}

\section{Sampling and Sample Preservation}

Water samples for inorganic and organic analyses were taken at several monitoring and extraction wells on the Southern California Edison Pole Yard complex. Each sampling event involved collecting water samples for both inorganic and organic analyses. Water samples were collected in the following sample containers: water samples for $\mathrm{pH}$ were collected in certified 40-mL VOA vials (I-Chem) and filled to eliminate any headspace; samples for total inorganic carbon (TIC) and anions were collected in 4-mL screw-cap vials and filled to eliminate any headspace; water for cations were collected in $500-\mathrm{mL}$ Nalgene bottles (high density polyethylene with polypropylene screw closure); water samples for semivolatile organic analyses by extraction and concentration using SPE cartridges were taken in certified clean 1-liter borosilicate amber bottles with Teflon ${ }^{\mathrm{TM}}$ lined caps; water samples for field liquid-liquid extraction were collected in $500-\mathrm{mL}$ volumetric flasks. Samples for cation analysis were acidified to $\mathrm{pH}<2$ with concentrated nitric acid, and water samples for both SPE extraction and field liquid-liquid extraction were acidified to $\mathrm{pH}<2$ with hydrochloric acid. An attempt was made to keep samples refrigerated until analysis.

\section{Extraction}

Liquid-Liquid Extraction. Water samples taken in the $500-\mathrm{mL}$ volumetric flasks were allowed to come to ambient temperature and volume adjusted to $500 \mathrm{~mL}$. To this flask was added $2.0 \mathrm{~mL}$ of hexane containing an internal standard (2-bromonaphthalene at $200 \mu \mathrm{g} / \mathrm{mL}$ ), and the flask was inverted several times and shaken for a duration of 1 minute to standardize the field extraction method.

Solid-Phase Extraction (SPE). Priority pollutants were extracted and concentrated by SPE prior to analysis by GC and GC-MS. Typically a water sample ranging in volume from 1 to 4 liters was flowed by positive pressure through an SPE cartridge packed with $200 \mathrm{mg}$ of ENV + (International Sorbent Technology), a highly crosslinked styrenedivinylbenzene resin suitable for extraction of nonpolar and polar compounds from water. After sample extraction, the SPE tubes were dried and eluted with $4.5 \mathrm{~mL}$ of a dichloromethane/isopropanol mixture (1:1). Sample bottles were also eluted with this solvent mix (1:1) to extract organic compounds adsorbed to the glass. All extracts were spiked with a six-component internal-standard mix.

\section{Field Analyses}

Measurement of $\mathrm{pH}$. The water samples taken for $\mathrm{pH}$ were allowed to come to ambient temperature before analysis. The measurement of $\mathrm{pH}$ was performed using a Sentron $2001 \mathrm{pH}$ meter employing a hydrogen-ion-sensitive ion-selective field effect transistor (ISFET) with automatic temperature compensation. Calibration of the meter was done at the beginning of each day using $\mathrm{pH}$ standard solutions ( $\mathrm{pH} 4$ and $\mathrm{pH} 7$ ) and checked before each measurement using the $\mathrm{pH} 7$ buffer solution.

Gas Chromatography. Field measurements of the total organic hexane extract were performed on an SRI 9300 gas chromatograph, equipped with a flame ionization detector (FID) in tandem with a dry clectrolytic conductivity detector (ELCD). Compounds were injected on-column and separated on an MXT-5 Restek 15-m mega- 
bore $\left(0.53 \mathrm{~mm}\right.$ i.d.) capillary column. 'l'he temperature was programmed from $40^{\circ} \mathrm{C}$ (initial hold time $1.0 \mathrm{~min}$ ) to $200^{\circ} \mathrm{C}$ at $10^{\circ} \mathrm{C} / \mathrm{min}$. Helium was used as the carrier gas. Data were acquired and integrated using SRI PeakSimple software. Quantitation for total organic carbon for components amenable to gas chromatographic analyses was calculated relative to the internal standard using a response factor of 1.0. Results of these analyses are presented elsewhere (Chiarappa et al., 1998).

\section{Laboratory Analyses}

Gas Chromatography. Laboratory analyses of the organic extracts were conducted on a Hewlett-Packard 5890 Series II gas chromatograph equipped with an FID and an HP 7673 automatic sampler. Compounds were injected in splitless mode on a $30-\mathrm{m}(0.53 \mathrm{~mm}$ i.d.) fused silica capillary column coated with methylpolysiloxane (DB-5, J \& W Scientific; film thickness $0.5 \mu \mathrm{m}$ ). Instrument temperature was increased from $60^{\circ} \mathrm{C}$ (initial hold time $2 \mathrm{~min}$ ) to $270^{\circ} \mathrm{C}$ at $12^{\circ} \mathrm{C} / \mathrm{min}$. Helium was used as the carrier gas. Data were acquired and integrated using the HP Series II Chemstation software. Results of these analyses are presented elsewhere (Chiarappa et al., 1998).

Gas chromatography-mass spectrometry. Gas chromatography-mass spectrometry (GC-MS) analyses of the SPE extracts were performed on a Hewlett Packard 6890 gas chromatograph equipped with a $30 \mathrm{~m} \times 0.25 \mathrm{~mm}$ i.d. HP- $5 \mathrm{~ms}(5 \%$ phenyl methylsiloxane) capillary column ( $0.25 \mu \mathrm{m}$ film thickness) coupled to a Hewlett Packard 6890 Series Mass Selective Detector, operated in electron impact mode (70 eV) over the mass range 35-450 dalton with a cycle time of $1.1 \mathrm{~s}$. The GC oven temperature was programmed at isothermal for $2 \mathrm{~min}$ at $50^{\circ} \mathrm{C}$, increasing by $8^{\circ} \mathrm{C} / \mathrm{min}$ to $300^{\circ} \mathrm{C}$, and isothermal for $6.75 \mathrm{~min}$, with the injector at $250^{\circ} \mathrm{C}$ and helium as the carrier gas. The MS data were processed using Hewlett Packard Chemstation software. Internal standard method, using relative response factors, was used to quantitate the target compounds. Target compounds quantitated for this study are listed in Appendix A.

Total Inorganic Carbon. TIC analyses were obtained using an OI Model 524 analyzer. A weighed sample was injected into a purge vessel containing a $25 \%$ phosphoric acid solution, which was continuously purged with nitrogen gas. The dissolved inorganic carbon converted to $\mathrm{CO}_{2}$ and was swept into a nondispersive infrared detector, where measurement of total inorganic carbon was made.

Anions. Anion concentrations were determined using a Hewlett Packard 1090M HPLC coupled to a Waters 431 conductivity detector. Data were processed using an online Hewlett Packard personal computer with Chemstation software.

Cations. Cation analysis was done by the Analytical Chemistry Section at LLNL using inductively-coupled plasma atomic emission spectrometry (ICP-AES).

Quality Assurance. A series of quality control and monitoring steps were followed during the field test. The major steps included field and laboratory blank tests, solvent tests to monitor for possible contaminants, and recovery experiments for a large set of representative polar and nonpolar standard compounds. 


\section{Results}

The field experiment at the Visalia Pole Yard involved injections of steam and steam with compressed air into the intermediate aquifer from injection Well S-4. The effects of the steaming operation were monitored by sampling the intermediate aquifer using Wells MW-36 and S-13, located approximately $90 \mathrm{ft}$ away. Wells MW-36 and S-13 were the two sampling wells regularly sampled to assess the progress of the steam injection experiments. Therefore, the water chemistry data for organic analyses were primarily from these two wells.

In addition to these two wells, water samples were periodically collected from S-12, S-14, S-15, MW-41, MW-44, EW-1, EW-2, EW-3, and EW-5. Two water samples of condensed steam from the steam injection Well S-4 were also collected and analyzed by GC-MS. Some miscellaneous water samples and free product samples were collected from venting wellheads or the treatment facility. One sample of creosote free product collected in 1996 was analyzed for comparison purposes. These samples were diluled in solvent and analyzed by GC-MS. The list of semivolatile organic target compounds quantitated during this study was derived from EPA Method $8270 \mathrm{C}$ and consisted primarily of polycyclic aromatic hydrocarbons (PAH) and phenols. This target compound list was expanded to include all three tetrachlorophenol isomers, three additional oxygenated compounds (fluorenone, anthrone, and 9,10-anthracenedione), and two nitrogen-containing PAH compounds (carbazole and 7,8-benzoquinoline). The analytical results of the GC-MS analyses are listed in Appendix B. Summarized at the bottom of each table in Appendix B are the following:

- Total Oxygenates $(\mu \mathrm{g} / \mathrm{L})$ : Sum of non-chlorinated phenols in EPA 8270C list plus benzoic acid, fluorenone, anthrone, and 9,10-anthracenedione

- Total PAH ( $\mu \mathrm{g} / \mathrm{L})$ : Sum of PAH in EPA 8270C list (including dibenzofuran) plus nitrogen-containing PAH (carbazole and 7,8-benzoquinoline)

- Total Cl-Phenols $(\mu \mathrm{g} / \mathrm{L})$ : Sum of three tetrachlorophenol isomers and pentachlorophenol

- Total GC-MS ( $\mu \mathrm{g} / \mathrm{L})$ : Sum of all compounds in entire expanded EPA 8270C target compound list

Although Total GC-MS $(\mu \mathrm{g} / \mathrm{L})$ is a sum of all target compounds, it does not represent the total amount of organic contaminants extracted from the water samples amenable by gas chromatography. The Total GC-MS $(\mu \mathrm{g} / \mathrm{L})$ value represents a sum of those compounds listed in the EPA Mcthod $8270 \mathrm{C}$ plus those compounds included in the expanded analyte list discussed above. This point can be illustrated by examining three examples of the raw GC-MS data and quantilation results. Figure 5 and Figure 6 are representative reconstructed ion chromatograms (RIC) for the GC-MS runs of the organic extracts from Wells S-13 (June 19 22:25) and S-14 (June 17 11:15), respectively. Figure 7 is the RIC for a sample of free product collected from the dissolved-air flotation tank (DAFT) on July 16; $y$ is abundance and $x$ is time. These three chromatograms represent abundances of the target analytes (labeled) relative to the six internal standards (labeled IS-1 through IS-6). From these three figures it is apparent that many compounds were not quantitated and, for some samples, a significant portion of the extracted organic compounds has remained chromatographically unresolved and unquantitated in the unresolved complex mixture (UCM). For example, the total amount of organic compounds quantitated by GC-MS using this target compound list for the 
DAFT (July 16) free product sample accounts for $16 \%$ of the sample mass. The remaining, unquantitated portion consists of alkylated PAH (i.e., di- and trimethylnaphthylenes) and compounds which make up the UCM. Therefore, the Total GC-MS value is a sum of the compounds in the target compound list and represents a portion of the total organics amenable by GC and quantitated by a flame ionization detector (FID). A complete discussion of the results of GC-FID is presented by Chiarappa et al. (1998).

For simplicity in the results and discussion sections, the PAH compounds have been further subdivided by molecular weight into three groups; low molecular weight PAH (two-ring PAH, i.e., naphthalene and 2-methylnaphthalene), intermediate molecular weight PAH (three-ring PAH, i.e., acenaphthene, fluorene, and phenanthrene), and high molecular weight PAH (four- and five-ring PAH, i.e., fluoranthene, pyrene, chrysene, benzo(b)fluoranthenc, benzo(k)fluoranthene, and benzo(a)pyrene). This classification aids in the general description of the distribution of the organic compounds present in the water samples.

The analyses quantitated by GC-MS were compounds whose positive identifications were confirmed by GC retention time match and mass spectral match with a standard mixture made up of pure compounds at known concentrations (Hale and Aneiro, 1997). The oxygenated compounds in the analyte list, although possibly present in the creosote-contaminated soil as minor compounds, could also be formed during HPO and may be representative of partially oxidized PAH compounds. The complete GC-MS results are presented in Appendix B, Tables 1-9. A brief description of the results from each well follows.

\section{Well MW-36}

Table 1 lists the results of the groundwater analyses from Well MW-36. This well was sampled for groundwater organic pollutants on May 7 to obtain a baseline sample representative of groundwater before the injection of steam and was found to be clean of organic contaminants.

The first injection of steam into S-4 began on May 21 and lasted until May 23. Six samples were collected during this period and analyzed for TIC and semivolatile organics before the pump temporarily failed on May 22. This set of samples represents groundwater that has been displaced by the growing steam zone. Total semivolatile organic analyses for these six samples were low, with an average total semivolatile organic level of approximately $12 \mathrm{ppb}$, and exhibited no trends in organic contaminant levels as a function of time.

Ten samples were taken for semivolatile organic analyses from May 28 to June 4. During this time organic-compound levels were increased substantially over the earlier samples. The water sample of May 28 17:10 had PAH components ranging from naphthalene (molecular weight 128) to pyrene (molecular weight 202), with the most abundant being phenanthrene (molecular weight 178) at a concentration of $350 \mathrm{ppb}$. Some oxygenated compounds were present, and a total oxygenate concentration of $44 \mathrm{ppb}$ was quantitated. The most abundant oxygenate was fluorenone at a concentration of $27 \mathrm{ppb}$. Eight water samples taken from June 2 to June 4 exhibited large variabilities in concentrations of groundwater organics. Difficulties were encountered during this period with the pump installed in the well; some of the large variations in organic concentrations may have been due to these operational difficulties and not to actual groundwater fluctuations. But it was obvious that the levels of PAH and oxygenates in these water samples were still elevated and similar in composition to the May 28 17:10 sample discussed above. The average total oxygenate concentration was 
$41 \mathrm{ppb}$, with benzoic acid and fluorenone being the most abundant oxygenated compounds present. The average total PAH concentration was $650 \mathrm{ppb}$ for these three samples, with phenanthrene being the most abundant single PAH component.

A total of 13 water samples were extracted and analyzed by GC-MS from June 17 to June 30 . This sample set covers the time when steam and compressed air were injected into S-4 (June 17-20). The earliest sample taken on June 17 had total organics at approximately $200 \mathrm{ppb}$. The levels of organics in MW-36 did not change much until June 20, when the total organic level increased to $>1000 \mathrm{ppb}$, and it peaked at $2300 \mathrm{ppb}$ on June 26, approximately one week after the steam/compressed-air injection. The level of total oxygenates also peaked at $55 \mathrm{ppb}$ approximately one week after the injection. Fluorenone, 9,10-anthracenedione, and benzoic acid were the most abundant oxygenated compounds.

The four histograms in Figure 8 show how the relative abundances of the target analytes changed over time. As stated above, the pre-steam baseline sample was clean of semivolatile compounds. From May 28 to the end of sampling on June 30 , the most abundant compound was phenanthrene, but over this time there was a relative increase in the higher molecular weight PAH compounds (i.e., fluoranthene and pyrene).

\section{Well S-13}

Table 2 lists the results of the groundwater analyses from Well S-13. Sampling at this well began on May 23 and continued throughout the field experiment. The last regular sample to monitor the S-4 steam injection was taken on July 16. Two additional spotcheck samples were acquired on October 23 and December 16.

The earliest sample acquired from S-13 (May 23 08:30) was taken as the steam front from the initial steaming event reached the vicinity of the S-13/MW-36 sampling location. Total organics for this sample was $4307 \mathrm{ppb}$. A sample taken later on the same day (S-13 May 23 13:50), after the collapse of the steam zone, had the same distribution of organics but at a lower total concentration (682 ppb).

The next sample was taken on May 28 and was elevated in both total oxygenates and total PAH (primarily phenanthrene). The levels of contaminants steadily decreased during the following two weeks and stabilized by June 17 at a total organic level of approximately $700 \mathrm{ppb}$. Steam/compressed-air injection into S-4 began on June 17 and continued to June 20 . Contaminant levels were elevated by June $1922: 25$. The total oxygenate concentration was $89 \mathrm{ppb}$, consisting primarily of benzoic acid, fluorenone, and 9,10-anthracenedione, and the total PAH concentration was $>4000^{\circ} \mathrm{ppb}$ with phenanthrene being the most abundant compound. The contaminant level remained elevated for another week. By June 30 the contaminant level started to decrease, and by July 16 the oxygenate and PAH concentrations were at their lowest levels.

Figure 9 shows histograms of the semivolatile organic data for May 23, June 16, June 30, and December 16. In Figure 9a through Figure 9c the relative distribution of semivolatile compounds remained quite constant. There was a slight shift to higher molecular weight compounds during this period. The most abundant compound during this time was phenanthrene, but the relative abundances of the lower molecular weight compounds decreased while two higher molecular weight compounds (fluoranthene and pyrene) increased in relative concentration. The last sample, taken on December 16 (Figure 9d), had a much different compound distribution. The relative amounts of oxygenates were up (i.e., benzoic acid and fluorenone), but, unlike all the previous water samples from S-13, pentachlorophenol and two tetrachlorophenol isomers were elevated in the water sample. 


\section{Well S-12}

Table 3 lists the results of the groundwater analyses from Well S-12. This well was sampled six times from May 20 to July 16. These water samples were high in organic contaminants; total organics by GC-MS ranged in concentrations from approximately $1000 \mathrm{ppb}$ to nearly $5000 \mathrm{ppb}$. The contaminants consisted primarily of the intermediate molecular weight PAH compounds (i.e., phenanthrene). Total oxygenate concentrations steadily decreased from $283 \mathrm{ppb}$ on May 20 to $31 \mathrm{ppb}$ measured on June 17 . By July 17 the total oxygenate concentration was again elevated to a value of $215 \mathrm{ppb}$. Although the total oxygenate concentrations were dominated by the compound fluorenone, there. were also significant amounts of total phenols, anthrone, and 9,10-anthracenedione present in the water samples.

Figure 10 presents four histograms showing the distributions of semivolatile compounds from May 20 to July 16 for Well S-12. The first sample taken from this well was unique in that it had relatively high concentrations of heteroaromatic compounds (i.e., carbazole and dibenzofuran) in addition to the relatively high levels of oxygenates (primarily fluorenone). As seen with the distribution of semivolatile compounds over time in Wells MW-36 and S-13, a relative shift to higher molecular weight compounds over time was also observed in the water samples from this well.

\section{Well S-14}

Table 4 lists the results of the groundwater analyses from Well S-14. This well was sampled seven times from May 6 to July 16, with one additional sample taken on December 16. The results of May 6 represent a pre-steam cold baseline sample, high in PAI I (i.e., naphthalene, acenaphthene and phenanthrene) and low in oxygenates. A general increase in total organics was observed during the period of the field test, with a large spike of total organics on June 30 . A steady increase in total oxygenates was observed during the field test. On July 16 the total oxygenates value was $270 \mathrm{ppb}$, much higher that the value of $12 \mathrm{ppb}$ measured in the baseline sample of May 6. Although there was a steady increase in the level of the oxygenates, the percentage of oxygenates remained relatively low and constant throughout the entire test period.

Figure 11 shows histograms of the semivolatile analyses from May 6, June 17, July 16 and December 16. No real systematic variations in the semivolatile compound distributions were evident over the six-month period when samples from this well were collected. The baseline sample of May 6 consisted primarily of low (i.e., naphthalene and 2-methylnaphthalene) and intermediate (i.e., acenaphthene, fluorene, and phenanthrene) semivolatile organic compounds, with significant amounts of carbazole and dibenzofuran. By June 17, the distribution became dominated by the low molecular weight compounds. When sampled again on July 17, the compound distribution again resembled the baseline sample of May 6. The last sample (December 16) was again dominated by the low molecular weight PAH and resembled the sample of June 17.

\section{Well S-15}

Table 5 lists the results of the groundwater analyses from Well S-15. This well was sampled for organics three times during the HPO field test, on May 28, June 30, and July 16, with two additional samples collected on December 16 as spot-check samples. This well exhibited the same trends in contaminant concentrations seen in Well S-14, showing increases in total oxygenates and total PAH over time. The earliest sampling date of May 28 had a total organic level of $4280 \mathrm{ppb}$. The level of organics increased to 
$12000 \mathrm{ppb}$ on June 30 and $15300 \mathrm{ppb}$ on July 16. The levels of total oxygenates increased from $150 \mathrm{ppb}$ on May 28 to nearly $400 \mathrm{ppb}$ on July 16. The most abundant compounds present were the low and intermediate molecular weight PAH compounds (i.e., naphthalene and phenanthrene) and pentachlorophenol. Although the level of pentachlorophenol was low (18 ppb) in the May 28 sample, the PCP level increased to $2000 \mathrm{ppb}$ by June 30 and was measured at $3400 \mathrm{ppb}$ on July 16 .

Figure 12 presents four histograms sampled from May 28 to December 16, covering approximately the same time period as was shown in Figure 11 for Well S-14. The sample of May 28 consisted of compounds spanning a large molecular weight range, from naphthalene to pyrene. On June 30 the distribution was dominated by naphthalene with lesser amounts of the other PAH. A similar distribution was found on July 17. On December 16 the major compound present was phenanthrene.

\section{Miscellaneous Wells (MW-41, MW-44, EW-1, EW-2, EW-3, EW-5)}

Table 6 lists the results of the groundwater analyses from a set of assorted wells. The wells listed in this section were not sampled on a regular basis but rather were collected as spot checks around the site.

MW-41 was sampled three times during the field test. The first sample was taken on May 6 and represented a baseline sample before steaming operations began. The water on this date was clean of semivolatile compounds, and none of the target compounds were detected. Midway through the steaming operations, another sample was taken (June 18) and some target compounds were detected at very low levels. The total semivolatile compound level quantitated by GC-MS was approximately $20 \mathrm{ppb}$. A final sample was taken on July 16 and was similar to the previous sample taken on June 18. Most of the compounds detected were in the range of 1-7 ppb with the exception of pentachlorophenol, which was at $19 \mathrm{ppb}$.

One sample from MW-44 was taken on July 17. A few semivolatile organic compounds were detected at very low levels (approximately $1 \mathrm{ppb}$ ). EW-1 was sampled on May 8 and June 16. PAH compounds at concentrations $<40 \mathrm{ppb}$ were found in both samples and both had total semivolatile levels of approximately $140 \mathrm{ppb}$. EW-3 was sampled on May 6 and June 16. The May 6 sample consisted primarily of intermediate molecular weight PAH (i.e., acenaphthene, dibenzofuran, and phenanthrene) at approximately $40 \mathrm{ppb}$ and a total semivolatile organic loading of $180 \mathrm{ppb}$. The EW-3 sample taken on June 16 had a similar compound distribution except for elevated levels of fluorenone and phenanthrene. This sample had a total semivolatile concentration of $390 \mathrm{ppb}$. EW-5 was sampled once (July 17) and was relatively clean, having a total semivolatile concentration of $28 \mathrm{ppb}$. Wells EW-5, MW-41 and MW-44 were the cleanest of all the wells sampled after the steaming operations began.

\section{Injection Well S-4}

The steam injection Well S-4 was sampled twice for organic analyses by GC-MS. The results are presented in Appendix B, Table 7. The sample dated May 23 13:30 was collected by condensing steam from the S-4 wellhead into ice, so the concentrations for this sampling event include an unknown dilution factor and should be used only as a qualitative look at which organic compounds vented from this well. The analysis showed the condensed steam was quite clean in hydrocarbons with phenanthrene as the compound in highest concentration.

Well S- 4 was sampled on June $2013: 00$ by condensing the steam in a copper coil submerged in an ice bath, then collecting the water in a $1 \mathrm{~L}$ amber sampling bottle. This 
analysis revealed that the major compounds present were the intermediate molecular weight PAH compounds of phenanthrene (89 ppb), pyrene (23 ppb), fluoranthene $(11 \mathrm{ppb})$ and anthracene (10 ppb). A small grab sample from Well S-4 was also taken on June $2011: 00$ and analyzed for $\mathrm{pH}(\mathrm{pH}=7)$ and $\mathrm{TIC}\left(75.9 \mu \mathrm{g} \mathrm{C} / \mathrm{g} \mathrm{H}_{2} \mathrm{O}\right)$.

\section{Miscellaneous Water and Free Product}

Miscellaneous water samples are listed in Table 8, and miscellaneous free product and solid samples are listed in Table 9 . The water samples submitted for organic analyses and listed in Table 8 were either condensed vapor samples from Well S-13 or water samples from the treatment facility. As expected for samples of this type, all of these water samples were elevated in organics. Two histograms of condensed vapor from S-13 are presented in Figure 13a and Figure 13b. These samples were unique because they both had extremely elevated organic concentrations but also very limited in the distribution of organic compounds present. For example, the S-13 (June 20) condensed vapor sample consisted primarily of phenanthrene, and the S-13 (June 30) sample consisted almost exclusively of phenanthrene, anthracene, fluoranthene, and pyrene. The distribution of organic compounds found in the water samples from the treatment facility were nearly identical, with the major compound being 2-methylnaphthalene.

Selected histograms of free products, sludge samples, or emulsion samples are presented in Figure 14 and Figure 15. Figure 14a is a histogram of a creosote sample recovered in 1996 from the vicinity of Well S-14. Figure $14 \mathrm{~b}$ is a sample of the free product collected from the gravity separator on June 19. The distribution of compounds found in this sample is similar to the creosote sample. The bottom sludge samplc collected at the same time is depleted in the lower molecular weight components. The sample from the D $\Lambda F T$ (June 19) consisted primarily of intermediate and high molecular weight compounds of phenanthrene, fluoranthene, and pyrene. Figure 15 presents free product samples taken from various locations in the treatment facility. They are all similar in composition, consisting primarily of 2-methylnaphthalene, with lesser amounts naphthalene and the intermediate molecular weight PAH.

Figure 16a and Figure $16 \mathrm{~b}$ present results from solid samples, collected on June 30 , of material that had condensed on the S-13 wellhead. The distributions consisted primarily of intermediate and high molecular weight compounds (i.e., phenanthrene, anthracene, fluoranthene, and pyrene). Figure $16 \mathrm{c}$ and Figure $16 \mathrm{~d}$ are organic compounds extracted from carbonate scales collected from Wells S-13 and S-15. Like the S-13 wellhead samples, these samples had very limited distributions of organic compounds consisting primarily of phenanthrene and the higher molecular weight compounds fluoranthene and pyrene. 


\section{Discussion}

Large variations were found in groundwater contaminant concentrations and compound distributions in water samples from the Southern California Edison Pole Yard. The possible causes of these variations are numerous. Some of the observed differences could have resulted from more than one creosote, dense, nonaqueous-phase liquid (DNAPL) type being present in the intermediate aquifer. The composition of a complex creosote DNAPL pool also can be altered by a variety of physical, chemical, and biochemical processes (Goerlitz et al., 1985). An example of a physical alteration would be the preferential loss of more soluble compounds to the groundwater (Johansen et al., 1997), and an example of a chemical alteration would be the chemical oxidation that occurs at extremely slow rates under ambient conditions but can be greatly accelerated by steam injections (Knauss et al., 1998a; Leif et al., 1998). An example of a biochemical alteration would be the selective utilization of certain types of creosote compounds by microorganisms (Erlich et al., 1982; Mueller et al., 1991).

Prior to any clean-up attempts, the alteration processes acting on the creosote DNAPL and contaminated groundwater were not occurring fast enough to allow natural attenuation to contain the contaminated groundwater plume or remediate the source DNAPL on the site. The application of pump and treat technology contained the plume but did not remove the large source of DNAPL at an acceptable rate.

The implementation of the thermally-enhanced in situ remediation technologies of dynamic underground stripping (DUS) and hydrous pyrolysis/oxidation (HPO) directly targeted the source DNAPL, both by accelerating the physical removal with steam stripping and by accelerating the chemical destruction or mineralization with aqueous oxidation (Knauss et al., 1998a; 1998b). During steam injection, creosote components partition and fractionate into the steam or hot water and are mobilized as a function of their physical properties (Wauchope and Getzen, 1972; Peters et al., 1997). When sufficient oxygen is present, organic compounds can also be completely oxidized to carbon dioxide. The rates of oxidation and tendencies to form partially oxidized intermediates are functions of their chemical reactivities. The injection of steam rapidly heated the entire subsurface to its boiling point and most likely greatly reduced the population of the groundwater microbial community. Therefore, the results of the semivolatile organic analyses during the field test were primarily a reflection of the physical and chemical processes that resulted from the steam injections.

The main effect of DUS was the dramatic increase in creosote components extracted from the groundwater. Changes in groundwater chemistry at Wells MW-36 and S-13 correlated with steam injections from Well S-4. Figure 17 shows a plot of total PAH and total oxygenates as a function of time for Well MW-36. MW-36 was initially a clean well, but groundwater samples from it clearly demonstrated the processes of enhanced dissolution and transport of organic compounds due to the subsurface heating. Two maximums occurred in the groundwater creosote concentrations from Well MW-36 during the field test. The total organic concentration reached a maximum approximately one week after each steam pulse. Figure 18 is a similar plot for Well S-13 and shows the same increases in groundwater organics one week after the steam pulses. Increases in the levels of groundwater organics during the field test were observed at other sampling wells, such as S-14 and S-15. It is difficult to relate such increases directly to specific steaming events because of the complex nature of the operations influencing these wells. Wells S-14 and S-15 were affected to varying degrees by numerous steam injections from 
multiple injection wells, but, in general, creosote content was definitely enhanced by the steaming operations in these two wells.

In addition to changes in total organic concentrations, the distributions of compounds, relative to each other, in the groundwaters also changed over time. Well MW-36 is an example where the distribution of organics gradually changed during the field test. The histograms in Figure 8 show a moderate progression toward higher molecular weight PAH over time, reflecting the ability of the heated groundwater to mobilize these $\mathrm{PAH}$, which are difficult to remediate under ambient groundwater conditions due to their extremely low aqueous solubilities at lower temperatures. This trend toward an increase in higher molecular weight compounds was also observed in Well S-13 (Figure 9).

The main effect attributed to HPO was the production of partially oxidized intermediate compounds. As reported earlier for the laboratory-based HPO experiments using an actual creosote from this site (Leif et al., 1998), low molecular weight phenols and benzoic acid were formed. These oxygenated compounds represent partially oxidized intermediates formed during the HPO of a complex creosote DNAPL. Figure 17 and Figure 18 show how the concentrations of these same low molecular weight oxygenates changed in response to the steam injections into Well S-4. The levels of total oxygenates reached maximums immediately after both steaming events. Although these compounds cannot be unequivocally attributed to be the products of $\mathrm{HPO}$ chemistry, their presence is consistent with the aqueous-phase oxidation expected under these conditions.

The measurement of dissolved oxygen also aided in the evaluation of the HPO process. During the application of HPO, it is critical to know the dissolved-oxygen level in the groundwater, because the fundamental principle of HPO is the ability of hot, oxygenated water to completely mineralize organic compounds to carbon dioxide. As long as there is sufficient dissolved oxygen present, oxidation will occur. Figure 19 is a plot of the dissolved-oxygen measurements from Well MW-36 as a function of time during the field test. A steady decrease in the level of dissolved oxygen was observed during the field test and is consistent with the HPO chemistry, where dissolved oxygen is the oxidant in the chemical oxidation of the aqueous organic species.

Another analytical tool used for evaluating the progress of the HPO remediation process was the measurement of carbon isotope abundances $\left({ }^{12} \mathrm{C},{ }^{13} \mathrm{C}\right.$, and $\left.{ }^{14} \mathrm{C}\right)$ of the dissolved inorganic carbon (DIC). Because both ${ }^{13} \mathrm{C} /{ }^{12} \mathrm{C}$ and ${ }^{14} \mathrm{C} /{ }^{12} \mathrm{C}$ isotopic signatures of the creosote are distinct relative to the native groundwater, these measurements were used to trace carbon derived from the oxidation of creosote compounds. Figure 20 shows the variations in ${ }^{14} \mathrm{C}$ versus $\delta^{13} \mathrm{C}$ values of DIC in groundwater. The groundwater end-member value was the isotopic signature prior to steaming. The DIC became "older" after steaming, consistent with the production of DIC by the oxidation of "dead" creosote carbon.

In summary, the creosote-derived groundwater contaminants present in the intermediate aquifer of the Southern California Edison Pole Yard exhibited large variations in both compound distributions and contaminant amounts depending on when and where the water samples were taken. The differences in the pre-steam baseline samples can be explained by spatial differences in the compositions of the source DNAPL and proximity to a DNAPL pool. Some of these variations could be the result of physical, chemical, and biological weathering processes that have occurred at the site prior to the injection of steam. The creosote most likely has undergone some alteration, especially in aquifers with high groundwater flow. 
Observations consistent with the process of DUS were increases in dissolved organic compound content following increases in groundwater temperature, and enhancements in the relative concentrations of higher molecular weight organics over time. These processes were well documented in the primary sampling wells, MW-36 and S-13.

Observations consistent with the process of HPO were increases in groundwater oxygenate concentrations, decreases in dissolved-oxygen levels, and shifts in carbon isotope abundances in the inorganic carbon pool. Aqueous concentrations of partially oxidized organic compounds (i.e., phenols and benzoic acid) also reached maximum after the steaming events, correlating with the observed increases in PAH concentrations that were a result of DUS. Although oxygenated compounds may be preferentially mobilized by the steam and hot water due to their high aqueous solubilities, their presence is consistent with the process of HPO. Formation of abundant low molecular weight phenols has been observed in laboratory-based HPO experiments using creosote obtained from this site. One oxygenated compound, benzoic acid, was found neither in the creosote nor in the baseline water samples prior to steam injection. This compound is tentatively identified as a partially-oxidized intermediate formed exclusively during HPO. Dissolved oxygen exhibited a steady decrease throughout the test period, consistent with oxygen consumption by hydrocarbon oxidation during HPO. Observed shifts in dissolved- $\mathrm{CO}_{2}$ carbon-isotope values reflect a contribution from creosote oxidation. 


\section{Conclusions}

It is clear from the Visalia Field Test at the Southern California Edison Pole Yard that the combined applications of two in situ, thermal-remediation technologies, dynamic underground stripping (DUS) and hydrous pyrolysis/oxidation (HPO), have greatly accelerated the remediation of this creosote-contaminated site. Application of DUS to the site has accelcrated the mobilization and removal of creosotc. The following observations are evidence for DUS:

- Increases in the concentrations of PAH compounds were observed following the steaming events.

- Increases in the relative amounts of higher molecular weight compounds occurred during the field test.

The application of HPO to the Southern California Edison Pole Yard has accelerated site remediation by oxidizing crcosote components. The following observations are evidence supporting HPO:

- Increases in the concentration of partially oxidized organic compounds (i.e., phenol, methyl phenols, benzoic acid) were observed following the steaming events.

- A steady decrease in dissolved oxygen was observed in the intermediate aquifer, consistent with oxygen consumption by creosote oxidation during HPO.

- Carbon isotope shifts in the dissolved inorganic carbon pool coincided with the observed increase in the groundwater oxygenate concentrations. The shifts to "lighter" and "older" isotopic compositions are consistent with creosote oxidation.

From June 20 to August 6, Southern California Edison has reported the following:

- 200,000 lb free product removed (as LNAPL and DNAPL)

- 17,500 lb hydrocarbon collected by activated carbon filtration

- 29,400 lb hydrocarbon burned in boilers

- 45,500 lb of carbon removed as $\mathrm{CO}_{2}$ produced from creosote oxidation 


\section{Acknowledgments}

The authors thank Allen Elsholz and Ben Johnson for field support, and Daniel Mew and Fowzia Zaka for analytical support. We also thank the employees of Visalia Southern California Edison Co. and the employees of SteamTech Environmental Services for expert assistance at the site. This work was performed under the auspices of the U.S. Department of Energy by the Lawrence Livermore National Laboratory under Contract W-7405-Eng-48. Partial support provided by the Southern California Edison Company was greatly appreciated. 


\section{References}

Chiarappa, M., et al. (1998). On-Site and Laboratory Semivolatile Organic Analyses of Groundwater Samples during the HPO Field Demonstration in Visalia, California. Livermore. California: Lawrence Livermore National Laboratory (in preparation).

Erlich, G.G., D.F. Goerlitz, E.M. Godsy, and M.F. Hult (1982). "Degradation of phenolic contaminants in ground water by anaerobic bacteria: St. Louis Park, Minnesota." Ground Water 20:703-710.

Goerlitz, D.F., D.E. Troutman, E.M. Godsy, and B.J. Franks (1985). "Migration of woodpreserving chemical in contaminated groundwater in a sand aquifer at Pensacola, Florida." Environ. Sci. Tech. 19:955-961.

Hale, R.C., and K.M. Aneiro (1997). "Determination of coal tar and creosote constituents in the aquatic environment." J. Chrom. A 774:79-95.

Johansen, S.S., A.B. Hansen, Mosbæek, and E. Arvin (1997). “Identification of heteroaromatic and other organic compounds in ground water at creosote sites in Denmark."Ground Water Monitor. Remed. 17:106-115.

Knauss, K.G., M.J. Dibley, R.N. Leif, D.A. Mew, and R.D. Aines (1998a). “Aqueous oxidation of trichloroethylene (TCE): A kinetic analysis." Applied Geochem. (submitted).

Knauss, K.G., M.J. Dibley, R.N. Leif, D.A. Mew, and R.D. Aines (1998b). "The aqueous solubility of trichloroethylene (TCE) and tetrachloroethene (PCE) as a function of temperature and calculated thermodynamic quantities." Applied Geochem. (submitted).

Leif, R.N., R.D. Aines, and K.G. Knauss (1998). Hydrous Pyrolysis of Pole Treating Chemicals: A) Initial Measurement of Hydrous Pyrolysis Rates for Naphthalene and Pentachlorophenol; B) Solubility of Flourene at Temperatures Up To $150^{\circ} \mathrm{C}$. Livermore, California: Lawrence Livermore National Laboratory, UCRL-CR-129838.

Mueller, J.G., D.P. Middaugh, S.E. Lantz, and P.J. Chapman (1991). "Biodegradation of creosote and pentachlorophenol in contaminated groundwater: Chemical and biological assessment." Appl. Environ. Microbiol. 57:1277-1285.

Newmark, R.L., and R.D. Aines (1995). Summary Of The LLNL Gasoline Spill Demonstration: Dynamic Underground Stripping Project. Livermore, California: Lawrence Livermore National Laboratory, UCRL-ID-120416.

Peters, C. A., S. Mukherji, C.D. Knightes, and W.J. Weber, Jr. (1997). "Phase stability of multicomponent NAPLs containing PAHs." Environ. Sci. Tech. 31:2540-2546.

Wauchope, R.D., and F.W. Getzen (1972). "Temperature dependence of solubilities in water and heats of fusion of solid aromatic hydrocarbons." J. Chem. Eng. Data 17:38-41. 
Figures

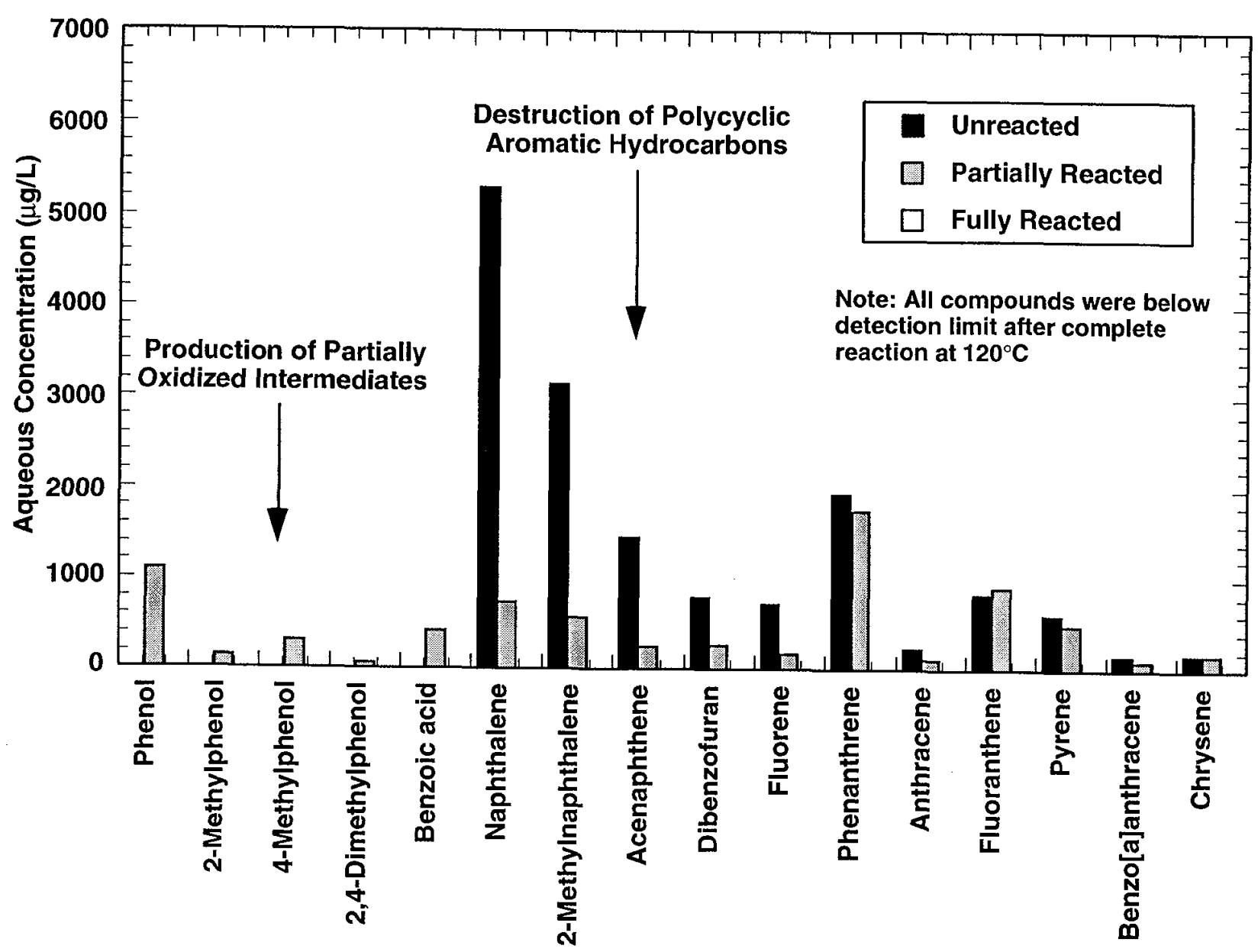

Figure 1. Aqueous concentrations of organic compounds (EPA method 8270A) during laboratory-scale HPO experiment. Starting concentrations are shown in black; partially reacted are shown in gray. Complete destruction of creosote components was achieved at $120^{\circ} \mathrm{C}$. 


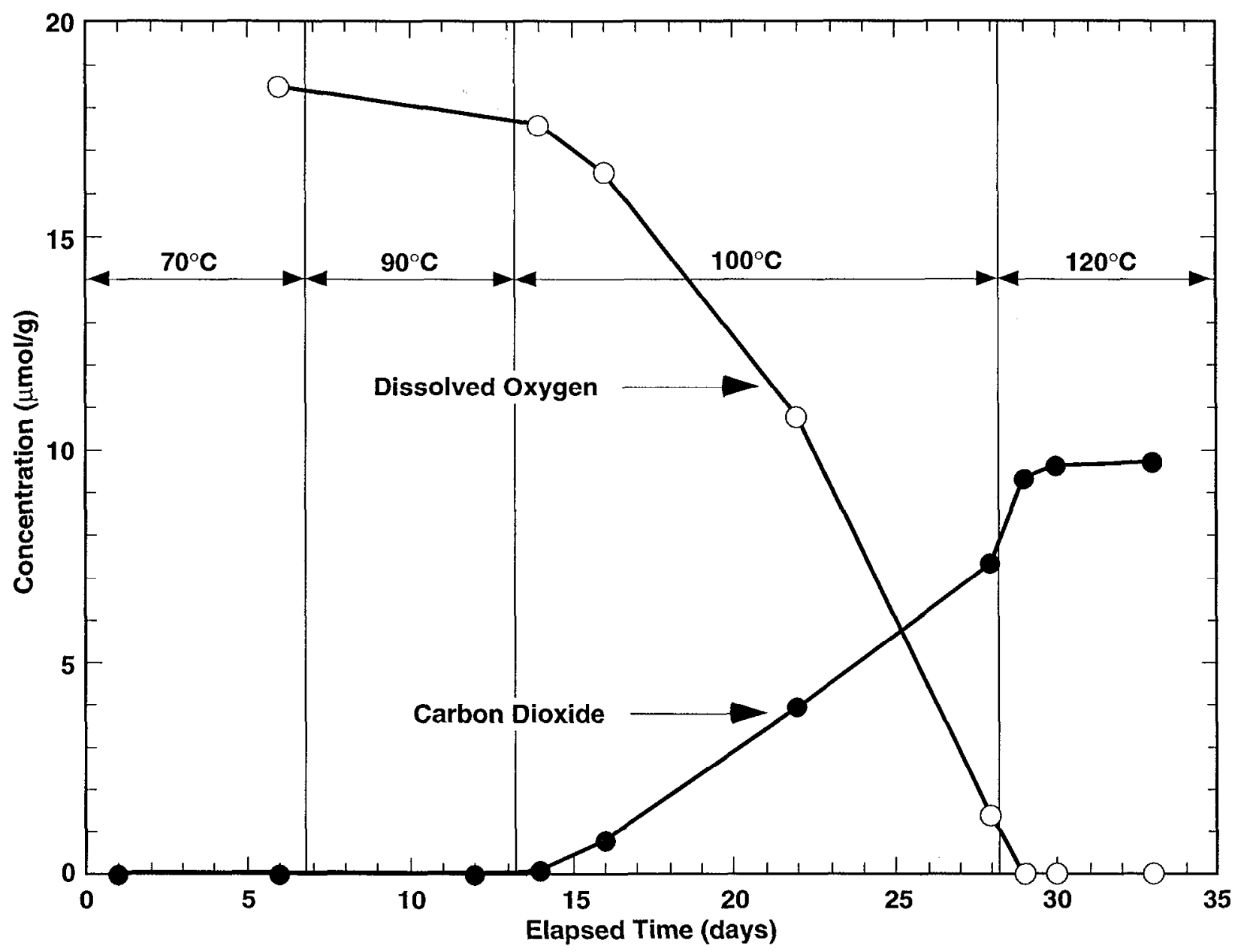

Figure 2. Oxygen consumption and carbon dioxide generation during a laboratory-scale HPO experiment where the reaction temperature was increased from $70^{\circ} \mathrm{C}$ to $120^{\circ} \mathrm{C}$ over a duration of 33 days. Complete oxidation of creosote components is shown by the production of $\mathrm{CO}_{2}$. 


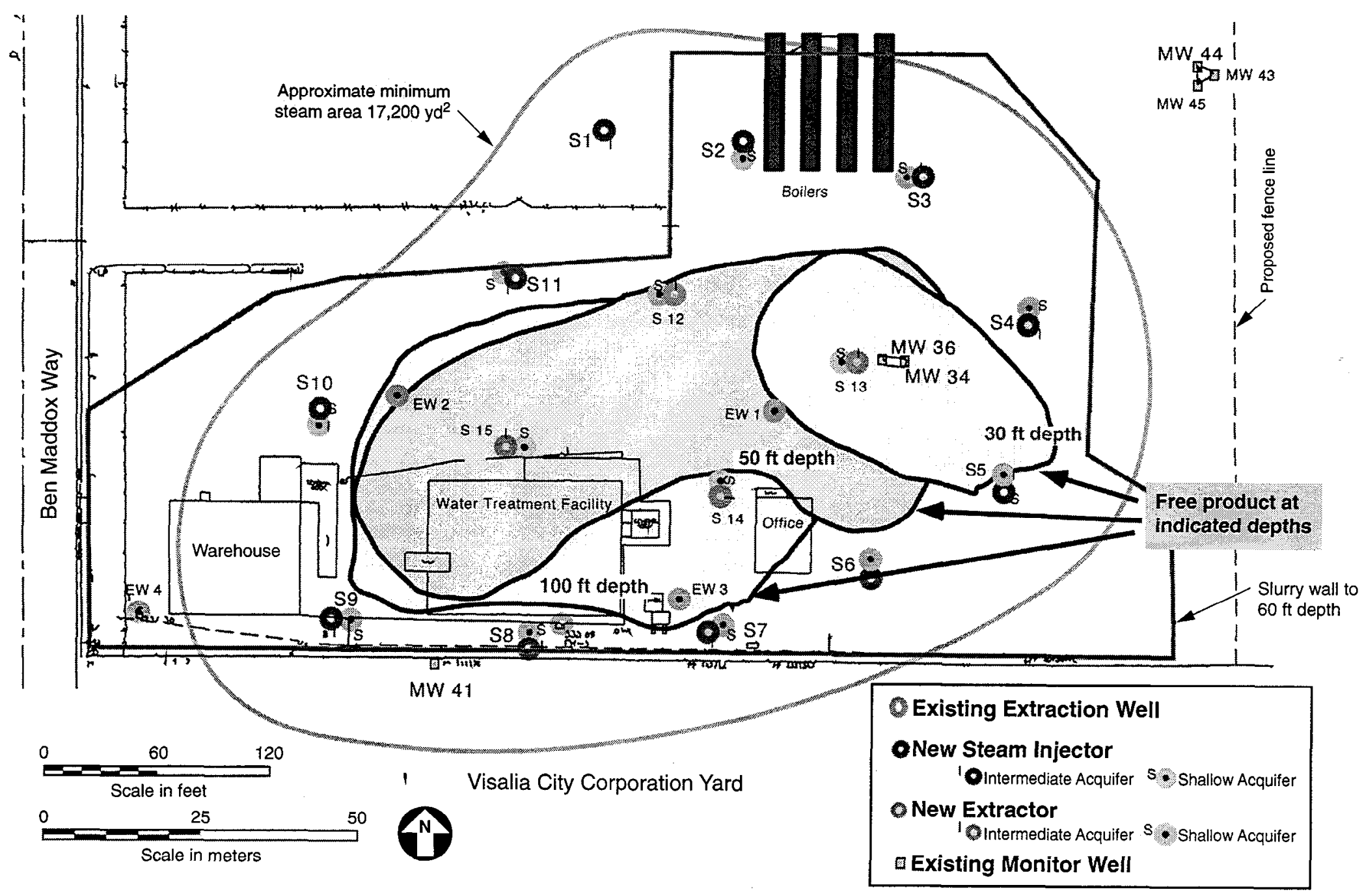

Figure 3. Map of the Southern California Edison Pole Yard showing locations of injection, extraction, and monitoring wells. Injection Well S-4 was used for the HPO demonstration and groundwater chemistry ( $\mathrm{pH}$, anions, cations, organic semivolatile compounds) was monitored at Wells S-13 and MW-36 (approximately $90 \mathrm{ft}$ away). 


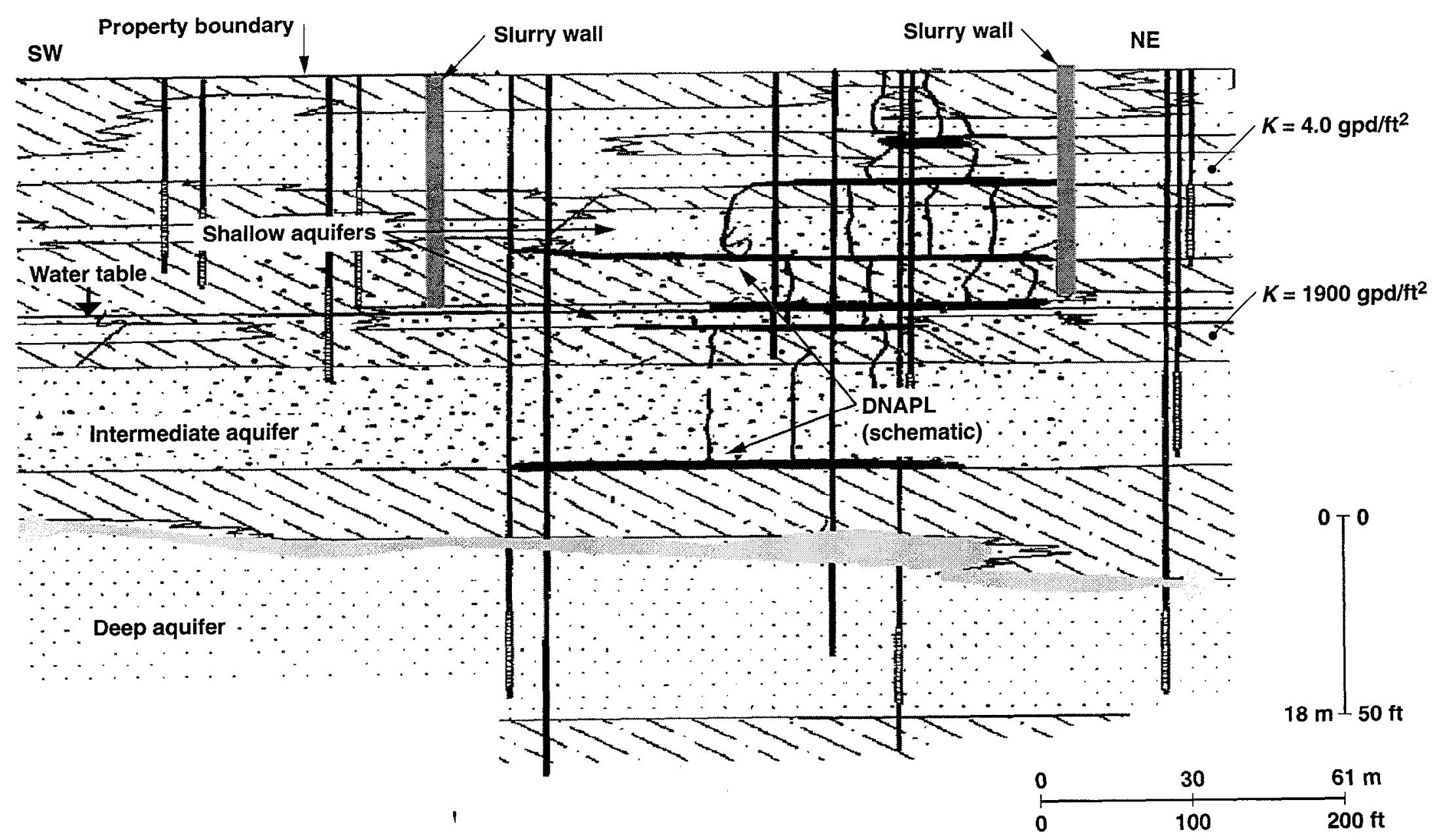

Figure 4. Cross section (approximately northeast-southwest) through the Visalia site, showing the lithology and approximate location of DNAPL contaminant prior to steaming. Depth to water is about $60 \mathrm{ft}$ (the shallow aquifer is unsaturated). Drinking water is produced from the uncontaminated deep aquifer. 


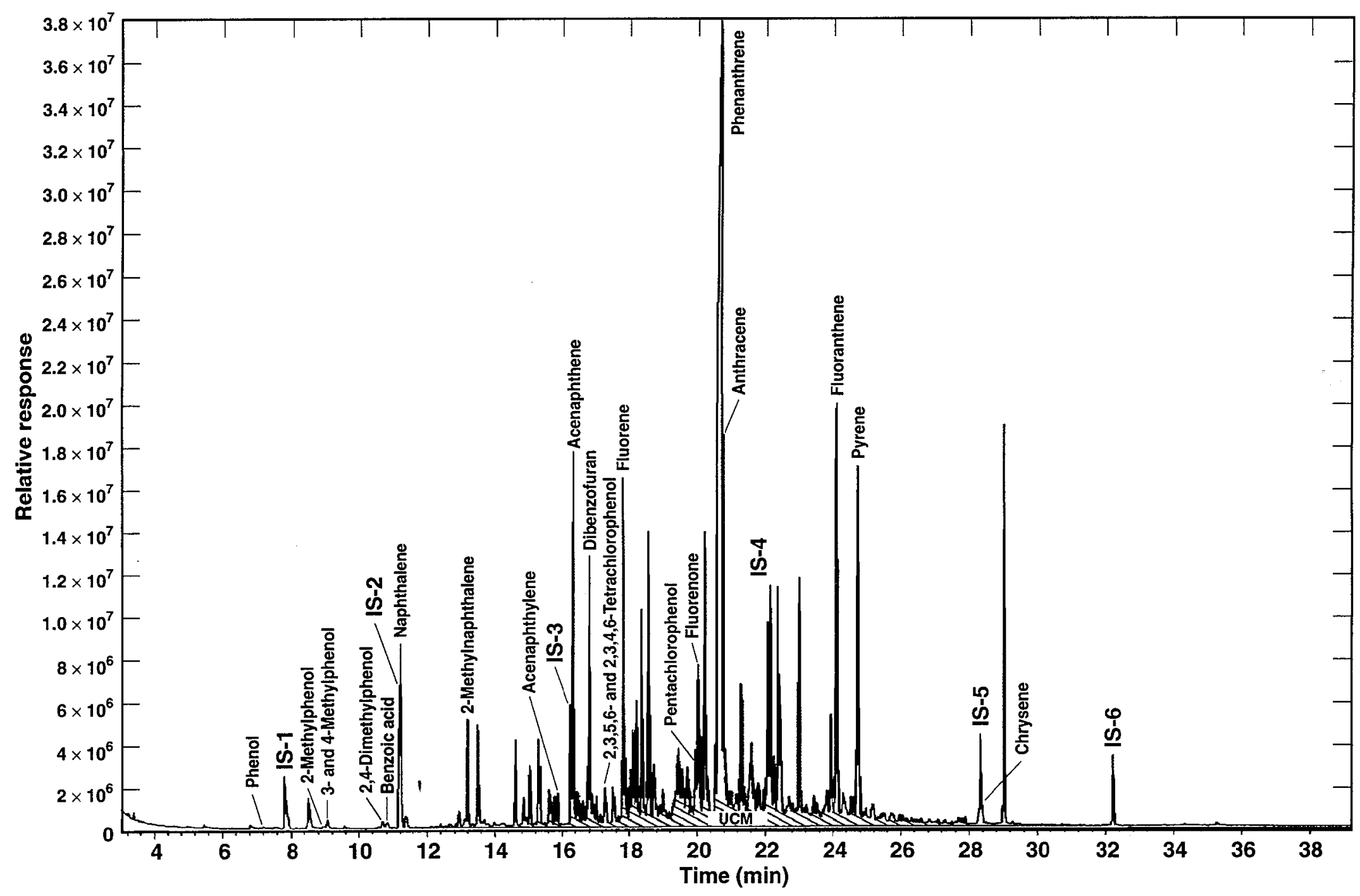

Figure 5. Reconstructed ion chromatogram (RIC) for the GC-MS run of the organic extract from Well S-13 taken on June 19 22:25. The internal standards are labeled IS-1 through IS-6 and quantitated compounds are labeled on the RIC. The unresolved complex mixture (UCM) represents that portion of the extract which remained chromatographically unresolved and not quantitated by GC-MS. 


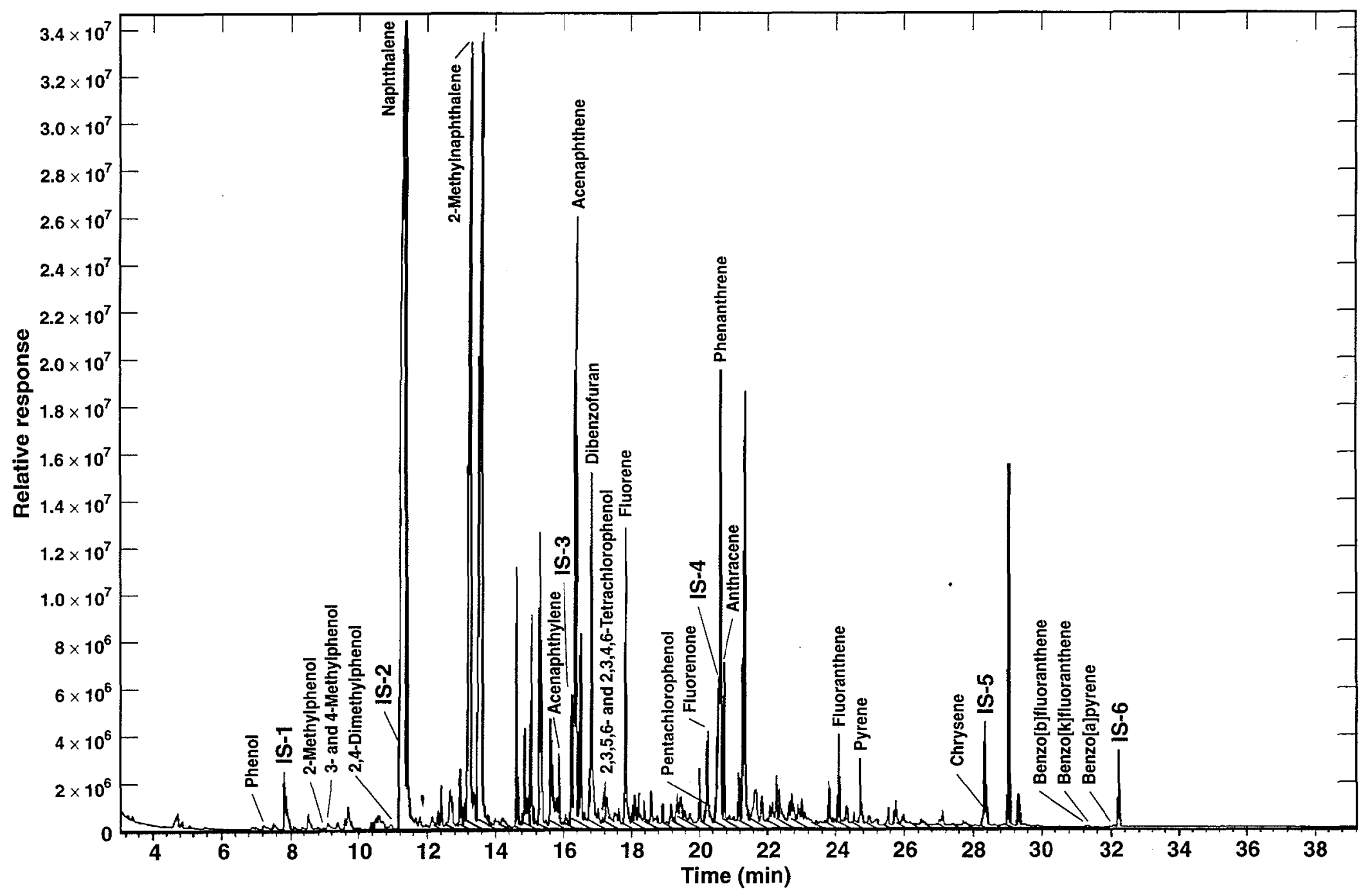

Figure 6. Reconstructed ion chromatogram (RIC) for the GC-MS run of the organic extract from Well S-14 taken on June 17 11:15. The internal standards are labeled IS-1 through IS- 6 and quantitated compounds are labeled on the RIC. The unresolved complex mixture (UCM) represents that portion of the extract which remained chromatographically unresolved and not quantitated by GC-MS. 


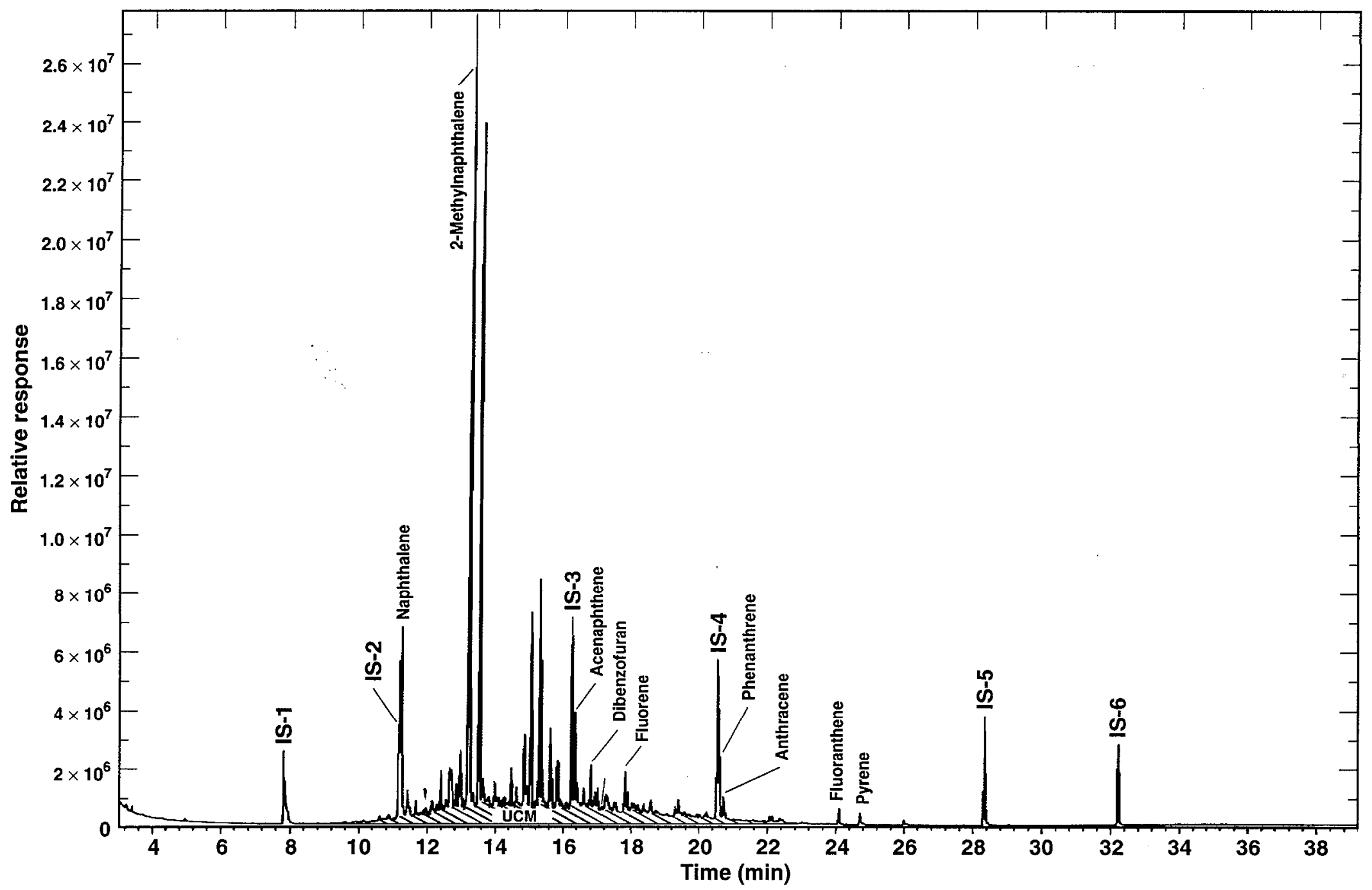

Figure 7. Reconstructed ion chromatogram (RIC) for the GC-MS run of the organic free product from the DAFT taken on July 16. The internal standards are labeled IS-1 through IS- 6 and quantitated compounds are labeled on the RIC. The unresolved complex mixture (UCM) represents that portion of the extract which remained chromatographically unresolved and not quantitated by GC-MS. 
a)
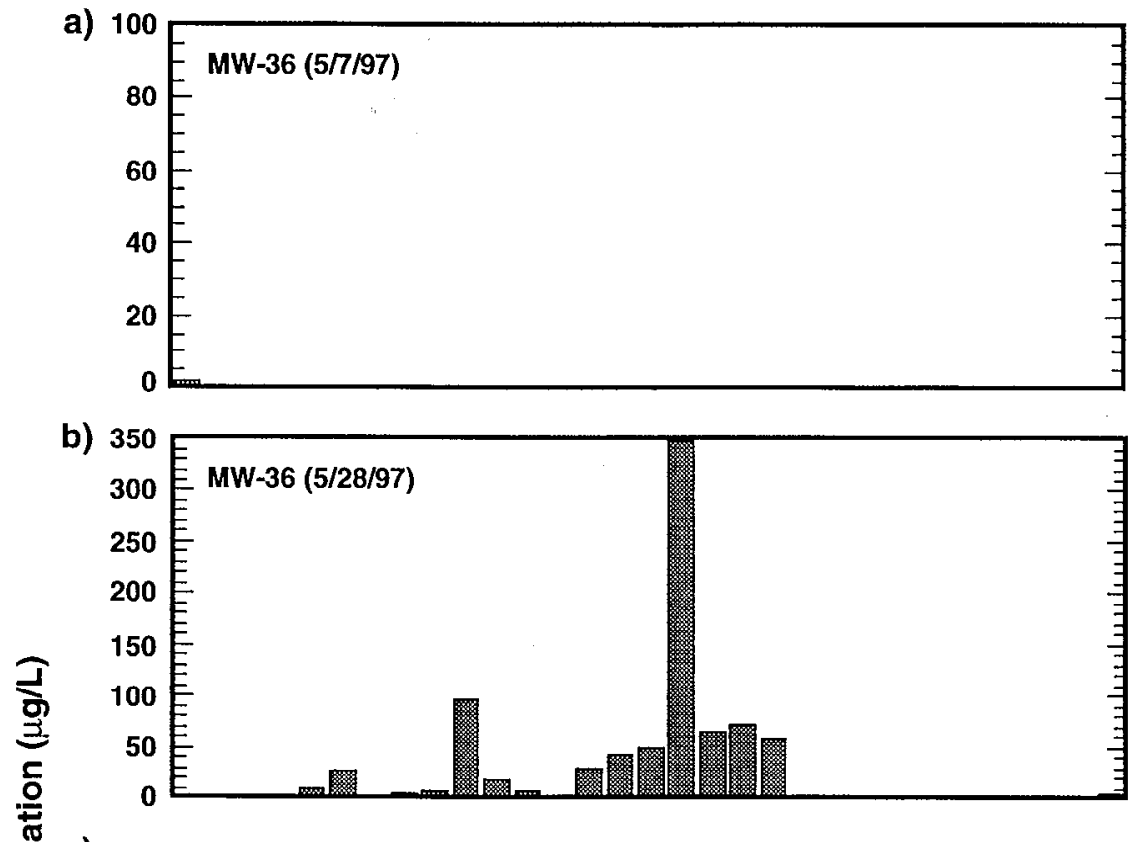

$\stackrel{\text { क्ष }}{=}$ c)

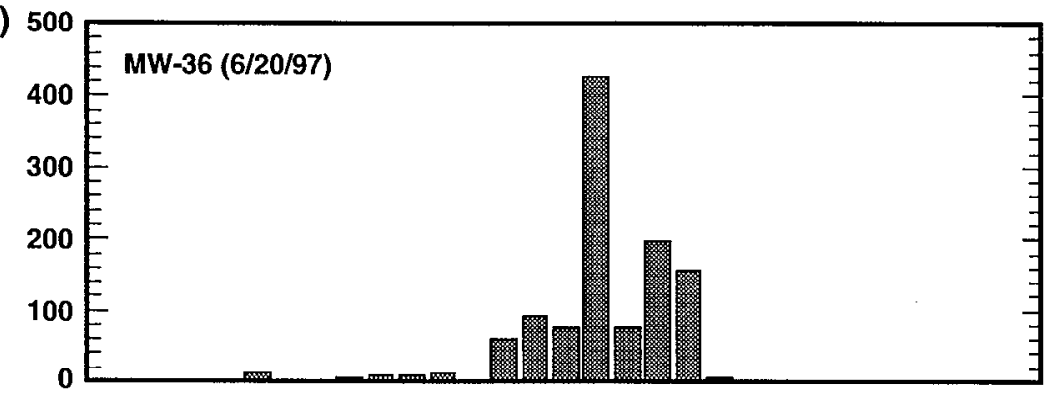

d)

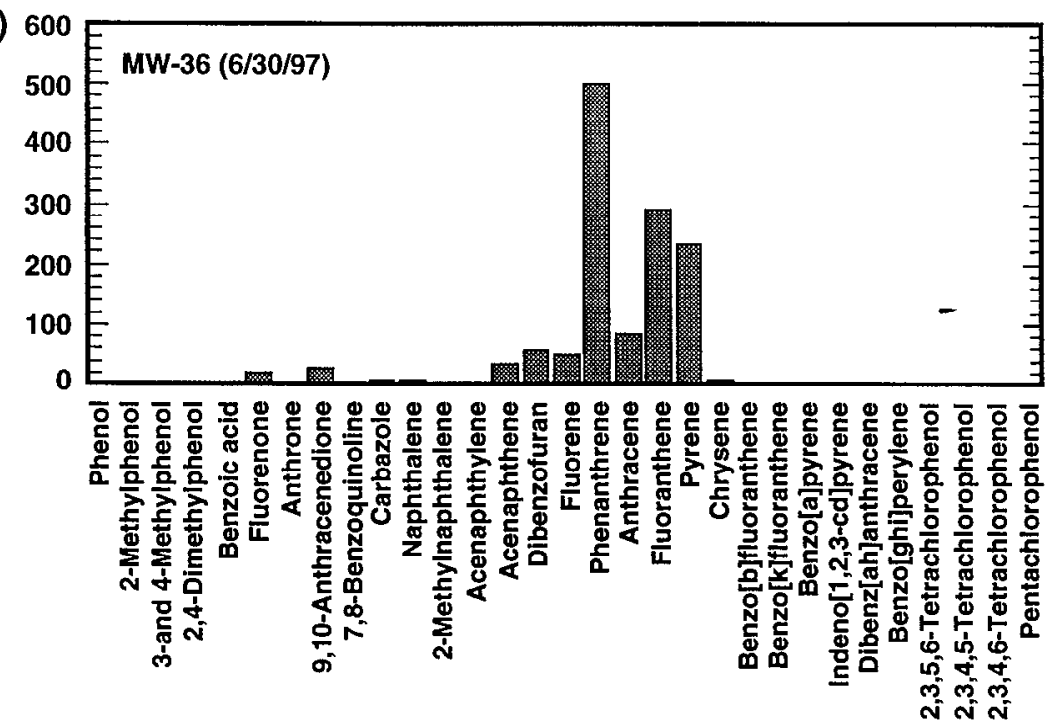

Figure 8. Histograms of the major semivolatile organic compounds present in water sample from Well MW-36: (a) May 7; (b) May 28; (c) June 20; (d) June 30. 

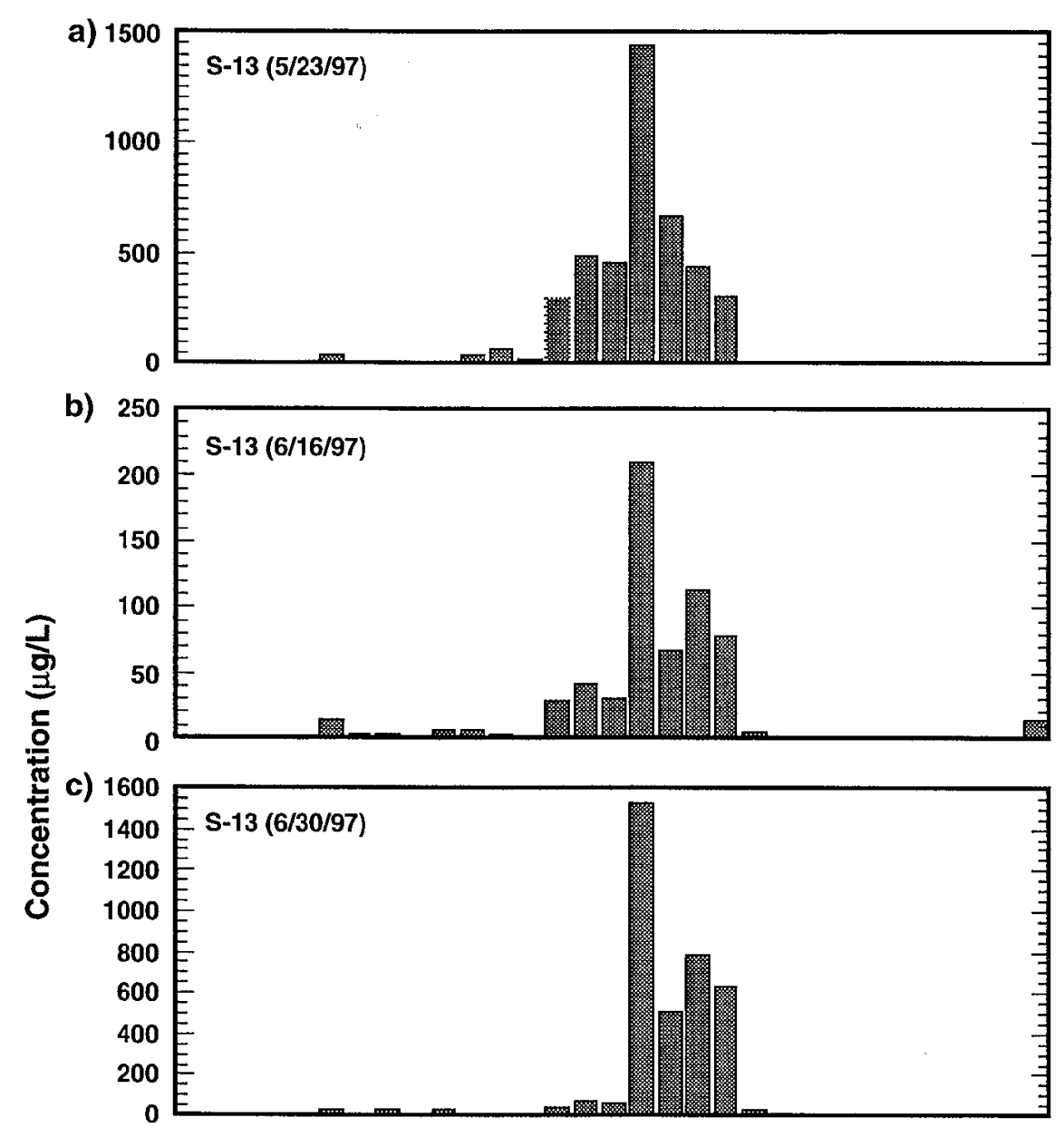

d)

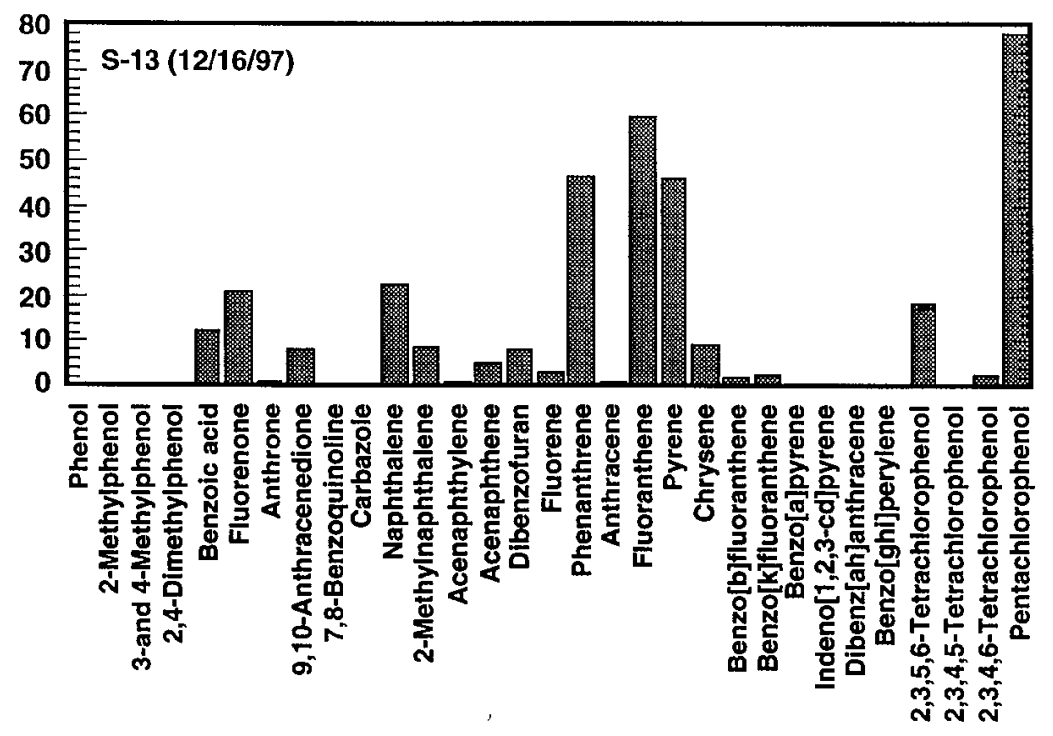

Figure 9. Histograms of the major semivolatile organic compounds present in water samples from Well S-13: (a) May 23; (b) June 16; (c) June 30; (d) December 16. 

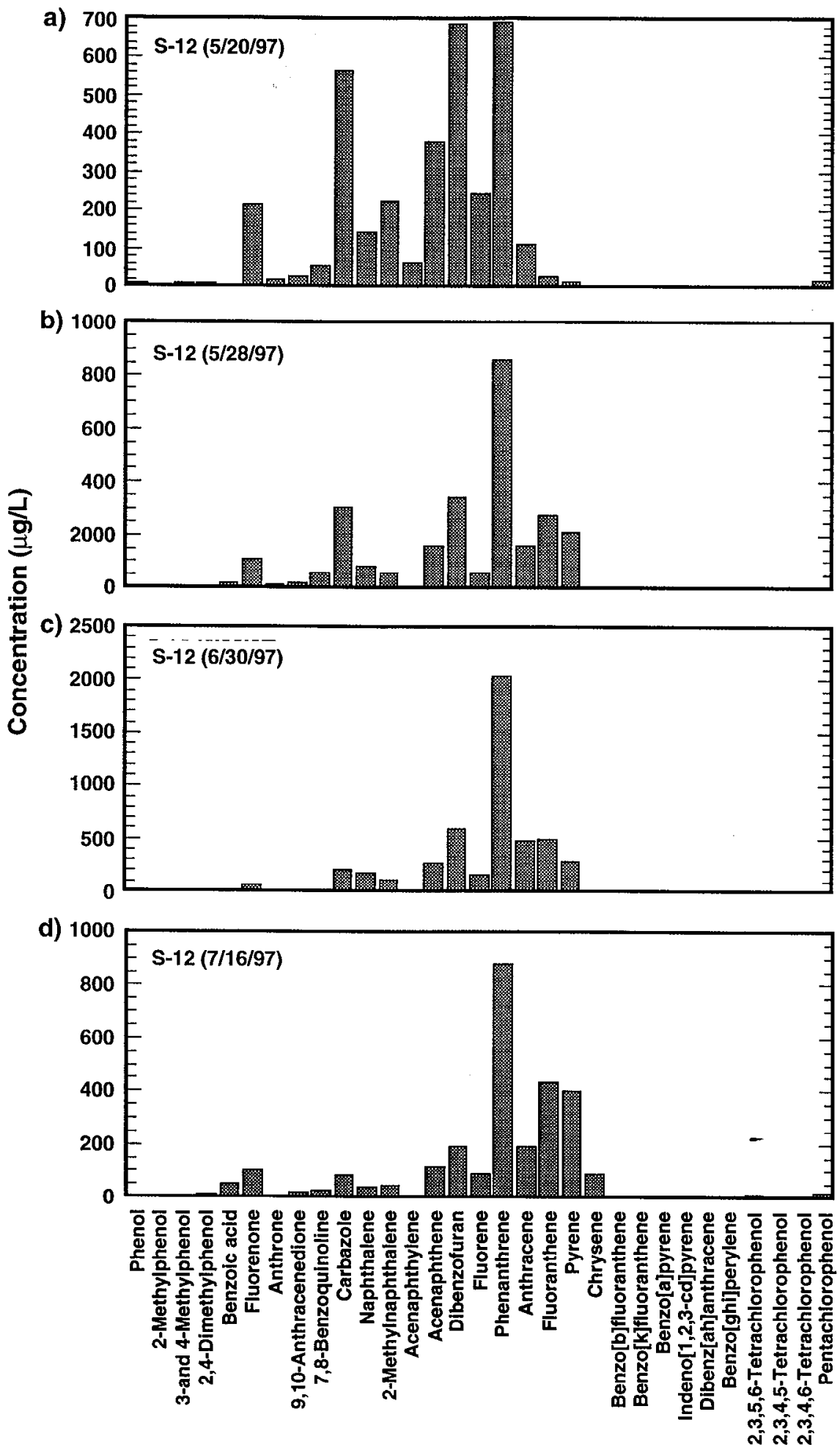

Figure 10. Histograms of the major semivolatile organic compounds present in water samples from Well S-12: (a) May 20; (b) May 28; (c) June 30; (d) July 16. 

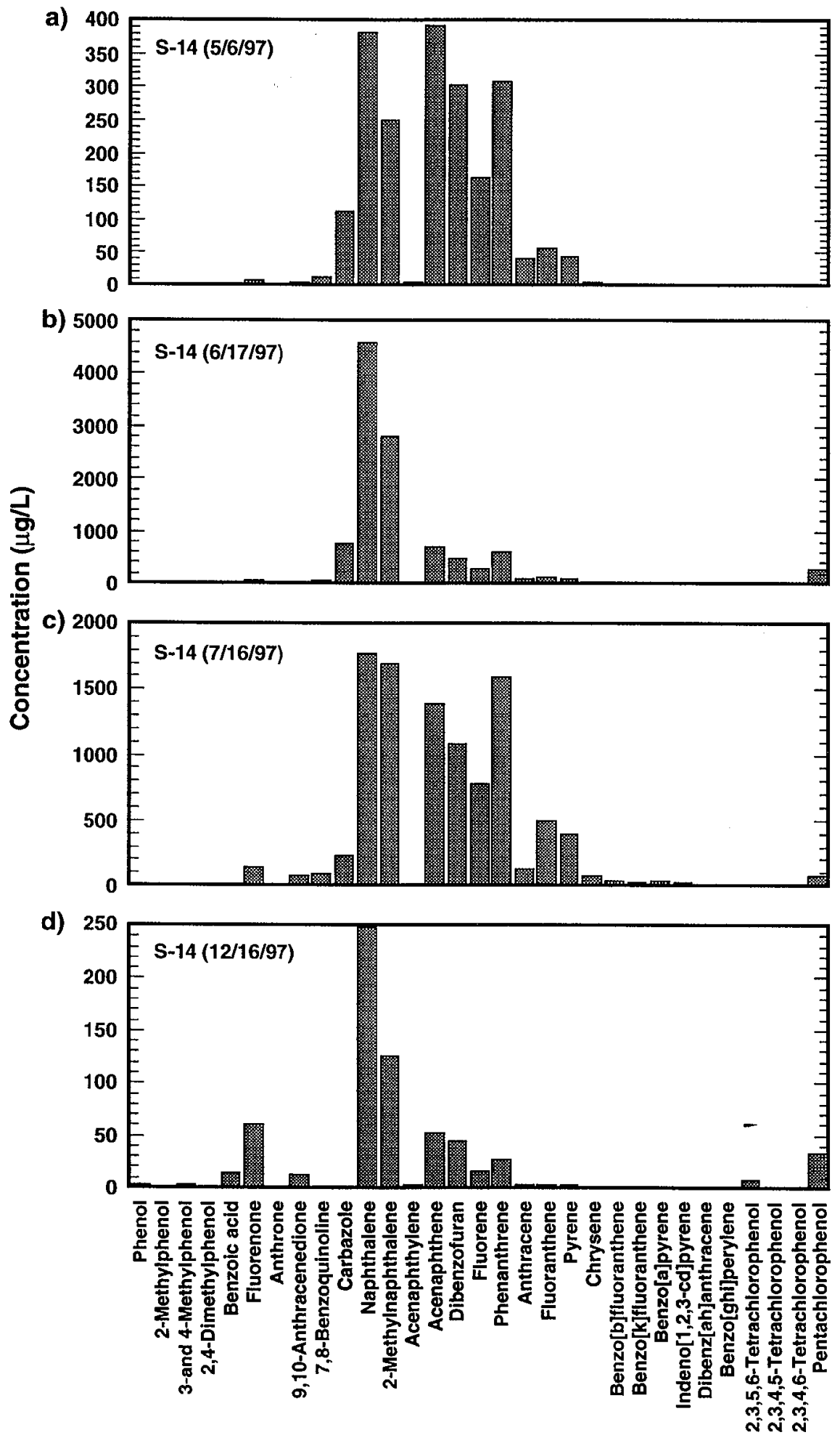

Figure 11. Histograms of the major semivolatile organic compounds present in water samples from Well S-14: (a) May 16; (b) June 17; (c) July 16; (d) December 16. 

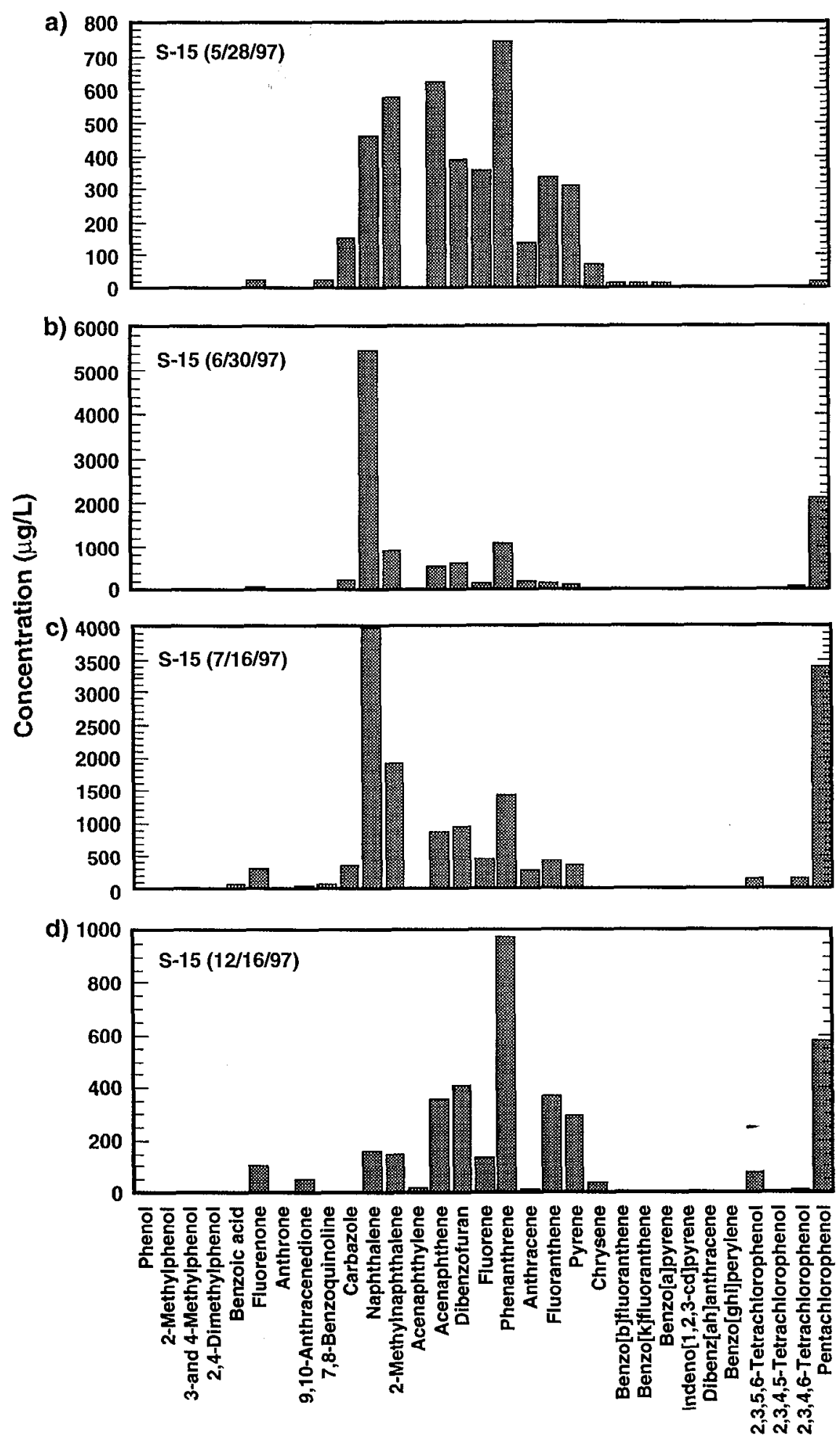

Figure 12. Histograms of the major semivolatile organic compounds present in water samples from Well S-15: (a) May 28; (b) June 30; (c) July 16; (d) December 16. 

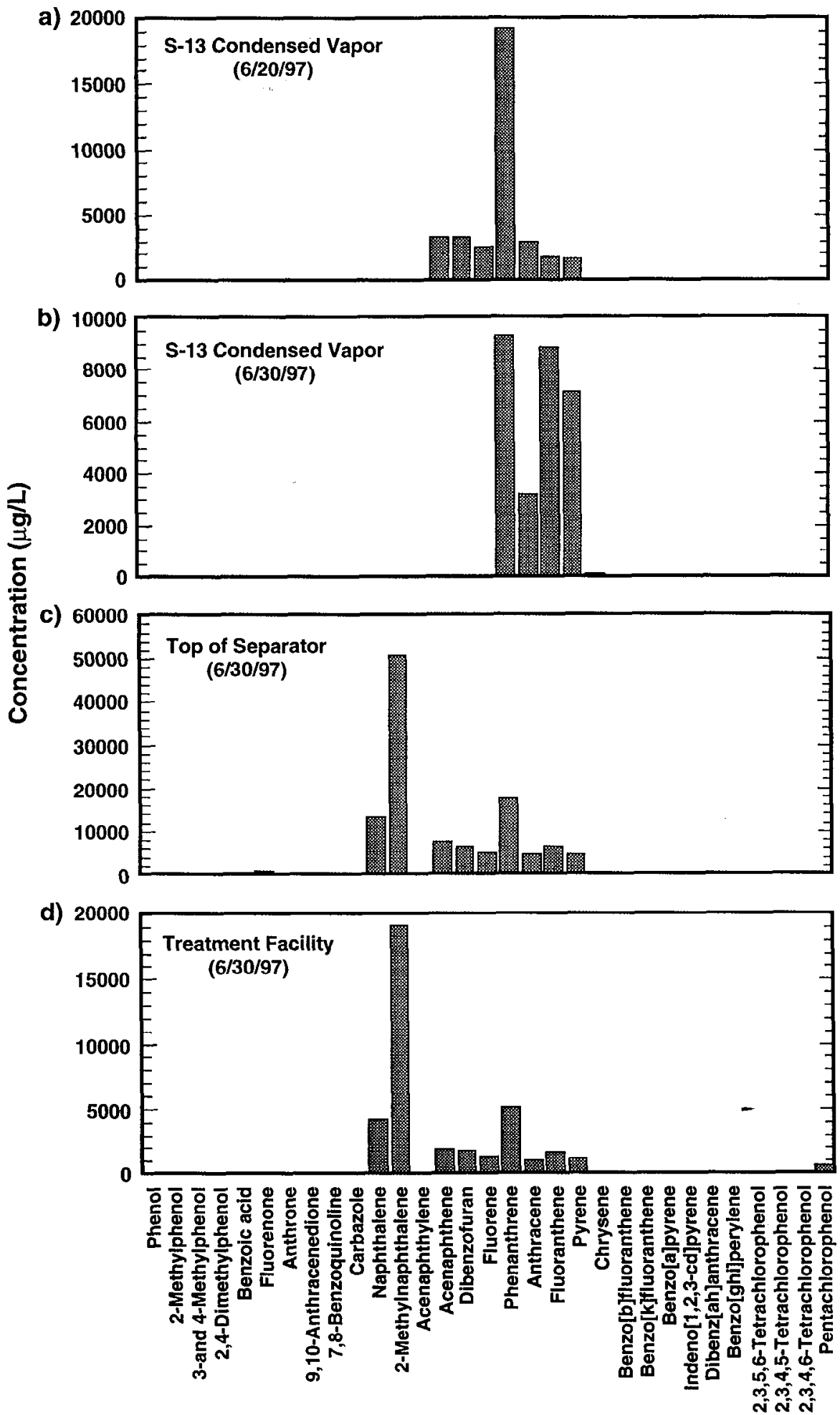

Figure 13. Histograms of the major semivolatile organic compounds present in water samples from miscellaneous sampling sites: (a) S-13 condensed vapor (June 20); (b) S-13 condensed vapor (June 30); (c) Top of separator (June 20); (d) Treatment facility (June 30). 

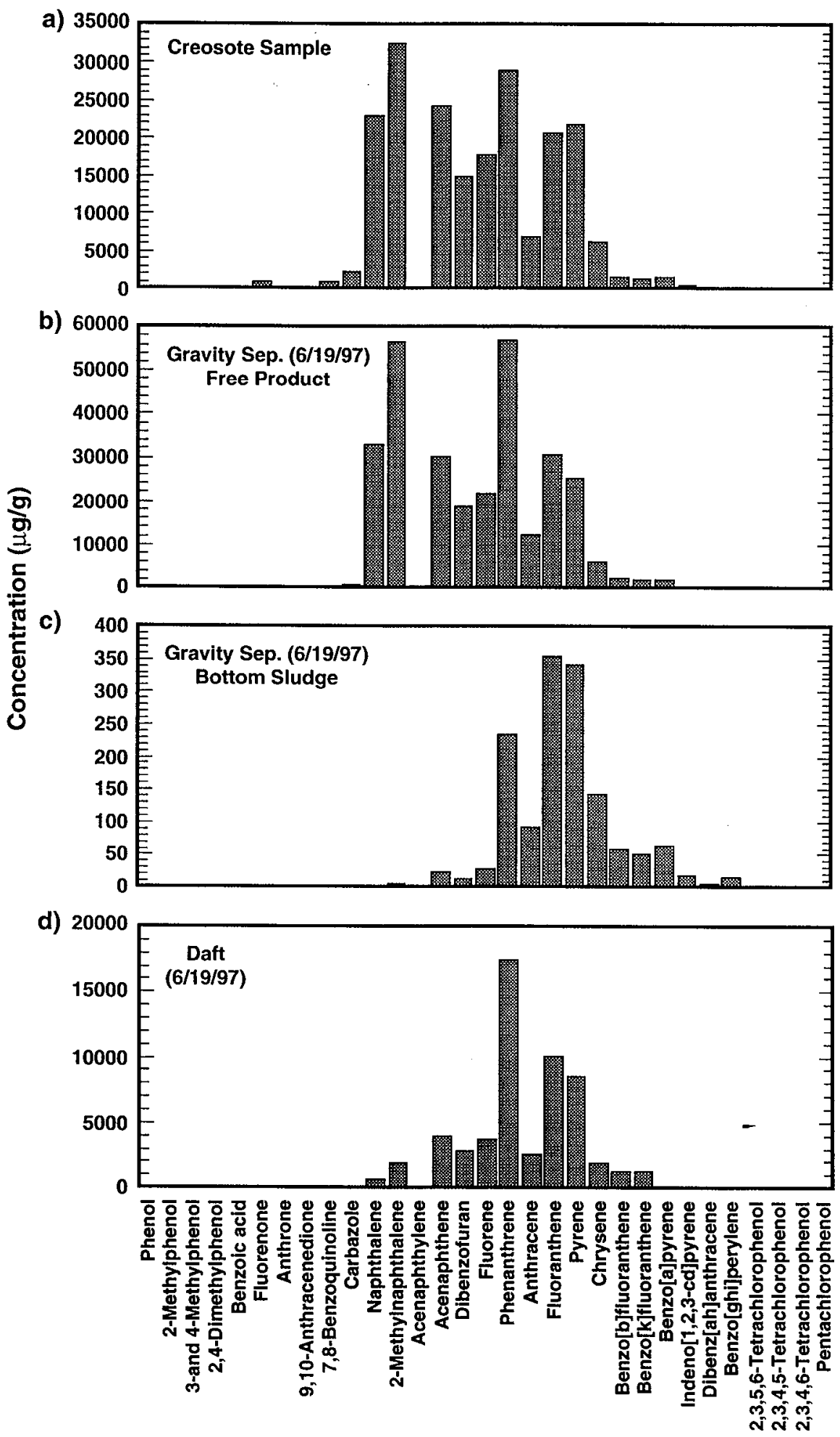

Figure 14. Histograms of the major semivolatile organic compounds present in miscellaneous free product samples: (a) Creosote; (b) Gravity separator (June 19); (c) Gravity separator bottom sludge (June 19); (d) DAFT (June 19). 

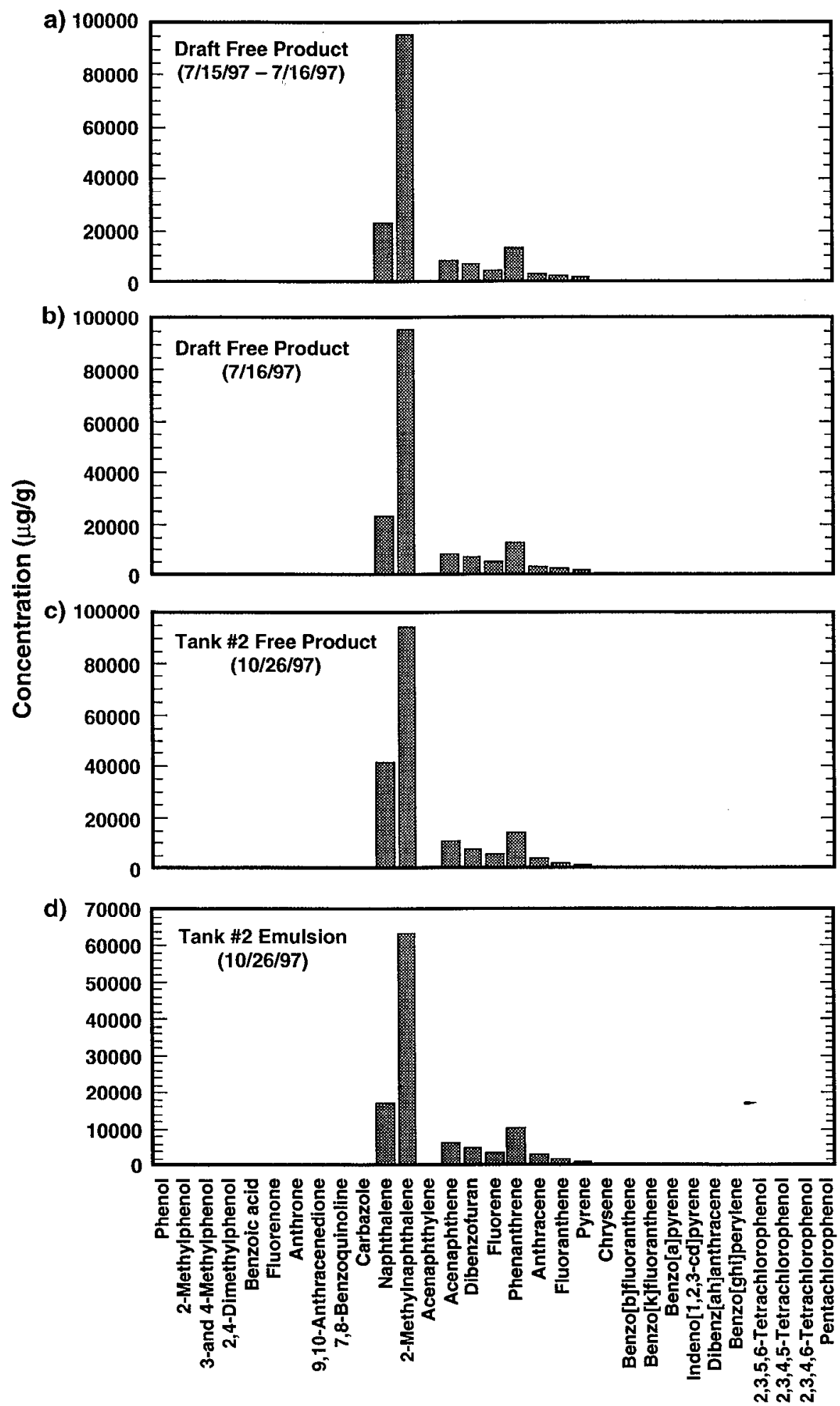

Figure 15. Histograms of the major semivolatile organic compounds present in miscellaneous free product samples: (a) DAFT free product (July 15-16); (b) DAFT free product (July 16); (c) Tank 2 free product (October 26); (d) Tank 2 emulsion (October 26). 
a)
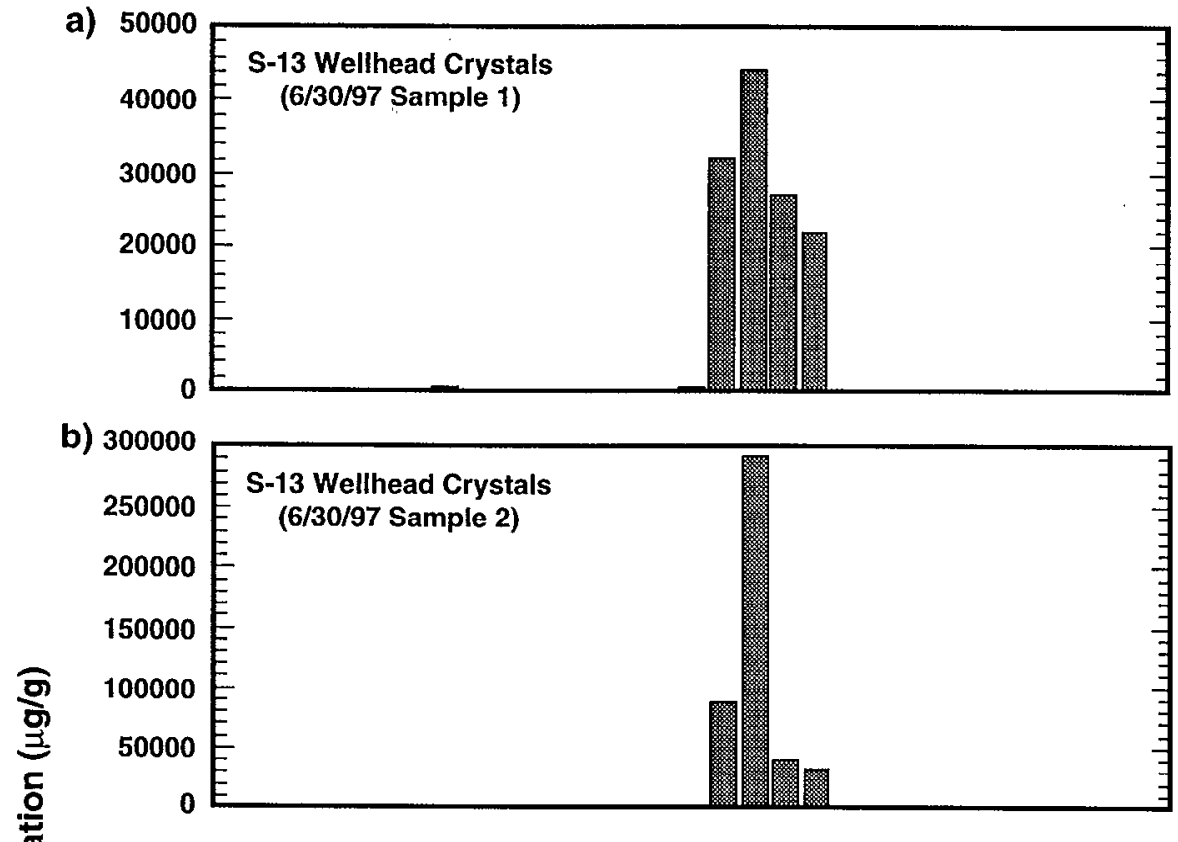

c)

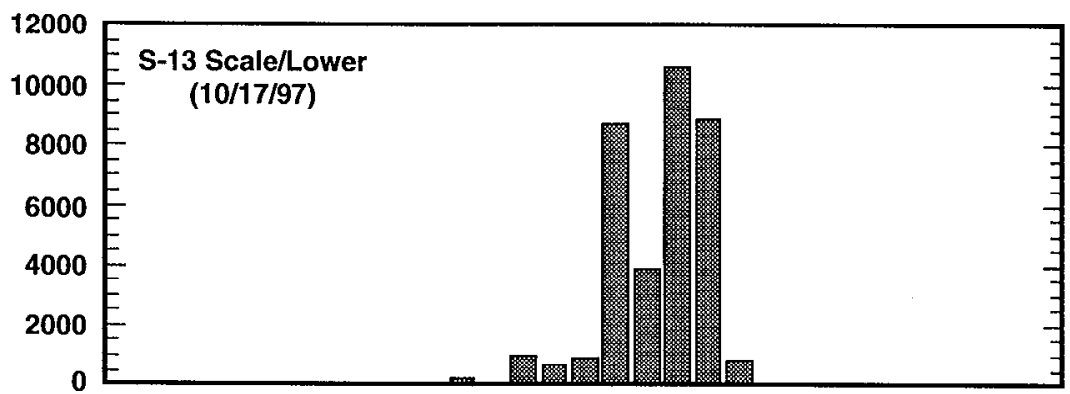

d)
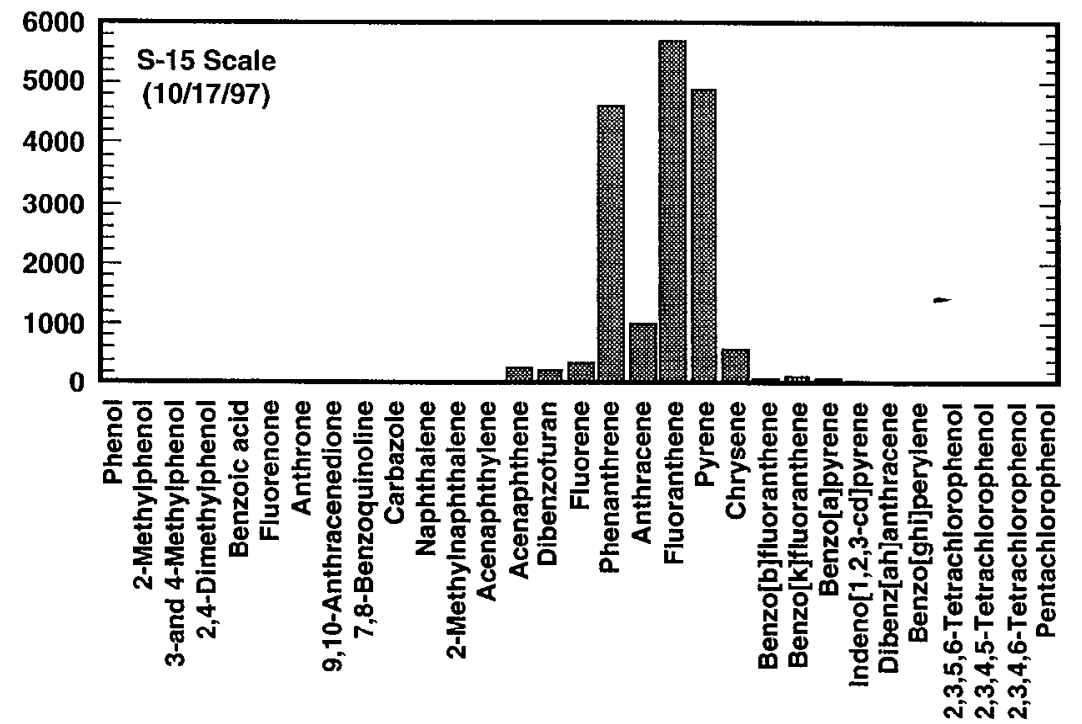

Figure 16. Histograms of the major semivolatile organic compounds present in miscellaneous solid samples: (a) S-13 Wellhead crystals (June 30 Sample 1); (b) S-13 Wellhead crystals (June 30 Sample 2); (c) S-13 scale/lower (October 17); (d) S-15 scale (October 17). 


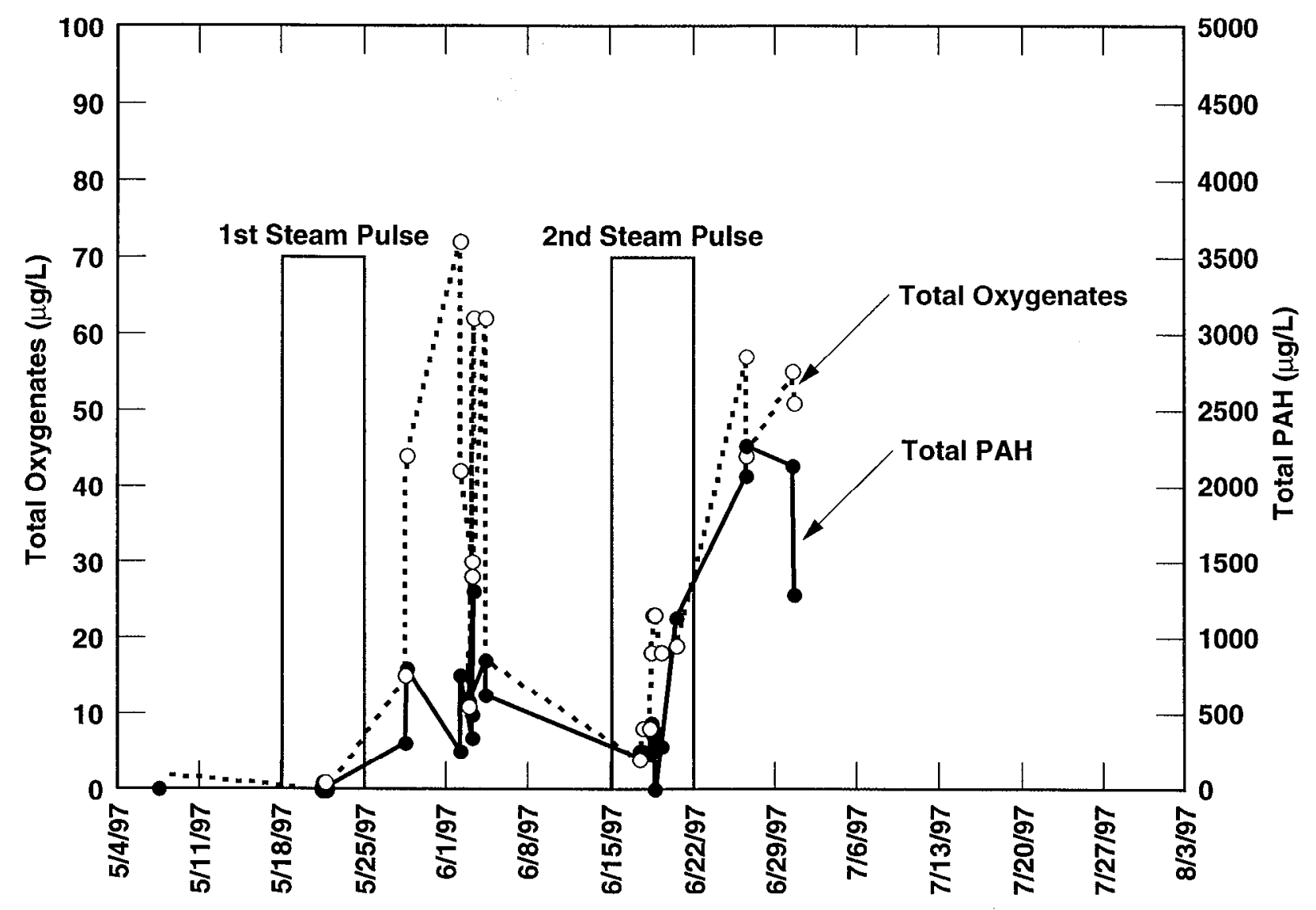

Figure 17. Concentrations of total oxygenates and total PAH (polycyclic aromatic hydrocarbons, EPA Method 8270C) from Well MW-36 during HPO test period. Elevated PAH concentrations reflect enhanced mobilization due to DUS. Oxygenate increases are consistent with partial hydrocarbon oxidation by HPO. 


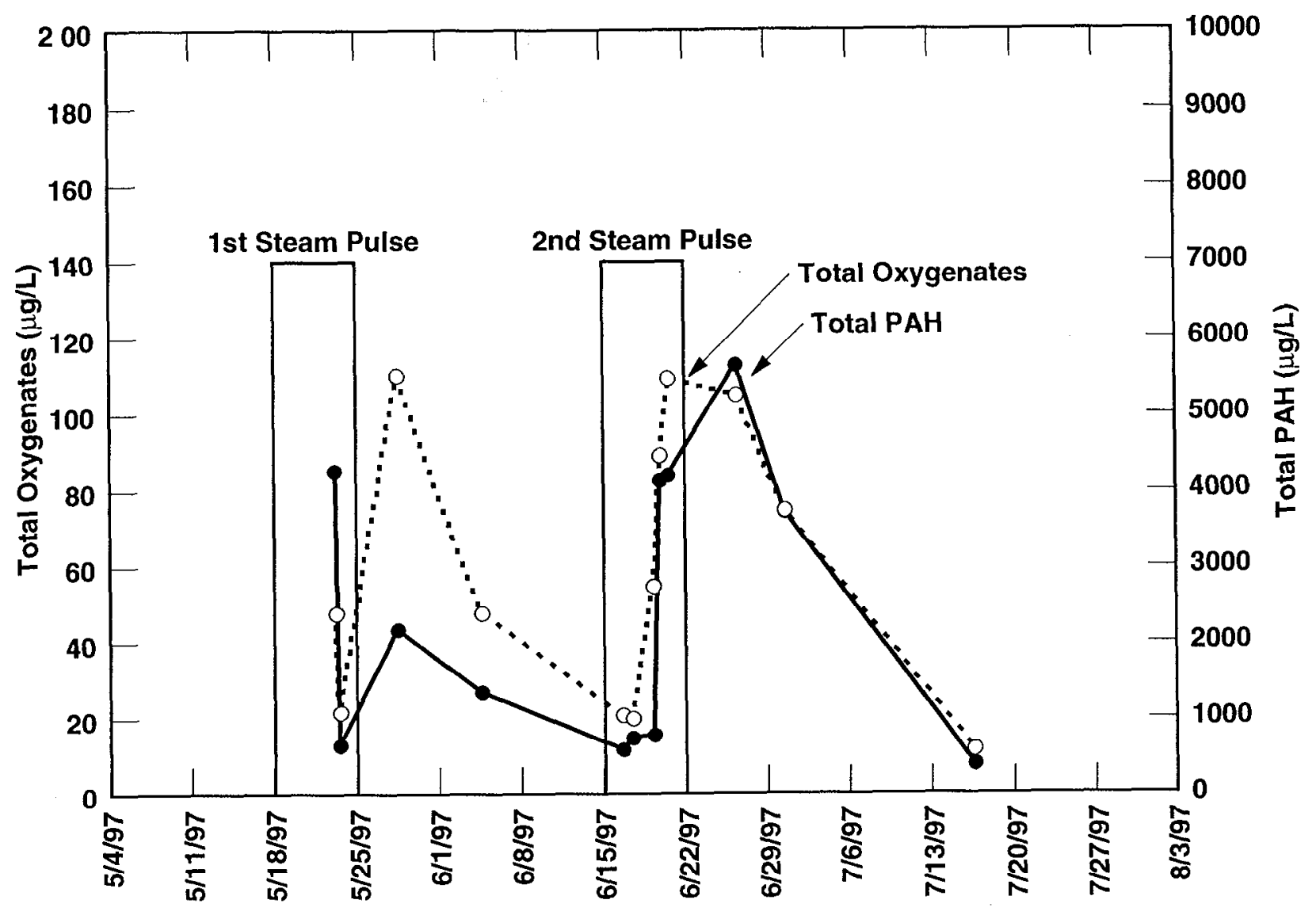

Figure 18. Concentrations of total oxygenates and total PAH (polycyclic aromatic hydrocarbons, EPA Method 8270C) from Well S-13 during HPO test period. Elevated PAH concentrations reflect enhanced mobilization due to DUS. Oxygenate increases are consistent with partial hydrocarbon oxidation by HPO. 


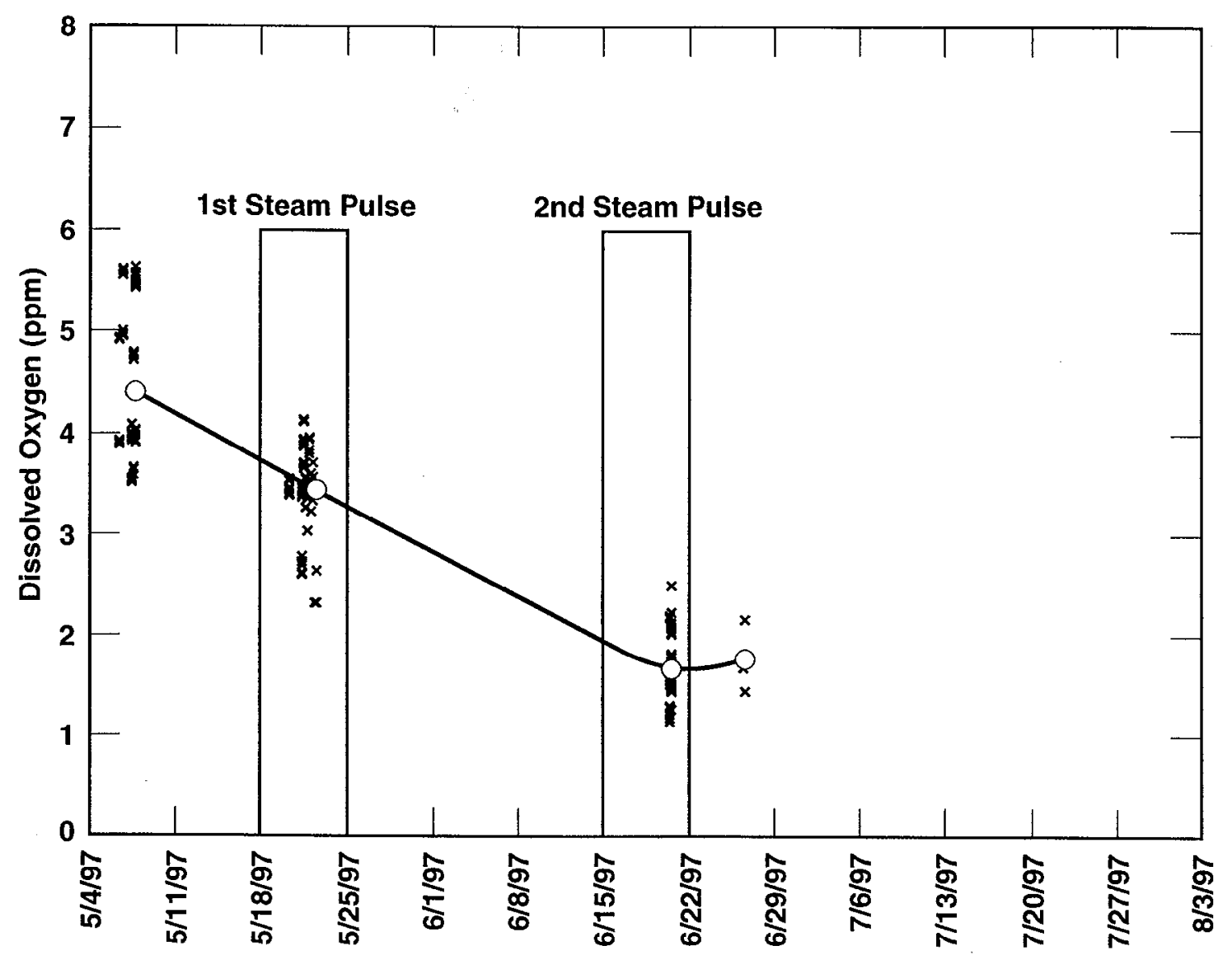

Figure 19. Concentration of dissolved oxygen in Well MW-36 as a function of time during HPO test. Average dissolved oxygen concentrations (open circles) were calculated using the combined values from three different analytical techniques. Dissolved-oxygen levels dropped from $4.4 \mathrm{ppm}$ to $1.7 \mathrm{ppm}$ during the test period. 


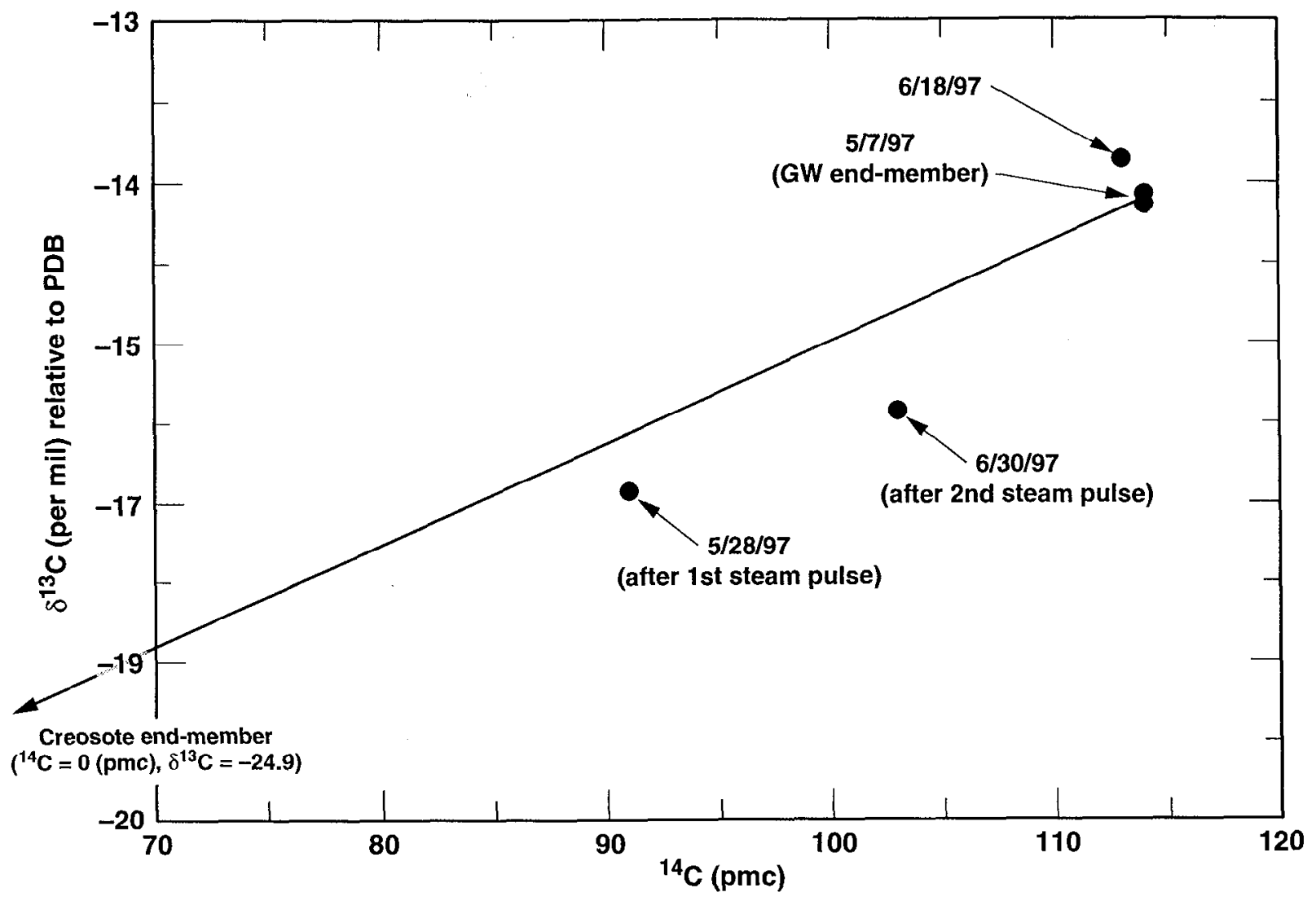

Figure 20. Variations in ${ }^{14} \mathrm{C}$ versus $\delta^{13} \mathrm{C}$ values of dissolved inorganic carbon (DIC) in groundwater. The groundwater end-member value was the isotopic signature prior to steaming. The DIC became "older" after steaming, consistent with the production of DIC by the oxidation of "dead" creosote carbon. 


\section{Appendix A: Chemical Structure Diagrams for the Semivolatile Organic Compounds Quantitated by GC-MS}

\section{Oxygenated Compounds}<smiles>Oc1ccccc1</smiles>

Phenol<smiles>Cc1ccccc1O</smiles>

2-Methylphenol<smiles>Cc1cccc(O)c1</smiles>

3-Methylphenol<smiles>Cc1ccc(O)cc1</smiles>

4-Methylphenol<smiles>Cc1ccc(O)c(C)c1</smiles>

2,4-Dimethylphenol<smiles>O=C(O)c1ccccc1</smiles>

Benzoic Acid<smiles>O=C1c2ccccc2-c2ccccc21</smiles>

Fluorenone<smiles>O=C1c2ccccc2Cc2ccccc21</smiles>

Anthrone<smiles>O=C1c2ccccc2C(=O)c2ccccc21</smiles>

9,10-Anthracenedione 


\section{Polycyclic Aromatic Hydrocarbons}<smiles>c1cnc2c(c1)ccc1cccnc12</smiles>

7,8-Benzoquinoline<smiles>c1ccc2c(c1)[nH]c1ccccc12</smiles>

Carbazole<smiles>c1ccc2c(c1)oc1ccccc12</smiles>

Dibenzofuran<smiles>c1ccc2ccccc2c1</smiles>

Naphthalene<smiles>Cc1ccc2ccccc2c1</smiles>

2-Methylnaphthalene<smiles>C1=Cc2cccc3cccc1c23</smiles>

Acenaphthylene<smiles>c1cc2c3c(cccc3c1)CC2</smiles>

Acenaphthene<smiles>c1ccc2c(c1)Cc1ccccc1-2</smiles>

Fluorene<smiles></smiles>

Fluoranthene

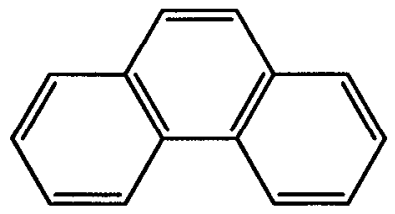

Phenanthrene<smiles></smiles>

Pyrene<smiles>c1ccc2cc3ccccc3cc2c1</smiles>

Anthracene<smiles>c1ccc2c(c1)ccc1c3ccccc3ccc21</smiles>

Chrysene 
Polycyclic Aromatic Hydrocarbons (continued)<smiles>c1ccc2c3cc(cc2c1)-c1cccc2c-3cccc12</smiles><smiles>c1ccc2cc3c(cc2c1)-c1cccc2cccc-3c12</smiles><smiles>c1ccc2c(c1)cc1ccc3cccc4ccc2c1c34</smiles>

Benzo[a]pyrene<smiles>c1ccc2c(c1)ccc1cc3c(ccc4ccccc43)cc12</smiles>

Dibenz[a,h]anthracene<smiles></smiles>

Indeno[1,2,3-cd]pyrene<smiles></smiles>

Benzo[ghi]perylene 


\section{Chlorinated Phenols}<smiles>Oc1c(Cl)ccc(Cl)c1Cl</smiles>

2,3,5,6-Tetrachlorophenol<smiles>Oc1cc(Cl)c(Cl)c(Cl)c1Cl</smiles><smiles>Oc1c(Cl)c(Cl)c(Cl)c(Cl)c1Cl</smiles>

Pentachlorophenol<smiles>Oc1c(Cl)cc(Cl)c(Cl)c1Cl</smiles>

2,3,4,6-Tetrachlorophenol 


\section{Appendix B: Tables of Analytical Results of Samples}

Table 1. Results of groundwater chemical analyses for Well MW-36 (TIC = total inorganic carbon)

\begin{tabular}{|c|c|c|c|c|c|c|c|c|c|c|c|c|c|c|c|c|c|}
\hline Sample Name & $\begin{array}{c}\text { MW-36 } \\
(5 / 7 \\
1400)\end{array}$ & $\begin{array}{c}M W-36 \\
(5 / 7 \\
1500)\end{array}$ & $\begin{array}{c}\text { MW-36 } \\
(5 / 7 \\
1700)\end{array}$ & $\begin{array}{c}M W-36 \\
(5 / 21 \\
1100)\end{array}$ & $\begin{array}{c}\text { MW-36 } \\
(5 / 21 \\
1600)\end{array}$ & $\begin{array}{c}M W-36 \\
(5 / 21 \\
1800)\end{array}$ & $\begin{array}{c}M W-36 \\
(5 / 21 \\
1850)\end{array}$ & $\begin{array}{c}M W-36 \\
(5 / 21 \\
2000)\end{array}$ & $\begin{array}{c}M W-36 \\
(5 / 21 \\
2100)\end{array}$ & $\begin{array}{c}M W-36 \\
(5 / 28 \\
1508)\end{array}$ & $\begin{array}{c}M W-36 \\
(5 / 28 \\
1710)\end{array}$ & $\begin{array}{c}M W-36 \\
(6 / 2 \\
0550)\end{array}$ & $\begin{array}{c}M-36 \\
(6 / 2 \\
0603)\end{array}$ & $\begin{array}{c}M W-36 \\
(6 / 3 \\
0730)\end{array}$ & $\begin{array}{c}M W-36 \\
(6 / 3 \\
0740)\end{array}$ & $\begin{array}{c}M W-36 \\
(6 / 3 \\
1045)\end{array}$ & $\begin{array}{c}\text { MW-36- } \\
\text { SPE } \\
\text { (6/3 } \\
\text { Last } \\
\text { Bailed) }\end{array}$ \\
\hline Date/Time Sampled & $\begin{array}{l}5 / 7 / 97 \\
14: 00\end{array}$ & $\begin{array}{l}5 / 7 / 97 \\
15: 00\end{array}$ & $\begin{array}{l}5 / 7 / 97 \\
17: 00\end{array}$ & $\begin{array}{c}5 / 21 / 97 \\
11: 00\end{array}$ & $\begin{array}{c}5 / 21 / 97 \\
16: 00\end{array}$ & $\begin{array}{c}5 / 21 / 97 \\
18: 00\end{array}$ & $\begin{array}{c}5 / 21 / 97 \\
18: 50\end{array}$ & $\begin{array}{c}5 / 21 / 97 \\
20: 00\end{array}$ & $\begin{array}{c}5 / 21 / 97 \\
21: 00\end{array}$ & $\begin{array}{c}5 / 28 / 97 \\
15: 08\end{array}$ & $\begin{array}{c}5 / 28 / 97 \\
17: 10\end{array}$ & $\begin{array}{c}6 / 2 / 97 \\
5: 50\end{array}$ & $\begin{array}{c}6 / 2 / 97 \\
6: 03\end{array}$ & $\begin{array}{c}6 / 3 / 97 \\
7: 30\end{array}$ & $\begin{array}{c}6 / 3 / 97 \\
7: 40\end{array}$ & $\begin{array}{l}6 / 3 / 97 \\
10: 45\end{array}$ & $\begin{array}{c}6 / 3 / 97 \\
0: 00\end{array}$ \\
\hline$\overline{\mathrm{pH}}$ & 7.0 & 6.9 & 7.0 & 7.0 & 6.9 & 6.9 & 7.0 & 7.0 & 7.0 & 6.9 & NA & NA & NA & NA & NA & NA & NA \\
\hline $\operatorname{TIC}(\mu \mathrm{g} \mathrm{C} / \mathrm{g})$ & 53.3 & 54.1 & 53.7 & 51.4 & 51.7 & 50.2 & 49.2 & 48.9 & 48.9 & 25.5 & NA & NA & NA & NA & NA & NA & NA \\
\hline \multicolumn{18}{|l|}{ Cations $(\mu g / g)$} \\
\hline Al & ND & ND & ND & ND & ND & ND & ND & ND & ND & ND & NA & NA & NA & NA & NA & NA & NA \\
\hline B & ND & ND & ND & ND & ND & ND & ND & ND & ND & 0.20 & NA & NA & NA & NA & NA & NA & NA \\
\hline $\mathrm{Ca}$ & 77.17 & 77.04 & 74.89 & 77.77 & 78.91 & 77.25 & 77.22 & 79.51 & 80.00 & 34.50 & NA & NA & NA & NA & NA & NA & NA \\
\hline $\mathrm{Cr}$ & 0.03 & ND & ND & ND & ND & ND & ND & ND & ND & ND & NA & NA & NA & NA & NA & NA & NA \\
\hline $\mathrm{Cu}$ & ND & ND & ND & ND & ND & 0.04 & 0.02 & 0.02 & ND & 0.01 & NA & NA & NA & NA & NA & NA & NA \\
\hline $\mathrm{Fe}$ & 0.02 & ND & ND & 0.10 & ND & 0.13 & 0.13 & 0.13 & 1.26 & 8.96 & NA & NA & NA & NA & NA & NA & NA \\
\hline $\mathrm{K}$ & 1.94 & 1.18 & 1.60 & 1.87 & 2.08 & 1.97 & 1.90 & 1.86 & 1.70 & 1.90 & NA & NA & NA & NA & NA & NA & NA \\
\hline $\mathrm{Mg}$ & 13.72 & 13.87 & 13.42 & 13.81 & 13.99 & 13.86 & 13.76 & 13.87 & 14.40 & 5.62 & NA & NA & NA & NA & NA & NA & NA \\
\hline $\mathrm{Mn}$ & ND & ND & ND & ND & ND & ND & ND & ND & 0.02 & 0.13 & NA & NA & NA & NA & NA & NA & NA \\
\hline $\mathrm{Na}$ & 17.86 & 17.35 & 17.38 & 17.80 & 18.57 & 18.00 & 18.08 & 17.70 & 18.90 & 20.10 & NA & NA & NA & NA & NA & NA & NA \\
\hline S & 1.81 & 1.80 & 1.74 & 1.86 & 1.84 & 1.88 & 1.83 & 1.83 & 11.40 & 6.20 & NA & NA & NA & NA & NA & NA & NA \\
\hline $\mathrm{Si}$ & 14.15 & 14.50 & 14.16 & 14.44 & 14.51 & 14.50 & 14.33 & 14.41 & 14.40 & 9.58 & NA & NA & NA & NA & NA & NA & NA \\
\hline $\mathrm{Sr}$ & 0.04 & 0.04 & 0.04 & 0.04 & 0.04 & 0.04 & 0.04 & 0.04 & 0.55 & 0.26 & NA & NA & NA & NA & NA & NA & NA \\
\hline $\mathrm{Zn}$ & ND & ND & ND & ND & ND & ND & ND & ND & 0.04 & 0.06 & NA & NA & NA & NA & NA & NA & NA \\
\hline \multicolumn{18}{|l|}{ Anions $(\mu g / g)$} \\
\hline Fluoride & ND & ND & ND & ND & ND & ND & ND & ND & ND & NA & NA & NA & NA & NA & NA & NA & NA \\
\hline Chloride & 18.1 & 17.2 & 17.4 & 18.1, & 18.7 & 18.8 & 18.8 & 18.4 & 18.0 & NA & NA & NA & NA & NA & NA & NA & NA \\
\hline Nitrite & ND & ND & ND & ND & ND & ND & ND & ND & ND & NA & NA & NA & NA & NA & NA & NA & NA \\
\hline Bromide & ND & ND & ND & ND & ND & ND & ND & ND & ND & NA & NA & NA & NA & NA & NA & NA & NA \\
\hline Nitrate & 35.1 & 33.6 & 34.8 & 39.5 & 39.4 & 39.4 & 37.7 & 41.0 & 37.4 & NA & NA & NA & NA & NA & NA & NA & NA \\
\hline Phosphate & ND & ND & ND & ND & ND & ND & ND & ND & ND & NA & NA & NA & NA & NA & NA & NA & NA \\
\hline Sulfate & 31.5 & 30.5 & 35.0 & 34.8 & 33.8 & 30.8 & 35.1 & 40.0 & 39.1 & NA & NA & NA & NA & NA & NA & NA & NA \\
\hline \multicolumn{18}{|c|}{ Semivolatile Organics $(\mu \mathrm{g} / \mathrm{L})$} \\
\hline Phenol & 2.0 & NA & NA & ND & 0.7 & 0.7 & ND & ND & ND & 1.6 & 2.0 & 3.3 & ND & ND & ND & 1.8 & ND \\
\hline 2-Methylphenol & ND & NA & NA & ND & ND & ND & ND & ND & ND & ND & 0.4 & ND & ND & ND & ND & ND & ND \\
\hline 3- and 4-Methylphenol & ND & NA & NA & ND & ND & ND & ND & ND & ND & ND & 0.9 & 3.4 & ND & ND & ND & ND & ND \\
\hline 2,4-Dimethylphenol & ND & NA & NA & ND & ND & ND & ND & ND & ND & ND & ND & ND & ND & ND & ND & ND & ND \\
\hline
\end{tabular}




\begin{tabular}{|c|c|c|c|c|c|c|c|c|c|c|c|c|c|c|c|c|c|}
\hline Sample Name & $\begin{array}{c}M W-36 \\
(5 / 7 \\
1400)\end{array}$ & $\begin{array}{c}M W-36 \\
(5 / 7 \\
1500)\end{array}$ & $\begin{array}{c}M W-36 \\
(5 / 7 \\
1700)\end{array}$ & $\begin{array}{c}M W-36 \\
(5 / 21 \\
1100)\end{array}$ & $\begin{array}{c}M W-36 \\
(5 / 21 \\
1600)\end{array}$ & $\begin{array}{c}M W-36 \\
(5 / 21 \\
1800)\end{array}$ & $\begin{array}{c}M W-36 \\
(5 / 21 \\
1850)\end{array}$ & $\begin{array}{c}\text { MW-36 } \\
(5 / 21 \\
2000)\end{array}$ & $\begin{array}{c}M W-36 \\
(5 / 21 \\
2100)\end{array}$ & $\begin{array}{c}M W-36 \\
(5 / 28 \\
1508)\end{array}$ & $\begin{array}{c}M W-36 \\
(5 / 28 \\
1710)\end{array}$ & $\begin{array}{c}M W-36 \\
(6 / 2 \\
0550)\end{array}$ & $\begin{array}{c}M W-36 \\
(6 / 2 \\
0603)\end{array}$ & $\begin{array}{c}M W-36 \\
(6 / 3 \\
0730)\end{array}$ & $\begin{array}{c}\text { MW-36 } \\
(6 / 3 \\
0740)\end{array}$ & $\begin{array}{c}M W-36 \\
(6 / 3 \\
1045)\end{array}$ & $\begin{array}{c}\text { MW-36- } \\
\text { SPE } \\
\text { (6/3 } \\
\text { Last } \\
\text { Bailed) }\end{array}$ \\
\hline Date/Time Sampled & $\begin{array}{c}5 / 7 / 97 \\
14: 00 \\
\end{array}$ & $\begin{array}{l}5 / 7 / 97 \\
15: 00 \\
\end{array}$ & $\begin{array}{l}5 / 7 / 97 \\
17: 00\end{array}$ & $\begin{array}{c}5 / 21 / 97 \\
11: 00\end{array}$ & $\begin{array}{c}5 / 21 / 97 \\
16: 00 \\
\end{array}$ & $\begin{array}{c}5 / 21 / 97 \\
18: 00 \\
\end{array}$ & $\begin{array}{c}5 / 21 / 97 \\
18: 50\end{array}$ & $\begin{array}{c}5 / 21 / 97 \\
20: 00 \\
\end{array}$ & $\begin{array}{c}5 / 21 / 97 \\
21: 00 \\
\end{array}$ & $\begin{array}{c}5 / 28 / 97 \\
15: 08 \\
\end{array}$ & $\begin{array}{c}5 / 28 / 97 \\
17: 10 \\
\end{array}$ & $\begin{array}{c}6 / 2 / 97 \\
5: 50 \\
\end{array}$ & $\begin{array}{c}6 / 2 / 97 \\
6: 03 \\
\end{array}$ & $\begin{array}{c}6 / 3 / 97 \\
7: 30 \\
\end{array}$ & $\begin{array}{c}6 / 3 / 97 \\
7: 40 \\
\end{array}$ & $\begin{array}{l}6 / 3 / 97 \\
10: 45 \\
\end{array}$ & $\begin{array}{c}6 / 3 / 97 \\
0: 00 \\
\end{array}$ \\
\hline Benzoic acid & ND & NA & NA & ND & ND & ND & ND & ND & ND & ND & 8.2 & 48.3 & ND & ND & ND & 16.9 & ND \\
\hline Fluorenone & ND & NA & NA & 0.4 & 0.6 & 0.5 & 0.6 & 0.5 & 0.4 & 11.6 & 27.4 & 15.2 & 33.8 & 26.4 & 24.3 & 37.7 & 11.4 \\
\hline Anthrone & ND & NA & NA & ND & ND & ND & ND & ND & ND & ND & ND & ND & 3.0 & ND & ND & ND & ND \\
\hline 9,10 -Anthracenedione & ND & NA & NA & ND & ND & ND & ND & ND & ND & 2.1 & 4.7 & 2.0 & 5.2 & 3.9 & 3.6 & 5.8 & ND \\
\hline 7,8-Benzoquinoline & ND & NA & NA & ND & ND & ND & ND & ND & ND & 3.0 & 6.1 & 4.1 & 4.4 & ND & 3.4 & 5.4 & ND \\
\hline Carbazole & ND & NA & NA & ND & ND & ND & ND & ND & ND & 43.3 & 96.1 & 45.8 & 78.0 & 45.1 & 63.2 & 80.1 & ND \\
\hline Naphthalene & ND & NA & NA & 5.2 & 4.8 & 4.5 & 4.5 & 5.4 & 4.7 & 14.6 & 17.6 & 13.0 & 33.6 & 24.2 & 25.2 & 40.9 & 17.1 \\
\hline 2-Methylnaphthalene & ND & NA & NA & ND & ND & ND & ND & ND & ND & 8.9 & 6.6 & 6.3 & 9.5 & 8.6 & 7.7 & 15.8 & ND \\
\hline Acenaphthylene & ND & NA & NA & ND & ND & ND & ND & ND & ND & ND & 1.8 & 1.5 & 2.3 & ND & ND & ND & ND \\
\hline Acenaphthene & ND & NA & NA & ND & 4.1 & 4.1 & 4.7 & ND & 3.9 & 13.9 & 28.7 & 16.4 & 35.0 & 22.3 & 24.4 & 48.5 & ND \\
\hline Dibenzofuran & ND & NA & NA & ND & ND & ND & ND & ND & ND & 18.5 & 43.1 & 20.3 & 41.5 & 26.1 & 31.3 & $49: 0$ & ND \\
\hline Fluorene & ND & NA & NA & ND & ND & ND & ND & ND & ND & 17.6 & 49.7 & 18.9 & 41.3 & 24.2 & 30.1 & 50.8 & 24.1 \\
\hline Phenanthrene & ND & NA & NA & 2.9 & 5.8 & 4.6 & 5.4 & ND & 5.1 & 127.5 & 347.5 & 90.1 & 341.3 & 144.3 & 223.8 & 565.0 & 300.4 \\
\hline Anthracene & ND & NA & NA & 0.2 & 0.4 & 0.4 & 0.4 & ND & 0.3 & 19.0 & 65.3 & 14.7 & 52.1 & 20.5 & 35.0 & 96.7 & 43.0 \\
\hline Fluoranthene & ND & NA & NA & ND & ND & ND & ND & ND & ND & 21.6 & 72.0 & 9.8 & 65.6 & 14.3 & 24.6 & 184.2 & 115.4 \\
\hline Pyrene & ND & NA & NA & ND & ND & ND & ND & ND & ND & 17.3 & 58.3 & 7.5 & 49.6 & 10.2 & 19.5 & 162.9 & 78.5 \\
\hline Chrysene & ND & NA & NA & ND & ND & ND & ND & ND & ND & ND & ND & ND & ND & ND & ND & 11.1 & ND \\
\hline Benzo[b]fluoranthene & ND & NA & NA & ND & ND & ND & ND & ND & ND & ND & ND & ND & ND & ND & ND & 0.7 & ND \\
\hline Benzo[k]fluoranthene & ND & NA & NA & ND & ND & ND & ND & ND & ND & ND & ND & ND & ND & ND & ND & ND & ND \\
\hline Benzo[a]pyrene & ND & NA & NA & ND & ND & ND & ND & ND & ND & ND & ND & ND & ND & ND & ND & 0.5 & ND \\
\hline Indeno[1,2,3-cd]pyrene & ND & NA & NA & ND & ND & ND & ND & ND & ND & ND & ND & ND & ND & ND & ND & ND & ND \\
\hline Dibenz[ah]anthracene & ND & NA & NA & ND & ND & ND & ND & ND & ND & ND & ND & ND & ND & ND & ND & ND & ND \\
\hline Benzo[ghilperylene & ND & NA & NA & ND & ND & ND & ND & ND & ND & ND & ND & ND & ND & ND & ND & ND & ND \\
\hline 2,3,5,6-Tetrachlorophenol & ND & NA & NA & ND & ND & ND & ND & ND & ND & ND & ND & ND & ND & ND & ND & ND & ND \\
\hline 2,3,4,5-Tetrachlorophenol & ND & NA & NA & ND & ND & ND & ND & ND & ND & ND & ND & ND & ND & ND & ND & ND & ND \\
\hline 2,3,4,6-Tetrachlorophenol & ND & NA & NA & ND & ND & ND & ND & ND & ND & ND & ND & ND & ND & ND & ND & ND & ND \\
\hline Pentachlorophenol & 0.4 & NA & NA & ND & ND & ND & ND & ND & 0.2 & 2.6 & 4.9 & 5.0 & 4.4 & 2.7 & 3.0 & 4.2 & ND \\
\hline Total Oxygenates $(\mu \mathrm{g} / \mathrm{L})$ & 2 & - & - & 0 & 1 & 1 & 1 & 0 & 0 & 15 & 44 & 72 & 42 & 30 & 28 & 62 & 11 \\
\hline Total PAH $(\mu \mathrm{g} / \mathrm{L})$ & 0 & - & - & 8 & 15 & 14 & 15 & 5 & 14 & 305 & 793 & 248 & 754 & 340 & 488 & 1311 & 579 \\
\hline Total Cl-Phenols $(\mu \mathrm{g} / \mathrm{L})$ & 0 & - & - & 0 & 0 & 0 & 0 & 0 & 0 & 3 & 5 & 5 & 4 & 3 & 3 & 4 & 0 \\
\hline Total GC-MS $(\mu \mathrm{g} / L)$ & 2 & - & - & 9 & 16 & 15 & 16 & 6 & 15 & 323 & 841 & 326 & 801 & 373 & 519 & 1378 & 590 \\
\hline$\%$ Oxygenates & 81.6 & - & - & 4.2 & 7.5 & 8.1 & 4.0 & 7.8 & 3.0 & 4.7 & 5.2 & 22.2 & 5.2 & 8.1 & 5.4 & 4.5 & 1.9 \\
\hline
\end{tabular}


Table 1 (continued). Results of groundwater chemical analyses for Well MW-36

\begin{tabular}{|c|c|c|c|c|c|c|c|c|c|c|c|c|c|c|c|c|c|}
\hline Sample Name & $\begin{array}{c}\text { MW-36 } \\
(6 / 4 \\
0902)\end{array}$ & $\begin{array}{c}M W-36 \\
(6 / 4 \\
1114)\end{array}$ & $\begin{array}{c}M W-36 \\
(6 / 17 \\
1305)\end{array}$ & $\begin{array}{c}M W-36 \\
(6 / 17 \\
1330)\end{array}$ & $\begin{array}{c}M W-36 \\
(6 / 17 \\
1720)\end{array}$ & $\begin{array}{c}M W-36 \\
(6 / 18 \\
0940)\end{array}$ & $\begin{array}{c}M W-36 \\
(6 / 18 \\
1330)\end{array}$ & $\begin{array}{c}\text { MW-36 } \\
(6 / 18 \\
1630)\end{array}$ & $\begin{array}{c}M W-36 \\
(6 / 18 \\
1835)\end{array}$ & $\begin{array}{c}M W-36 \\
(6 / 18 \\
2030)\end{array}$ & $\begin{array}{c}M W-36 \\
(6 / 19 \\
0805)\end{array}$ & $\begin{array}{c}M W-36 \\
(6 / 19 \\
1420)\end{array}$ & $\begin{array}{c}\text { MW-36 } \\
(6 / 19 \\
1830)\end{array}$ & $\begin{array}{c}\text { MW-36 } \\
(6 / 19 \\
2255)\end{array}$ & $\begin{array}{c}M W-36 \\
(6 / 20 \\
0955)\end{array}$ & $\begin{array}{c}M W-36 \\
(6 / 20 \\
1200)\end{array}$ & $\begin{array}{c}M W-36 \\
(6 / 20 \\
1345)\end{array}$ \\
\hline Date/Time Sampled & $\begin{array}{c}6 / 4 / 97 \\
9: 02 \\
\end{array}$ & $\begin{array}{c}6 / 4 / 97 \\
11: 14 \\
\end{array}$ & $\begin{array}{c}6 / 17 / 97 \\
13: 05\end{array}$ & $\begin{array}{c}6 / 17 / 97 \\
13: 30 \\
\end{array}$ & $\begin{array}{c}6 / 17 / 97 \\
17: 20 \\
\end{array}$ & $\begin{array}{c}6 / 18 / 97 \\
9: 40\end{array}$ & $\begin{array}{c}6 / 18 / 97 \\
13: 30 \\
\end{array}$ & $\begin{array}{c}6 / 18 / 97 \\
16: 30 \\
\end{array}$ & $\begin{array}{c}6 / 18 / 97 \\
18: 35 \\
\end{array}$ & $\begin{array}{c}6 / 18 / 97 \\
20: 30 \\
\end{array}$ & $\begin{array}{c}6 / 19 / 97 \\
8: 05\end{array}$ & $\begin{array}{c}6 / 19 / 97 \\
14: 20\end{array}$ & $\begin{array}{c}6 / 19 / 97 \\
18: 30\end{array}$ & $\begin{array}{l}\text { 6/19/97 } \\
22: 55\end{array}$ & $\begin{array}{c}6 / 20 / 97 \\
9: 55\end{array}$ & $\begin{array}{c}6 / 20 / 97 \\
12: 00\end{array}$ & $\begin{array}{c}6 / 20 / 97 \\
13: 45\end{array}$ \\
\hline$\overline{\mathrm{pH}}$ & NA & NA & 7.0 & 7.0 & 7.0 & 7.0 & 6.8 & 6.7 & 6.8 & 6.7 & 6.8 & 6.9 & 6.8 & 6.8 & 6.8 & 6.9 & 6.9 \\
\hline $\mathrm{TIC}(\mu \mathrm{g} \mathrm{C/g})$ & NA & $\mathrm{NA}$ & 46.6 & 46.0 & 47.0 & 49.3 & 47.5 & 47.6 & 46.3 & 48.2 & 48.2 & 49.8 & 48.5 & 48.3 & 51.7 & 50.4 & 50.5 \\
\hline \multicolumn{18}{|l|}{ Cations $(\mu g / g)$} \\
\hline Al & NA & NA & NA & NA & NA & NA & NA & NA & NA & NA & NA & NA & NA & NA & NA & NA & NA \\
\hline$B$ & NA & NA & NA & NA & NA & NA & NA & NA & NA & NA & NA & NA & NA & NA & NA & NA & NA \\
\hline $\mathrm{Ca}$ & NA & NA & NA & NA & NA & NA & NA & NA & NA & NA & NA & NA & NA & NA & NA & NA & NA \\
\hline $\mathrm{Cr}$ & NA & NA & NA & NA & NA & NA & NA & NA & NA & NA & NA & NA & NA & NA & NA & NA & NA \\
\hline $\mathrm{Cu}$ & NA & NA & NA & NA & NA & NA & NA & NA & NA & NA & NA & NA & NA & NA & NA & NA & NA \\
\hline $\mathrm{Fe}$ & NA & NA & NA & NA & NA & NA & NA & NA & NA & NA & NA & NA & NA & NA & NA & NA & NA \\
\hline$K$ & NA & NA & NA & NA & NA & NA & NA & NA & NA & NA & NA & NA & NA & NA & NA & NA & NA \\
\hline $\mathrm{Mg}$ & NA & NA & NA & NA & NA & NA & NA & NA & NA & NA & NA & NA & NA & NA & NA & NA & NA \\
\hline $\mathrm{Mn}$ & NA & NA & NA & NA & NA & NA & NA & NA & NA & NA & NA & NA & NA & NA & NA & NA & NA \\
\hline $\mathrm{Na}$ & NA & NA & NA & NA & NA & NA & NA & NA & NA & NA & NA & NA & NA & NA & NA & NA & NA \\
\hline$S$ & NA & NA & NA & NA & NA & NA & NA & NA & NA & NA & NA & NA & NA & NA & NA & NA & NA \\
\hline $\mathrm{Si}$ & NA & NA & NA & NA & NA & NA & NA & NA & NA & NA & NA & NA & NA & NA & NA & NA & NA \\
\hline $\mathrm{Sr}$ & NA & NA & NA & NA & NA & NA & NA & NA & NA & NA & NA & NA & NA & NA & NA & NA & NA \\
\hline $\mathrm{Zn}$ & NA & NA & NA & NA & NA & NA & NA & NA & NA & NA & NA & NA & NA & NA & NA & NA & NA \\
\hline \multicolumn{18}{|l|}{ Anions $(\mu \mathbf{g} / \mathbf{g})$} \\
\hline Fluoride & NA & NA & NA & NA & NA & NA & NA & NA & NA & NA & NA & NA & NA & NA & NA & NA & NA \\
\hline Chloride & NA & NA & NA & NA & NA & NA & NA & NA & NA & NA & NA & NA & NA & NA & NA & NA & NA \\
\hline Nitrite & NA & NA & NA & NA & NA & NA & NA & NA & NA & NA & NA & NA & NA & NA & NA & NA & NA \\
\hline Bromide & NA & NA & NA & NA & NA & NA & NA & NA & NA & NA & NA & NA & NA & NA & NA & NA & NA \\
\hline Nitrate & NA & NA & NA & NA & NA & NA & NA & NA & NA & NA & NA & NA & NA & NA & NA & NA & NA \\
\hline Phosphate & NA & NA & NA & NA & NA & NA & $N A$ & NA & NA & NA & NA & NA & NA & NA & NA & NA & NA \\
\hline Sulfate & NA & NA & NA & NA 1 & NA & NA & NA & NA & NA & NA & NA & NA & NA & NA & NA & NA & NA \\
\hline \multicolumn{18}{|c|}{ Semivolatile Organics $(\mu \mathrm{g} / \mathrm{L})$} \\
\hline Phenol & 1.8 & ND & ND & ND & ND & ND & ND & 0.3 & 0.3 & NA & ND & NA & NA & NA & NA & NA & 0.3 \\
\hline 2-Methylphenol & ND & ND & ND & ND & ND & ND & ND & 0.6 & 0.1 & NA & ND & NA & NA & NA & NA & NA & ND \\
\hline 3- and 4-Methylphenol & ND & ND & ND & ND & ND & ND & ND & 0.6 & 0.5 & NA & ND & NA & NA & NA & NA & NA & ND \\
\hline 2,4-Dimethylphenol & ND & ND & ND & ND & ND & ND & ND & 0.1 & 0.1 & NA & ND & NA & NA & NA & NA & NA & ND \\
\hline Benzoic acid & 13.3 & ND & ND & ND & ND & ND & ND & ND & 0.0 & NA & ND & NA & NA & NA & NA & NA & ND \\
\hline Fluorenone & 30.7 & 17.2 & 4.0 & 4.4 & 5.7 & 6.0 & 14.9 & 17.1 & 18.2 & NA & 9.9 & NA & NA & NA & NA & NA & 14.2 \\
\hline Anthrone & 3.0 & ND & ND & ND & ND & 0.5 & ND & 1.2 & 1.3 & NA & 0.8 & NA & NA & NA & NA & NA & 1.1 \\
\hline 9,10 -Anthracenedione & 13.2 & ND & ND & ND & 2.0 & 1.4 & 3.0 & 3.5 & 2.7 & NA & 7.4 & NA & NA & NA & NA & NA & 3.7 \\
\hline 7,8-Benzoquinoline & 4.3 & ND & ND & ND & ND & 0.9 & 1.9 & 5.0 & 5.6 & NA & 1.8 & NA & NA & NA & NA & NA & 5.8 \\
\hline
\end{tabular}




\begin{tabular}{|c|c|c|c|c|c|c|c|c|c|c|c|c|c|c|c|c|c|}
\hline Sample Name & $\begin{array}{c}M-36 \\
(6 / 4 \\
0902)\end{array}$ & $\begin{array}{c}M W-36 \\
(6 / 4 \\
1114)\end{array}$ & $\begin{array}{c}M W-36 \\
(6 / 17 \\
1305)\end{array}$ & $\begin{array}{c}M W-36 \\
(6 / 17 \\
1330)\end{array}$ & $\begin{array}{c}\text { MW-36 } \\
(6 / 17 \\
1720)\end{array}$ & $\begin{array}{c}M W-36 \\
(6 / 18 \\
0940)\end{array}$ & $\begin{array}{c}M W-36 \\
(6 / 18 \\
1330)\end{array}$ & $\begin{array}{c}M W-36 \\
(6 / 18 \\
1630)\end{array}$ & $\begin{array}{c}\text { MW-36 } \\
(6 / 18 \\
1835)\end{array}$ & $\begin{array}{c}W-36 \\
(6 / 18 \\
2030)\end{array}$ & $\begin{array}{c}\text { MW-36 } \\
(6 / 19 \\
0805)\end{array}$ & $\begin{array}{c}M W-36 \\
(6 / 19 \\
1420)\end{array}$ & $\begin{array}{c}\text { MW-36 } \\
(6 / 19 \\
1830)\end{array}$ & $\begin{array}{c}M W-36 \\
(6 / 19 \\
2255)\end{array}$ & $\begin{array}{c}\text { MW-36 } \\
(6 / 20 \\
0955)\end{array}$ & $\begin{array}{c}M W-36 \\
(6 / 20 \\
1200)\end{array}$ & $\begin{array}{c}M W-36 \\
(6 / 20 \\
1345)\end{array}$ \\
\hline Date/Time Sampled & $\begin{array}{c}6 / 4 / 97 \\
9: 02\end{array}$ & $\begin{array}{l}6 / 4 / 97 \\
11: 14\end{array}$ & $\begin{array}{c}6 / 17 / 97 \\
13: 05\end{array}$ & $\begin{array}{c}6 / 17 / 97 \\
13: 30\end{array}$ & $\begin{array}{c}6 / 17 / 97 \\
17: 20\end{array}$ & $\begin{array}{c}6 / 18 / 97 \\
9: 40\end{array}$ & $\begin{array}{c}6 / 18 / 97 \\
13: 30\end{array}$ & $\begin{array}{c}6 / 18 / 97 \\
16: 30\end{array}$ & $\begin{array}{c}6 / 18 / 97 \\
18: 35\end{array}$ & $\begin{array}{c}6 / 18 / 97 \\
20: 30\end{array}$ & $\begin{array}{c}6 / 19 / 97 \\
8: 05\end{array}$ & $\begin{array}{c}6 / 19 / 97 \\
14: 20\end{array}$ & $\begin{array}{c}6 / 19 / 97 \\
18: 30\end{array}$ & $\begin{array}{l}6 / 19 / 97 \\
22: 55\end{array}$ & $\begin{array}{c}6 / 20 / 97 \\
9: 55\end{array}$ & $\begin{array}{c}6 / 20 / 97 \\
12: 00\end{array}$ & $\begin{array}{c}6 / 20 / 97 \\
13: 45\end{array}$ \\
\hline Carbazole & 47.3 & 30.3 & 4.2 & 5.6 & 5.7 & 7.0 & 20.7 & 24.5 & 25.3 & NA & 7.8 & NA & NA & NA & NA & NA & 10.1 \\
\hline Naphthalene & 34.9 & 17.4 & 12.0 & 15.8 & 12.5 & 9.8 & 61.7 & 30.9 & 32.7 & NA & 10.2 & NA & NA & NA & NA & NA & 10.4 \\
\hline 2-Methylnaphthalene & 13.8 & ND & 2.3 & 5.8 & 2.3 & 2.1 & 6.1 & 3.8 & 5.4 & NA & 3.9 & NA & NA & NA & NA & NA & 12.8 \\
\hline Acenaphthylene & 2.5 & ND & ND & 0.3 & 0.3 & 0.4 & 1.0 & 1.5 & 1.6 & NA & 1.0 & NA & NA & NA & NA & NA & 2.5 \\
\hline Acenaphthene & 35.4 & 20.4 & 7.7 & 8.9 & 9.2 & 11.0 & 20.1 & 19.6 & 21.6 & NA & 19.9 & NA & NA & NA & NA & NA & 60.6 \\
\hline Dibenzofuran & 34.1 & 21.6 & 6.4 & 7.3 & 7.6 & 10.0 & 17.2 & 17.5 & 20.2 & NA & 24.7 & NA & NA & NA & NA & NA & 92.4 \\
\hline Fluorene & 38.5 & 22.0 & 7.7 & 8.6 & 9.2 & 10.2 & 17.1 & 16.9 & 19.0 & NA & 20.3 & NA & NA & NA & NA & NA & 75.9 \\
\hline Phenanthrene & 404.0 & 335.3 & 103.8 & 119.6 & 122.5 & 88.7 & 173.6 & 114.9 & 119.3 & NA & 113.4 & NA & NA & NA & NA & NA & 425.5 \\
\hline Anthracene & 55.1 & 50.9 & 19.4 & 22.5 & 22.8 & 24.7 & 32.1 & 32.3 & 39.4 & NA & 8.0 & NA & NA & $N A$ & NA & NA & 77.2 \\
\hline Fluoranthene & 103.4 & 69.1 & 29.3 & 35.1 & 36.2 & 41.3 & 50.5 & 52.8 & 58.0 & NA & 25.1 & NA & NA & NA & NA & NA & 196.9 \\
\hline Pyrene & 78.7 & 53.0 & 18.3 & 21.2 & 21.5 & 27.7 & 31.2 & 35.3 & 38.2 & NA & 41.4 & NA & NA & NA & NA & NA & 154.8 \\
\hline Chrysene & ND & ND & ND & ND & 0.5 & 0.7 & 0.7 & 0.9 & 1.1 & NA & 1.8 & NA & NA & NA & NA & NA & 6.9 \\
\hline Benzo[b]fluoranthene & ND & ND & ND & ND & ND & ND & ND & ND & ND & NA & ND & NA & NA & NA & NA & NA & ND \\
\hline Benzo[k]fluoranthene & ND & ND & ND & ND & ND & ND & ND & ND & ND & NA & ND & NA & NA & NA & NA & NA & ND \\
\hline Benzo[a]pyrene & ND & ND & ND & ND & ND & ND & ND & ND & ND & NA & ND & NA & NA & NA & NA & NA & 1.5 \\
\hline Indeno[1,2,3-cd]pyrene & ND & ND & ND & ND & ND & ND & ND & ND & ND & NA & ND & NA & NA & NA & NA & NA & ND \\
\hline Dibenz[ah]anthracene & ND & ND & ND & ND & ND & ND & ND & ND & ND & NA & ND & NA & NA & NA & NA & NA & ND \\
\hline Benzo[ghi]perylene & ND & ND & ND & ND & ND & ND & ND & ND & ND & NA & ND & NA & NA & NA & NA & NA & ND \\
\hline 2,3,5,6-Tetrachlorophenol & ND & ND & ND & ND & ND & ND & ND & ND & ND & NA & ND & NA & NA & NA & NA & NA & ND \\
\hline 2,3,4,5-Tetrachlorophenol & ND & ND & ND & ND & ND & ND & ND & ND & ND & NA & ND & NA & NA & NA & NA & NA & ND \\
\hline 2,3,4,6-Tetrachlorophenol & ND & ND & ND & ND & ND & ND & ND & ND & ND & NA & ND & NA & NA & NA & NA & NA & ND \\
\hline Pentachlorophenol & 7.2 & 1.9 & 1.5 & 1.8 & 3.5 & 1.3 & 3.0 & 2.8 & 3.3 & NA & 1.0 & NA & NA & NA & NA & NA & 1.0 \\
\hline Total Oxygenates $(\mu \mathrm{g} / \mathrm{L})$ & 62 & 17 & 4 & 4 & 8 & 8 & 18 & 23 & 23 & - & 18 & - & - & - & - & - & 19 \\
\hline Total PAH $(\mu \mathrm{g} / \mathrm{L})$ & 852 & 620 & 211 & 251 & 250 & 235 & 434 & 356 & 387 & - & 279 & - & - & - & - & - & 1133 \\
\hline Total Cl-Phenols $(\mu \mathrm{g} / \mathrm{L})$ & 7 & 2 & 2 & 2 & 3 & 1 & 3 & 3 & 3 & - & 1 & - & - & - & - & - & 1 \\
\hline Total GC-MS $(\mu \mathrm{g} / \mathrm{L})$ & 921 & 639 & 216 & 257 & 261 & 244 & 455 & 382 & 414 & - & 298 & - & - & - & - & - & 1153 \\
\hline$\%$ Oxygenates & 6.7 & 2.7 & 1.9 & 1.7 & 2.9 & 3.2 & 3.9 & 6.1 & 5.6 & - & 6.1 & - & - & - & - & - & 1.7 \\
\hline
\end{tabular}


Table 1 (continued). Results of groundwater chemical analyses for Well MW-36

\begin{tabular}{|c|c|c|c|c|c|}
\hline Sample Name & $\begin{array}{c}M W-36 \\
(6 / 20 \\
1415)\end{array}$ & $\begin{array}{c}M W-36 \\
(6 / 26 \\
1330)\end{array}$ & $\begin{array}{c}M W-36 \\
(6 / 26 \\
1450)\end{array}$ & $\begin{array}{c}M W-36 \\
(6 / 30 \\
1340)\end{array}$ & $\begin{array}{c}M W-36 \\
(6 / 30 \\
1810)\end{array}$ \\
\hline Date/Time Sampled & $\begin{array}{c}6 / 20 / 97 \\
14: 15\end{array}$ & $\begin{array}{c}6 / 26 / 97 \\
13: 30\end{array}$ & $\begin{array}{c}6 / 26 / 97 \\
14: 50\end{array}$ & $\begin{array}{c}6 / 30 / 97 \\
13: 40\end{array}$ & $\begin{array}{c}6 / 30 / 97 \\
18: 10\end{array}$ \\
\hline$\overline{\mathrm{pH}}$ & NA & 7.1 & 7.0 & 6.9 & 7.0 \\
\hline $\mathrm{TIC}(\mu \mathrm{g} \mathrm{C} / \mathrm{g})$ & NA & 44.6 & 45.7 & 48.4 & 47.1 \\
\hline \multicolumn{6}{|l|}{ Cations $(\mu \mathrm{g} / \mathrm{g})$} \\
\hline Al & ND & ND & ND & ND & ND \\
\hline$B$ & ND & ND & ND & ND & ND \\
\hline $\mathrm{Ca}$ & 73.18 & 66.72 & 68.02 & 68.85 & 75.19 \\
\hline $\mathrm{Cr}$ & ND & ND & ND & ND & ND \\
\hline $\mathrm{Cu}$ & ND & 0.02 & ND & ND & ND \\
\hline $\mathrm{Fe}$ & 0.23 & 0.32 & 0.24 & 0.21 & 0.36 \\
\hline K & 2.11 & 2.40 & 2.80 & 2.61 & 2.54 \\
\hline $\mathrm{Mg}$ & 12.29 & 10.95 & 11.07 & 11.52 & 12.28 \\
\hline $\mathrm{Mn}$ & ND & ND & ND & ND & ND \\
\hline $\mathrm{Na}$ & 18.72 & 19.23 & 19.66 & 19.45 & 18.24 \\
\hline S & 1.74 & 1.70 & 1.77 & 1.76 & 1.84 \\
\hline $\mathrm{Si}$ & 16.88 & 21.87 & 22.75 & 21.40 & 19.95 \\
\hline $\mathrm{Sr}$ & 0.04 & 0.03 & 0.03 & 0.03 & 0.04 \\
\hline $\mathrm{Zn}$ & ND & ND & ND & ND & ND \\
\hline \multicolumn{6}{|l|}{$\overline{\text { Anions }(\mu \mathrm{g} / \mathrm{g})}$} \\
\hline Fluoride & NA & ND & ND & ND & ND \\
\hline Chloride & NA & 19.5 & 18.8 & 20.3 & 20.7 \\
\hline Nitrite & NA & ND & ND & ND & ND \\
\hline Bromide & NA & ND & ND & ND & ND \\
\hline Nitrate & NA & 35.6 & 35.4 & 36.5 & 37.7 \\
\hline Phosphate & NA & ND & ND & ND & ND \\
\hline Sulfate & NA & 34.1 & 34.1 & 36.81 & 36.8 \\
\hline \multicolumn{6}{|c|}{ Semivolatile Organics $(\mu \mathrm{g} / \mathrm{L})$} \\
\hline Phenol & NA & 0.6 & 0.5 & 0.3 & 0.2 \\
\hline 2-Methylphenol & NA & 0.3 & 0.2 & 0.2 & 0.1 \\
\hline 3- and 4-Methylphenol & NA & 1.2 & 0.9 & 0.7 & 0.4 \\
\hline 2,4-Dimethylphenol & NA & 1.8 & 0.1 & ND & 0.0 \\
\hline Benzoic acid & NA & 8.4 & 0.0 & 5.2 & 4.0 \\
\hline Fluorenone & NA & 27.4 & 24.8 & 19.4 & 17.7 \\
\hline Anthrone & NA & 3.3 & 3.5 & 4.1 & 2.2 \\
\hline
\end{tabular}

\begin{tabular}{|c|c|c|c|c|c|}
\hline Sample Name & $\begin{array}{c}M W-36 \\
(6 / 20 \\
1415)\end{array}$ & $\begin{array}{c}M W-36 \\
(6 / 26 \\
1330)\end{array}$ & $\begin{array}{c}M W-36 \\
(6 / 26 \\
1450)\end{array}$ & $\begin{array}{c}M W-36 \\
(6 / 30 \\
1340)\end{array}$ & $\begin{array}{c}M W-36 \\
(6 / 30 \\
1810)\end{array}$ \\
\hline Date/Time Sampled & $\begin{array}{c}6 / 20 / 97 \\
14: 15\end{array}$ & $\begin{array}{c}6 / 26 / 97 \\
13: 30\end{array}$ & $\begin{array}{c}6 / 26 / 97 \\
14: 50\end{array}$ & $\begin{array}{c}6 / 30 / 97 \\
13: 40\end{array}$ & $\begin{array}{c}6 / 30 / 97 \\
18: 10\end{array}$ \\
\hline 9,10 -Anthracenedione & NA & 14.3 & 14.1 & 25.5 & 26.7 \\
\hline 7,8-Benzoquinoline & NA & 9.3 & 7.9 & 5.6 & 2.7 \\
\hline Carbazole & NA & 15.2 & 11.7 & 6.7 & 8.6 \\
\hline Naphthalene & NA & 3.1 & 5.0 & 6.4 & 7.3 \\
\hline 2-Methylnaphthalene & NA & 9.3 & 11.6 & 5.1 & 4.0 \\
\hline Acenaphthylene & NA & 3.4 & 4.1 & 2.1 & 2.3 \\
\hline Acenaphthene & NA & 71.2 & 91.2 & 29.3 & 34.8 \\
\hline Dibenzofuran & NA & 105.7 & 132.4 & 49.4 & 58.2 \\
\hline Fluorene & NA & 89.2 & 105.2 & 57.5 & 51.0 \\
\hline Phenanthrene & NA & 836.1 & 873.2 & 763.2 & 500.4 \\
\hline Anthracene & NA & 178.2 & 169.6 & 166.3 & 85.8 \\
\hline Fluoranthene & NA & 379.3 & 442.1 & 610.3 & 292.2 \\
\hline Pyrene & NA & 344.0 & 377.0 & 408.1 & 235.2 \\
\hline Chrysene & NA & 22.0 & 23.7 & 17.2 & 6.2 \\
\hline Benzo[b]fluoranthene & NA & 1.7 & 1.6 & 1.4 & ND \\
\hline Benzo[k]fluoranthene & NA & 1.3 & 1.2 & 1.0 & ND \\
\hline Benzo[a]pyrene & NA & 1.8 & 1.9 & 1.6 & ND \\
\hline Indeno[1,2,3-cd]pyrene & NA & ND & ND & ND & ND \\
\hline Dibenz[ah]anthracene & NA & ND & ND & ND & ND \\
\hline Benzo[ghi]perylene & NA & ND & ND & ND & ND \\
\hline 2,3,5,6-Tetrachlorophenol & NA & 0.9 & 0.4 & 0.1 & 0.3 \\
\hline 2,3,4,5-Tetrachlorophenol & NA & ND & ND & ND & ND \\
\hline 2,3,4,6-Tetrachlorophenol & NA & 0.2 & 0.1 & 0.1 & 0.1 \\
\hline Pentachlorophenol & NA & 2.5 & 1.3 & 1.8 & 2.0 \\
\hline Total Oxygenates $(\mu \mathrm{g} / \mathrm{L})$ & - & 57 & 44 & 55 & 51 \\
\hline Total PAH $(\mu \mathrm{g} / \mathrm{L})$ & - & 2071 & 2259 & 2131 & 1289 \\
\hline Total Cl-Phenols $(\mu g / L)$ & - & 4 & 2 & 2 & 2 \\
\hline Total GC-MS $(\mu \mathrm{g} / \mathrm{L})$ & - & 2132 & 2305 & 2189 & 1342 \\
\hline$\%$ Oxygenates & - & 2.7 & 1.9 & 2.5 & 3.8 \\
\hline
\end{tabular}


Table 2. Results of groundwater chemical analyses for Well S-13

\begin{tabular}{|c|c|c|c|c|c|c|c|c|c|c|c|c|c|c|c|c|c|}
\hline Sample Name & $\begin{array}{l}\text { S-13 } \\
(5 / 23 \\
0830)\end{array}$ & $\begin{array}{l}S-13 \\
(5 / 23 \\
1350)\end{array}$ & $\begin{array}{c}S-13 \\
(5 / 28 \\
1255)\end{array}$ & $\begin{array}{c}S-13 \\
(6 / 4 \\
1605)\end{array}$ & $\begin{array}{l}\text { S-13 } \\
(6 / 16 \\
1700)\end{array}$ & $\begin{array}{l}S-13 \\
(6 / 17 \\
1140)\end{array}$ & $\begin{array}{l}S-13 \\
(6 / 18 \\
2320)\end{array}$ & $\begin{array}{l}-13 \\
(6 / 19 \\
0740)\end{array}$ & $\begin{array}{l}S-13 \\
(6 / 19 \\
1025)\end{array}$ & $\begin{array}{l}-13 \\
(6 / 19 \\
1340)\end{array}$ & $\begin{array}{l}S-13 \\
(6 / 19 \\
1750)\end{array}$ & $\begin{array}{l}S-13 \\
(6 / 19 \\
2225)\end{array}$ & $\begin{array}{l}S-13 \\
(6 / 20 \\
0830)\end{array}$ & $\begin{array}{l}S-13 \\
(6 / 20 \\
1145)\end{array}$ & $\begin{array}{l}S-13 \\
(6 / 20 \\
1330)\end{array}$ & $\begin{array}{l}S-13 \\
(6 / 26 \\
1245)\end{array}$ & $\begin{array}{l}\text { S-13 } \\
(6 / 30 \\
1445)\end{array}$ \\
\hline Date/Time Sampled & $\begin{array}{c}5 / 23 / 97 \\
8: 30\end{array}$ & $\begin{array}{c}5 / 23 / 97 \\
13: 50\end{array}$ & $\begin{array}{c}5 / 28 / 97 \\
12: 55\end{array}$ & $\begin{array}{l}6 / 4 / 97 \\
16: 05\end{array}$ & $\begin{array}{c}6 / 16 / 97 \\
17: 00\end{array}$ & $\begin{array}{c}6 / 17 / 97 \\
11: 40 \\
\end{array}$ & $\begin{array}{c}6 / 18 / 97 \\
23: 20 \\
\end{array}$ & $\begin{array}{c}6 / 19 / 97 \\
7: 40\end{array}$ & $\begin{array}{c}6 / 19 / 97 \\
10: 25\end{array}$ & $\begin{array}{c}6 / 19 / 97 \\
13: 40 \\
\end{array}$ & $\begin{array}{c}6 / 19 / 97 \\
17: 50 \\
\end{array}$ & $\begin{array}{c}6 / 19 / 97 \\
22: 25 \\
\end{array}$ & $\begin{array}{c}6 / 20 / 97 \\
8: 30 \\
\end{array}$ & $\begin{array}{c}6 / 20 / 97 \\
11: 45\end{array}$ & $\begin{array}{c}6 / 20 / 97 \\
13: 30 \\
\end{array}$ & $\begin{array}{c}6 / 26 / 97 \\
12: 45 \\
\end{array}$ & $\begin{array}{c}6 / 30 / 97 \\
14: 45 \\
\end{array}$ \\
\hline$\overline{\mathrm{pH}}$ & 7.0 & 7.0 & 7.0 & NA & 7.1 & 7.0 & 6.7 & 6.6 & 6.6 & 7.0 & 7.0 & 6.8 & 6.8 & 7.0 & 7.0 & 7.0 & 7.0 \\
\hline $\mathrm{TIC}(\mu \mathrm{g} \mathrm{C} / \mathrm{g})$ & 52.0 & 52.0 & 47.1 & NA & 47.6 & 49.1 & 50.4 & 51.5 & 51.4 & 50.7 & 50.4 & 48.8 & 48.7 & 48.2 & 47.4 & 41.0 & 44.2 \\
\hline \multicolumn{18}{|l|}{ Cations $(\mu \mathrm{g} / \mathrm{g})$} \\
\hline Al & NA & 0.07 & ND & NA & NA & NA & NA & NA & NA & ND & NA & NA & NA & NA & NA & 0.07 & 0.06 \\
\hline B & NA & ND & ND & NA & NA & NA & NA & NA & NA & ND & NA & NA & NA & NA & NA & ND & ND \\
\hline $\mathrm{Ca}$ & NA & 80.80 & 76.68 & NA & NA & NA & NA & NA & NA & 74.12 & NA & NA & NA & NA & NA & 66.27 & 71.20 \\
\hline $\mathrm{Cr}$ & NA & ND & ND & NA & NA & NA & NA & NA & NA & ND & NA & NA & NA & NA & NA & ND & 0.03 \\
\hline $\mathrm{Cu}$ & NA & 0.05 & ND & NA & NA & NA & $N A$ & NA & $N A$ & ND & NA & $N A$ & NA & NA & NA & 0.25 & 0.43 \\
\hline $\mathrm{Fe}$ & NA & 1.53 & 0.09 & NA & NA & NA & NA & NA & NA & 0.03 & NA & NA & NA & NA & NA & $=0.42$ & 0.68 \\
\hline $\mathrm{K}$ & NA & 1.80 & 3.31 & NA & NA & NA & NA & NA & $N A$ & 2.60 & NA & NA & NA & NA & NA & 2.82 & 3.02 \\
\hline $\mathrm{Mg}$ & NA & 14.40 & 12.59 & NA & NA & NA & NA & NA & NA & 12.21 & NA & NA & NA & NA & NA & 11.06 & 11.59 \\
\hline $\mathrm{Mn}$ & NA & 0.03 & ND & NA & NA & NA & NA & NA & NA & ND & $N A$ & NA & NA & NA & NA & ND & ND \\
\hline $\mathrm{Na}$ & NA & 18.60 & 24.23 & NA & NA & NA & NA & NA & NA & 22.23 & NA & NA & NA & NA & NA & 17.52 & 17.67 \\
\hline$S$ & NA & 11.40 & 2.80 & NA & NA & NA & NA & NA & NA & 1.91 & NA & NA & NA & $N A$ & NA & 1.71 & 1.73 \\
\hline $\mathrm{Si}$ & NA & 14.90 & 29.12 & NA & $N A$ & NA & NA & NA & NA & 22.65 & NA & NA & NA & NA & NA & 25.68 & 22.76 \\
\hline $\mathrm{Sr}$ & NA & 0.56 & 0.04 & NA & NA & NA & NA & NA & NA & 0.03 & $N A$ & NA & NA & NA & $N A$ & 0.03 & 0.03 \\
\hline Zn & NA & 0.08 & ND & NA & NA & NA & NA & NA & NA & 0.03 & NA & NA & NA & NA & NA & 0.09 & 0.18 \\
\hline \multicolumn{18}{|l|}{ Anions $(\mu g / g)$} \\
\hline Fluoride & NA & ND & NA & NA & NA & NA & NA & NA & NA & NA & NA & NA & NA & NA & NA & ND & NA \\
\hline Chloride & NA & 19.1 & NA & NA & NA & NA & NA & NA & NA & NA & NA & NA & NA & NA & NA & 19.6 & NA \\
\hline Nitrite & NA & ND & NA & NA & NA & NA & NA & NA & NA & NA & NA & NA & NA & NA & NA & ND & NA \\
\hline Bromide & NA & ND & NA & NA & NA & NA & NA & NA & NA & NA & NA & NA & NA & NA & NA & ND & NA \\
\hline Nitrate & NA & 34.4 & NA & NA & NA & NA & NA & NA & NA & NA & NA & NA & NA & NA & NA & 34.5 & NA \\
\hline Phosphate & NA & ND & NA & NA & NA & NA & NA & NA & NA & NA & NA & NA & NA & NA & NA & ND & NA \\
\hline Sulfate & NA & 40.9 & NA & NA 1 & NA & NA & NA & NA & NA & NA & NA & NA & NA & NA & NA & 32.0 & NA \\
\hline \multicolumn{18}{|c|}{ Semivolatile Organics ( $\mu \mathrm{g} / \mathrm{L})$} \\
\hline Phenol & 2.0 & 0.5 & 4.0 & ND & ND & ND & NA & 0.8 & NA & NA & NA & 1.3 & NA & NA & 2.1 & ND & ND \\
\hline 2-Methylphenol & 0.6 & ND & 0.8 & ND & ND & ND & NA & 1.6 & NA & NA & NA & 4.1 & NA & NA & 3.2 & 0.2 & ND \\
\hline 3- and 4-Methylphenol & 1.6 & ND & 3.0 & ND & ND & ND & NA & 2.0 & NA & NA & NA & 4.2 & NA & NA & 3.8 & 1.0 & ND \\
\hline 2,4-Dimethylphenol & ND & ND & ND & ND & ND & ND & NA & 1.4 & NA & NA & NA & 1.6 & NA & NA & 2.0 & ND & ND \\
\hline Benzoic acid & ND & ND & 16.6 & ND & ND & ND & NA & 6.8 & NA & NA & NA & 11.4 & NA & NA & 9.4 & ND & ND \\
\hline Fluorenone & 36.8 & 3.9 & 55.1 & 34.1 & 14.9 & 12.9 & NA & 16.7 & NA & NA & NA & 38.5 & NA & NA & 55.8 & 50.5 & 32.1 \\
\hline Anthrone & 3.5 & ND & 9.6 & 6.9 & 3.2 & 2.9 & NA & 3.4 & NA & NA & NA & 8.1 & NA & NA & 9.7 & 7.4 & 7.2 \\
\hline 9,10 -Anthracenedione & 3.2 & 18.0 & 21.5 & 6.9 & 3.1 & 4.4 & NA & 21.9 & NA & NA & NA & 19.6 & NA & NA & 22.8 & 45.4 & 36.1 \\
\hline 7,8-Benzoquinoline & 6.1 & ND & 9.3 & 4.1 & ND & ND & NA & 1.9 & NA & NA & NA & 8.5 & NA & NA & 7.8 & 8.2 & 4.6 \\
\hline
\end{tabular}




\begin{tabular}{|c|c|c|c|c|c|c|c|c|c|c|c|c|c|c|c|c|c|}
\hline Sample Name & $\begin{array}{l}S-13 \\
(5 / 23 \\
0830)\end{array}$ & $\begin{array}{l}S-13 \\
(5 / 23 \\
1350)\end{array}$ & $\begin{array}{l}S-13 \\
(5 / 28 \\
1255)\end{array}$ & $\begin{array}{c}S-13 \\
(6 / 4 \\
1605)\end{array}$ & $\begin{array}{c}\text { S-13 } \\
(6 / 16 \\
1700)\end{array}$ & $\begin{array}{l}S-13 \\
(6 / 17 \\
1140)\end{array}$ & $\begin{array}{c}S-13 \\
(6 / 18 \\
2320)\end{array}$ & $\begin{array}{l}S-13 \\
(6 / 19 \\
0740)\end{array}$ & $\begin{array}{l}S-13 \\
(6 / 19 \\
1025)\end{array}$ & $\begin{array}{l}\text { S-13 } \\
(6 / 19 \\
1340)\end{array}$ & $\begin{array}{l}\text { S-13 } \\
(6 / 19 \\
1750)\end{array}$ & $\begin{array}{l}S-13 \\
(6 / 19 \\
2225)\end{array}$ & $\begin{array}{l}\text { S-13 } \\
(6 / 20 \\
0830)\end{array}$ & $\begin{array}{l}S-13 \\
(6 / 20 \\
1145)\end{array}$ & $\begin{array}{l}S-13 \\
(6 / 20 \\
1330)\end{array}$ & $\begin{array}{l}S-13 \\
(6 / 26 \\
1245)\end{array}$ & $\begin{array}{l}\text { S-13 } \\
(6 / 30 \\
1445)\end{array}$ \\
\hline Date/Time Sampled & $\begin{array}{c}5 / 23 / 97 \\
8: 30\end{array}$ & $\begin{array}{c}5 / 23 / 97 \\
13: 50\end{array}$ & $\begin{array}{c}5 / 28 / 97 \\
12: 55\end{array}$ & $\begin{array}{l}6 / 4 / 97 \\
16: 05\end{array}$ & $\begin{array}{c}6 / 16 / 97 \\
17: 00\end{array}$ & $\begin{array}{c}6 / 17 / 97 \\
11: 40\end{array}$ & $\begin{array}{c}6 / 18 / 97 \\
23: 20\end{array}$ & $\begin{array}{c}6 / 19 / 97 \\
7: 40\end{array}$ & $\begin{array}{c}6 / 19 / 97 \\
10: 25\end{array}$ & $\begin{array}{c}6 / 19 / 97 \\
13: 40\end{array}$ & $\begin{array}{c}6 / 19 / 97 \\
17: 50\end{array}$ & $\begin{array}{c}6 / 19 / 97 \\
22: 25\end{array}$ & $\begin{array}{c}6 / 20 / 97 \\
8: 30\end{array}$ & $\begin{array}{c}6 / 20 / 97 \\
11: 45\end{array}$ & $\begin{array}{c}6 / 20 / 97 \\
13: 30\end{array}$ & $\begin{array}{c}6 / 26 / 97 \\
12: 45\end{array}$ & $\begin{array}{c}6 / 30 / 97 \\
14: 45\end{array}$ \\
\hline Carbazole & 14.7 & ND & 80.6 & 32.9 & 6.9 & 5.4 & NA & 15.7 & NA & NA & NA & 39.6 & NA & NA & 59.4 & 25.5 & 26.6 \\
\hline Naphthalene & 36.9 & 7.7 & 14.6 & 28.4 & 6.0 & 9.1 & NA & 18.2 & NA & NA & NA & 44.3 & NA & NA & 33.6 & 12.4 & 12.1 \\
\hline 2-Methylnaphthalene & 65.0 & 6.6 & 25.4 & 12.0 & 3.9 & 3.7 & NA & 4.8 & NA & NA & NA & 22.7 & NA & NA & 16.3 & 5.9 & 14.0 \\
\hline Acenaphthylene & 18.8 & 1.8 & 6.3 & 3.2 & ND & 0.8 & NA & 3.6 & NA & NA & NA & 7.2 & NA & NA & 10.0 & 4.8 & 2.3 \\
\hline Acenaphthene & 308.2 & 30.3 & 71.2 & 35.1 & 28.1 & 25.6 & NA & 29.1 & NA & NA & NA & 86.9 & NA & NA & 102.6 & 50.1 & 39.7 \\
\hline Dibenzofuran & 490.3 & 76.9 & 264.5 & 81.5 & 41.4 & 46.9 & NA & 37.0 & $N A$ & NA & NA & 96.4 & NA & NA & 117.3 & 99.2 & 75.0 \\
\hline Fiuorene & 457.4 & 65.2 & 199.8 & 49.4 & 29.6 & 30.6 & NA & 34.0 & NA & NA & NA & 124.3 & NA & NA & 111.0 & 113.7 & 57.2 \\
\hline Phenanthrene & 1446.4 & 376.6 & 878.7 & 721.0 & 210.9 & 359.7 & NA & 353.2 & NA & NA & NA & 1910.0 & NA & NA & 1898.1 & 2142.5 & 1532.9 \\
\hline Anthracene & 669.0 & 16.9 & 200.5 & 121.6 & 67.0 & 70.5 & NA & 51.7 & NA & NA & NA & 635.4 & NA & NA & 488.1 & 827.4 & 505.6 \\
\hline Fluoranthene & 437.2 & 47.3 & 228.9 & 150.5 & 112.8 & 107.8 & NA & 139.5 & NA & NA & NA & 672.2 & NA & NA & 763.3 & 1284.6 & 788.4 \\
\hline Pyrene & 308.6 & 30.5 & 187.1 & 117.3 & 77.7 & 73.1 & NA & 100.5 & NA & NA & NA & 478.9 & NA & NA & 570.0 & 1017.7 & 630.3 \\
\hline Chrysene & ND & ND & ND & ND & 4.6 & 1.5 & NA & 3.6 & NA & NA & NA & 13.9 & NA & $N A$ & 10.8 & 43.5 & 28.1 \\
\hline Benzo[b]fluoranthene & ND & ND & ND & ND & ND & ND & NA & ND & NA & NA & NA & ND & NA & NA & 1.3 & 1.5 & 2.1 \\
\hline Benzo[k]fluoranthene & ND & ND & ND & ND & ND & ND & NA & ND & NA & NA & NA & ND & NA & NA & 0.8 & 1.1 & 1.7 \\
\hline Benzo[a]pyrene & ND & ND & ND & ND & ND & ND & NA & ND & NA & NA & NA & 1.5 & NA & NA & 1.6 & 1.8 & 2.2 \\
\hline Indeno[1,2,3-cd]pyrene & ND & ND & ND & ND & ND & ND & NA & ND & NA & NA & NA & ND & NA & NA & ND & ND & ND \\
\hline Dibenz[ah]anthracene & ND & ND & ND & ND & ND & ND & NA & ND & NA & NA & NA & ND & NA & NA & ND & ND & ND \\
\hline Benzo[ghi]perylene & ND & ND & ND & ND & ND & ND & NA & ND & NA & NA & NA & ND & NA & NA & 0.1 & ND & ND \\
\hline 2,3,5,6-Tetrachlorophenol & ND & ND & ND & ND & ND & ND & NA & 0.1 & NA & NA & NA & 0.2 & NA & NA & 0.4 & 1.6 & 5.2 \\
\hline 2,3,4,5-Tetrachlorophenol & ND & ND & ND & ND & ND & ND & NA & ND & NA & NA & NA & ND & NA & NA & 0.1 & ND & ND \\
\hline 2,3,4,6-Tetrachlorophenol & ND & ND & ND & ND & ND & ND & NA & 0.1 & NA & NA & NA & 0.1 & NA & NA & 0.3 & 0.3 & ND \\
\hline Pentachlorophenol & 0.7 & ND & 6.1 & 2.3 & 13.7 & 0.8 & NA & 2.1 & NA & NA & NA & 2.5 & NA & NA & 4.3 & 1.1 & 4.2 \\
\hline Total Oxygenates $(\mu \mathrm{g} / \mathrm{L})$ & 48 & 22 & 110 & 48 & 21 & 20 & - & 55 & - & - & - & 89 & - & - & 109 & 105 & 75 \\
\hline Total PAH $(\mu \mathrm{g} / \mathrm{L})$ & 4258 & 660 & 2167 & 1357 & 589 & 735 & - & 793 & - & - & - & 4142 & - & - & 4192 & 5640 & 3723 \\
\hline Total Cl-Phenols $(\mu \mathrm{g} / L)$ & 1 & 0 & 6 & 2 & 14 & 1 & - & 2 & - & - & - & 3 & - & - & 5 & 3 & 9 \\
\hline Total GC-MS $(\mu \mathrm{g} / \mathrm{L})$ & 4307 & 682 & 2283 & 1407 & 624 & 756 & - & 850 & - & - & - & 4233 & - & - & 4306 & 5747 & 3808 \\
\hline$\%$ Oxygenates & 1.1 & 3.3 & 4.8 & 3.4 & 3.4 & 2.7 & - & 6.4 & - & - & - & 2.1 & - & - & 2.5 & 1.8 & 2.0 \\
\hline
\end{tabular}


Table 2 (continued). Results of groundwater chemical analyses for Well S-13

\begin{tabular}{|c|c|c|c|c|}
\hline Sample Name & $\begin{array}{l}S-13 \\
(7 / 16 \\
1155)\end{array}$ & $\begin{array}{l}S-13 \\
(7 / 16 \\
1650)\end{array}$ & $\begin{array}{c}\text { S-13 } \\
(10 / 23 \\
1030)\end{array}$ & $\begin{array}{c}S-13 \\
(12 / 16 \\
1445)\end{array}$ \\
\hline Date/Time Sampled & $\begin{array}{c}7 / 16 / 97 \\
11: 55\end{array}$ & $\begin{array}{c}7 / 16 / 97 \\
16: 50\end{array}$ & $\begin{array}{c}10 / 23 / 97 \\
10: 30\end{array}$ & $\begin{array}{c}12 / 16 / 97 \\
14: 45\end{array}$ \\
\hline$\overline{\mathrm{pH}}$ & 6.8 & 6.8 & 8.5 & 7.1 \\
\hline $\mathrm{TIC}(\mu \mathrm{g} \mathrm{C} / \mathrm{g})$ & 43.9 & 46.6 & 41.3 & 47.0 \\
\hline \multicolumn{5}{|l|}{ Cations $(\mu \mathrm{g} / \mathrm{g})$} \\
\hline $\mathrm{Al}$ & NA & NA & NA & NA \\
\hline$B$ & NA & NA & NA & NA \\
\hline $\mathrm{Ca}$ & NA & NA & NA & NA \\
\hline $\mathrm{Cr}$ & NA & NA & NA & NA \\
\hline $\mathrm{Cu}$ & NA & NA & NA & NA \\
\hline $\mathrm{Fe}$ & NA & NA & NA & NA \\
\hline K & NA & NA & NA & NA \\
\hline $\mathrm{Mg}$ & NA & NA & NA & NA \\
\hline $\mathrm{Mn}$ & NA & NA & NA & NA \\
\hline $\mathrm{Na}$ & NA & NA & NA & NA \\
\hline$S$ & NA & NA & NA & NA \\
\hline Si & NA & NA & NA & NA \\
\hline $\mathrm{Sr}$ & NA & NA & NA & NA \\
\hline $\mathrm{Zn}$ & NA & NA & NA & NA \\
\hline \multicolumn{5}{|l|}{ Anions $(\mu \mathbf{g} / \mathbf{g})$} \\
\hline Fluoride & ND & ND & NA & NA \\
\hline Chloride & 20.4 & 19.2 & NA & 16.8 \\
\hline Nitrite & ND & ND & NA & NA \\
\hline Bromide & ND & ND & NA & NA \\
\hline Nitrate & 37.2 & 36.4 & NA & 25.4 \\
\hline Phosphate & ND & ND & NA & NA \\
\hline Sulfate & 54.1 & 47.6 & NA & $31.3^{1}$ \\
\hline \multicolumn{5}{|c|}{ Semivolatile Organics $(\mu \mathrm{g} / \mathrm{L})$} \\
\hline Phenol & 0.7 & ND & ND & 0.7 \\
\hline 2-Methylphenol & 0.9 & ND & ND & 0.1 \\
\hline 3- and 4-Methylphenol & 1.9 & ND & ND & 0.7 \\
\hline 2,4-Dimethylphenol & ND & ND & ND & ND \\
\hline Benzoic acid & 4.7 & ND & ND & 12.4 \\
\hline Fluorenone & 16.1 & 5.9 & ND & 20.7 \\
\hline Anthrone & 1.2 & ND & ND & 0.8 \\
\hline
\end{tabular}

\begin{tabular}{lcccc}
\hline Sample Name & S-13 & S-13 & S-13 & S-13 \\
& $\mathbf{1 7 / 1 6}$ & $\mathbf{( 7 / 1 6}$ & $\mathbf{( 1 0 / 2 3}$ & $(\mathbf{1 2 / 1 6}$ \\
& $\mathbf{1 1 5 5 )}$ & $\mathbf{1 6 5 0 )}$ & $\mathbf{1 0 3 0 )}$ & $\mathbf{1 4 4 5 )}$ \\
Date/Time Sampled & $7 / 16 / 97$ & $7 / 16 / 97$ & $10 / 23 / 97$ & $12 / 16 / 97$ \\
& $11: 55$ & $16: 50$ & $10: 30$ & $14: 45$ \\
\hline 9,10-Anthracenedione & 36.6 & 6.2 & $\mathrm{ND}$ & 8.3 \\
7,8-Benzoquinoline & 1.3 & $\mathrm{ND}$ & $\mathrm{ND}$ & $\mathrm{ND}$ \\
Carbazole & 31.4 & 7.2 & $\mathrm{ND}$ & $\mathrm{ND}$ \\
Naphthalene & 13.1 & 7.8 & 2.3 & 22.7 \\
2-Methylnaphthalene & 14.1 & 7.0 & 3.1 & 8.7 \\
Acenaphthylene & 1.1 & $\mathrm{ND}$ & 0.4 & 0.8 \\
Acenaphthene & 15.5 & 4.4 & 6.0 & 5.3 \\
Dibenzofuran & 41.4 & 15.2 & 11.3 & 8.2 \\
Fluorene & 38.8 & 16.0 & 15.3 & 3.2 \\
Phenanthrene & 405.1 & 178.6 & 790.7 & 46.3 \\
Anthracene & 16.7 & 53.2 & 47.1 & 1.2 \\
Fluoranthene & 162.2 & 50.0 & 227.1 & 59.9 \\
Pyrene & 149.7 & 44.4 & 292.1 & 45.7 \\
Chrysene & 8.0 & 4.2 & 30.1 & 9.4 \\
Benzo[b]fluoranthene & $\mathrm{ND}$ & 1.2 & 1.5 & 2.3 \\
Benzo[k]fluoranthene & $\mathrm{ND}$ & 0.8 & 3.5 & 2.5 \\
Benzo[a]pyrene & 1.4 & 1.4 & 0.6 & 0.7 \\
Indeno[1,2,3-cd]pyrene & $\mathrm{ND}$ & $\mathrm{ND}$ & $\mathrm{ND}$ & $\mathrm{ND}$ \\
Dibenz[ah]anthracene & $\mathrm{ND}$ & $\mathrm{ND}$ & $\mathrm{ND}$ & $\mathrm{ND}$ \\
Benzo[ghi]perylene & $\mathrm{ND}$ & $\mathrm{ND}$ & $\mathrm{ND}$ & $\mathrm{ND}$ \\
2,3,5,6-Tetrachlorophenol & 2.4 & $\mathrm{ND}$ & $\mathrm{ND}$ & 18.2 \\
2,3,4,5-Tetrachlorophenol & $\mathrm{ND}$ & $\mathrm{ND}$ & $\mathrm{ND}$ & $\mathrm{ND}$ \\
2,3,4,6-Tetrachlorophenol & $\mathrm{ND}$ & $\mathrm{ND}$ & $\mathrm{ND}$ & 2.7 \\
Pentachlorophenol & 5.5 & $\mathrm{ND}$ & 13.9 & 77.9 \\
\hline Total Oxygenates $(\mu \mathrm{g} / \mathrm{L})$ & 62 & 12 & 0 & 44 \\
Total PAH ( $\mu$ g/L) & 900 & 391 & 1431 & 217 \\
Total Cl-Phenols $(\mu \mathrm{g} / \mathrm{L})$ & 8 & 0 & 14 & 99 \\
Total GC-MS $(\mu \mathrm{g} / \mathrm{L})$ & 970 & 404 & 1445 & 359 \\
\hline \% Oxygenates & 6.4 & 3.0 & 0.0 & 12.2 \\
\hline
\end{tabular}


Table 3. Results of groundwater chemical analyses for Well S-12

\begin{tabular}{|c|c|c|c|c|c|c|}
\hline Sample Name & $\begin{array}{l}\text { S-12 } \\
(5 / 20 \\
1515)\end{array}$ & $\begin{array}{l}S-12 \\
(5 / 22 \\
0845)\end{array}$ & $\begin{array}{l}S-12 \\
(5 / 28 \\
1440)\end{array}$ & $\begin{array}{l}\text { S-12 } \\
(6 / 17 \\
1125)\end{array}$ & $\begin{array}{l}S-12 \\
(6 / 30 \\
1525)\end{array}$ & $\begin{array}{l}S-12 \\
(7 / 16 \\
1255)\end{array}$ \\
\hline Date/Time Sampled & $\begin{array}{c}5 / 20 / 97 \\
15: 15 \\
\end{array}$ & $\begin{array}{c}5 / 22 / 97 \\
8: 45\end{array}$ & $\begin{array}{c}5 / 28 / 97 \\
14: 40 \\
\end{array}$ & $\begin{array}{c}6 / 17 / 97 \\
11: 25 \\
\end{array}$ & $\begin{array}{c}6 / 30 / 97 \\
15: 25 \\
\end{array}$ & $\begin{array}{c}7 / 16 / 97 \\
12: 55 \\
\end{array}$ \\
\hline $\mathrm{pH}$ & 7.0 & NA & 7.0 & 7.0 & 6.8 & 7.0 \\
\hline TIC $(\mu \mathrm{g} \mathrm{C} / \mathrm{g})$ & NA & NA & 49.1 & 49.6 & 40.1 & 30.1 \\
\hline \multicolumn{7}{|l|}{ Cations $(\mu \mathbf{g} / \mathbf{g})$} \\
\hline $\mathrm{Al}$ & NA & NA & NA & NA & ND & NA \\
\hline$B$ & NA & NA & NA & NA & ND & NA \\
\hline $\mathrm{Ca}$ & NA & NA & NA & NA & 84.39 & NA \\
\hline $\mathrm{Cr}$ & NA & NA & NA & NA & ND & NA \\
\hline $\mathrm{Cu}$ & NA & NA & NA & NA & 0.07 & NA \\
\hline $\mathrm{Fe}$ & NA & NA & NA & NA & ND & NA \\
\hline K & NA & NA & NA & NA & 5.50 & NA \\
\hline $\mathrm{Mg}$ & NA & NA & NA & NA & 12.35 & NA \\
\hline $\mathrm{Mn}$ & NA & NA & NA & NA & ND & NA \\
\hline $\mathrm{Na}$ & NA & NA & NA & NA & 45.29 & NA \\
\hline$S$ & NA & NA & NA & NA & 5.64 & NA \\
\hline $\mathrm{Si}$ & NA & NA & NA & NA & 31.94 & NA \\
\hline $\mathrm{Sr}$ & NA & NA & NA & NA & 0.05 & NA \\
\hline $\mathrm{Zn}$ & $\mathrm{NA}$ & NA & NA & NA & 0.12 & NA \\
\hline \multicolumn{7}{|l|}{ Anions $(\mu \mathrm{g} / \mathrm{g})$} \\
\hline Fluoride & NA & NA & NA & NA & ND & ND \\
\hline Chloride & NA & NA & NA & NA & 37.8 & 26.9 \\
\hline Nitrite & NA & NA & NA & NA & ND & ND \\
\hline Bromide & NA & NA & NA & NA & ND & ND \\
\hline Nitrate & NA & NA & NA & NA & 32.9 & 32.0 \\
\hline Phosphate & NA & NA & NA & NA & ND & ND \\
\hline Sulfate & NA & NA & NA & NA & 110.0 & 87.0 \\
\hline \multicolumn{7}{|c|}{ Semivolatile Organics ( $\mu \mathrm{g} / \mathrm{L})$} \\
\hline Phenol & 7.5 & 4.9 & 8.1 & 0.8 & ND & 4.8 \\
\hline 2-Methylphenol & 1.7 & 1.5 & 1.4 & ND & ND & 3.8 \\
\hline 3- and 4-Methylphenol & 7.5 & 5.4 & 4.2 & ND & ND & 9.2 \\
\hline 2,4-Dimethylphenol & 10.7 & 7.3 & ND & ND & ND & 14.8 \\
\hline Benzoic acid & ND & ND & 17.3 & ND & ND & 53.2 \\
\hline Fluorenone & 212.1 & 164.3 & 110.1 & 19.1 & 63.6 & 99.6 \\
\hline Anthrone & 17.4 & 22.0 & 13.2 & 4.2 & ND & 9.6 \\
\hline 9,10-Anthracenedione & 26.0 & 27.9 & 20.9 & 6.5 & ND & 20.5 \\
\hline 7,8-Benzoquinoline & 52.6 & 97.1 & 54.7 & 6.6 & ND & 25.4 \\
\hline
\end{tabular}




\begin{tabular}{lrrrrrr}
\hline Carbazole & 564.8 & 465.0 & 306.3 & 27.3 & 210.3 & 80.4 \\
Naphthalene & 142.1 & 125.8 & 86.1 & 17.7 & 174.8 & 40.8 \\
2-Methylnaphthalene & 223.1 & 89.4 & 55.2 & 34.5 & 111.2 & 43.3 \\
Acenaphthylene & 61.6 & 25.4 & 8.9 & 1.9 & 9.8 & 6.1 \\
Acenaphthene & 378.8 & 195.4 & 156.9 & 77.4 & 272.6 & 116.5 \\
Dibenzofuran & 686.5 & 469.5 & 341.3 & 90.6 & 591.7 & 194.4 \\
Fluorene & 245.1 & 146.8 & 56.8 & 39.6 & 163.8 & 87.4 \\
Phenanthrene & 692.4 & 906.3 & 857.7 & 356.3 & 2036.7 & 882.1 \\
Anthracene & 113.5 & 246.0 & 159.0 & 85.8 & 473.1 & 192.9 \\
Fluoranthene & 27.7 & 243.2 & 275.4 & 121.1 & 497.6 & 433.1 \\
Pyrene & 14.8 & 161.5 & 209.0 & 78.1 & 287.3 & 400.6 \\
Chrysene & ND & ND & ND & ND & ND & 88.4 \\
Benzo[b]fluoranthene & ND & ND & ND & ND & ND & 6.0 \\
Benzo[k]fluoranthene & ND & ND & ND & ND & ND & 4.4 \\
Benzo[a]pyrene & ND & ND & ND & ND & ND & 7.1 \\
Indeno[1,2,3-cd]pyrene & ND & ND & ND & ND & ND & ND \\
Dibenz[ah]anthracene & ND & ND & ND & ND & ND & ND \\
Benzo[ghi]perylene & ND & ND & ND & ND & ND & ND \\
2,3,5,6-Tetrachlorophenol & ND & ND & ND & ND & ND & 10.9 \\
2,3,4,5-Tetrachlorophenol & ND & ND & ND & ND & ND & ND \\
2,3,4,6-Tetrachlorophenol & ND & ND & ND & ND & ND & ND \\
Pentachlorophenol & 16.0 & 11.4 & 7.0 & 0.5 & ND & 18.0 \\
\hline Total Oxygenates ( $\mu$ g/L) & 283 & 233 & 175 & 31 & 64 & 215 \\
Total PAH ( $\mu$ g/L) & 3203 & 3171 & 2567 & 937 & 4829 & 2609 \\
Total Cl-Phenols ( $\mu$ g/L) & 16 & 11 & 7 & 1 & 0 & 29 \\
Total GC-MS $(\mu$ g/L) & 3502 & 3416 & 2749 & 968 & 4892 & 2853 \\
\hline \% Oxygenates & 8.1 & 6.8 & 6.4 & 3.2 & 1.3 & 7.6 \\
\hline
\end{tabular}


Table 4. Results of groundwater chemical analyses for Well S-14

\begin{tabular}{|c|c|c|c|c|c|c|c|c|c|}
\hline Sample Name & $\begin{array}{c}S-14 \\
(5 / 6 \\
1620)\end{array}$ & $\begin{array}{l}S-14 \\
(5 / 22 \\
1150)\end{array}$ & $\begin{array}{l}S-14 \\
(5 / 28 \\
1330)\end{array}$ & $\begin{array}{c}-14 \\
(6 / 4 \\
1605)\end{array}$ & $\begin{array}{l}S-14 \\
(6 / 17 \\
1115)\end{array}$ & $\begin{array}{l}S-14 \\
(6 / 30 \\
1318)\end{array}$ & $\begin{array}{l}\text { S-14 } \\
(7 / 16 \\
1600)\end{array}$ & $\begin{array}{c}S-14 \\
(12 / 16 \\
1254)\end{array}$ & $\begin{array}{c}S-14 \\
(12 / 16 \\
1254)\end{array}$ \\
\hline Date/Time Sampled & $\begin{array}{l}5 / 6 / 97 \\
16: 20 \\
\end{array}$ & $\begin{array}{c}5 / 22 / 97 \\
11: 50 \\
\end{array}$ & $\begin{array}{c}5 / 28 / 97 \\
13: 30 \\
\end{array}$ & $\begin{array}{l}6 / 4 / 97 \\
16: 05 \\
\end{array}$ & $\begin{array}{c}6 / 17 / 97 \\
11: 15 \\
\end{array}$ & $\begin{array}{c}6 / 30 / 97 \\
13: 18 \\
\end{array}$ & $\begin{array}{c}7 / 16 / 97 \\
16: 00 \\
\end{array}$ & $\begin{array}{c}12 / 16 / 97 \\
12: 54 \\
\end{array}$ & $\begin{array}{c}12 / 16 / 97 \\
12: 54 \\
\end{array}$ \\
\hline $\mathrm{pH}$ & 6.9 & 7.0 & 7.1 & NA & 6.8 & 7.0 & 6.8 & 7.0 & NA \\
\hline TIC $(\mu \mathrm{g} \mathrm{C} / \mathrm{g})$ & 51.5 & 51.0 & 54.4 & NA & 58.9 & 60.4 & 57.8 & 40.0 & NA \\
\hline \multicolumn{10}{|l|}{ Cations $(\mu \mathbf{g} / \mathbf{g})$} \\
\hline Al & ND & ND & ND & NA & NA & ND & NA & NA & NA \\
\hline$B$ & ND & ND & ND & NA & NA & ND & NA & NA & NA \\
\hline $\mathrm{Ca}$ & 62.48 & 76.92 & 76.17 & NA & NA & 76.69 & NA & NA & NA \\
\hline $\mathrm{Cr}$ & ND & ND & ND & NA & NA & 0.03 & NA & NA & NA \\
\hline $\mathrm{Cu}$ & ND & ND & 0.02 & NA & NA & ND & NA & NA & NA \\
\hline $\mathrm{Fe}$ & 0.18 & 0.04 & 0.04 & NA & NA & 0.14 & NA & NA & NA \\
\hline K & 1.99 & 1.64 & 1.53 & NA & NA & 2.79 & NA & NA & NA \\
\hline $\mathrm{Mg}$ & 10.79 & 13.24 & 13.22 & NA & NA & 12.72 & NA & NA & NA \\
\hline $\mathrm{Mn}$ & 0.07 & 0.07 & 0.07 & NA & NA & 0.03 & NA & NA & NA \\
\hline $\mathrm{Na}$ & 15.97 & 16.41 & 16.81 & NA & NA & 24.24 & NA & NA & NA \\
\hline S & 1.12 & 1.65 & 1.59 & NA & NA & 2.08 & NA & NA & NA \\
\hline $\mathrm{Si}$ & 15.07 & 13.94 & 14.13 & NA & NA & 24.45 & NA & NA & NA \\
\hline $\mathrm{Sr}$ & 0.03 & 0.04 & 0.04 & NA & NA & 0.04 & NA & NA & NA \\
\hline $\mathrm{Zn}$ & 0.12 & 0.05 & 0.13 & NA & NA & 0.77 & NA & NA & NA \\
\hline \multicolumn{10}{|l|}{ Anions $(\mu g / g)$} \\
\hline Fluoride & ND & ND & NA & NA & NA & ND & ND & ND & NA \\
\hline Chloride & 12.8 & 16.9 & NA & NA & NA & 19.8 & 20.5 & 16.8 & NA \\
\hline Nitrite & ND & ND & NA & NA & NA & ND & ND & ND & NA \\
\hline Bromide & ND & ND & NA & NA & NA & ND & ND & ND & NA \\
\hline Nitrate & ND & 14.7 & NA & NA & NA & ND & 7.3 & 27.1 & NA \\
\hline Phosphate & ND & ND & NA & NA & NA & ND & ND & ND & NA \\
\hline Sulfate & 17.1 & 38.5 & NA & NA & NA & 32.2 & 49.9 & 79.6 & NA \\
\hline \multicolumn{10}{|c|}{ Semivolatile Organics $(\mu g / L)$} \\
\hline Phenol & 0.8 & 1.2 & 0.7 & 7.1 & 16.6 & 35.0 & 12.7 & 3.6 & 4.2 \\
\hline 2-Methylphenol & ND & ND & ND & 2.8 & 5.1 & ND & 4.9 & 0.8 & 0.8 \\
\hline 3- and 4-Methylphenol & ND & ND & ND & 10.3 & 20.6 & ND & 13.3 & 3.2 & 3.6 \\
\hline 2,4-Dimethylphenol & ND & ND & ND & 23.8 & 29.3 & ND & 16.2 & 0.5 & 0.6 \\
\hline Benzoic acid & ND & ND & ND & ND & ND & ND & ND & 14.6 & 20.3 \\
\hline Fluorenone & 7.4 & 29.1 & 40.3 & 59.1 & 58.4 & 116.6 & 137.7 & 60.9 & 57.6 \\
\hline Anthrone & ND & ND & ND & 3.9 & 4.9 & ND & 3.4 & 1.4 & 1.4 \\
\hline 9,10-Anthracenedione & 4.2 & 5.4 & 11.9 & 9.7 & 4.3 & ND & 82.3 & 13.1 & 12.8 \\
\hline 7,8-Benzoquinoline & 12.4 & 26.6 & 33.0 & 59.2 & 74.4 & ND & 86.5 & ND & ND \\
\hline
\end{tabular}




\begin{tabular}{|c|c|c|c|c|c|c|c|c|c|}
\hline Sample Name & $\begin{array}{c}S-14 \\
(5 / 6 \\
1620)\end{array}$ & $\begin{array}{l}S-14 \\
(5 / 22 \\
1150)\end{array}$ & $\begin{array}{l}S-14 \\
(5 / 28 \\
1330)\end{array}$ & $\begin{array}{c}S-14 \\
(6 / 4 \\
1605)\end{array}$ & $\begin{array}{l}S-14 \\
(6 / 17 \\
1115)\end{array}$ & $\begin{array}{l}S-14 \\
(6 / 30 \\
1318)\end{array}$ & $\begin{array}{l}S-14 \\
(7 / 16 \\
1600)\end{array}$ & $\begin{array}{c}S-14 \\
(12 / 16 \\
1254)\end{array}$ & $\begin{array}{c}S-14 \\
(12 / 16 \\
1254)\end{array}$ \\
\hline Date/Time Sampled & $\begin{array}{l}5 / 6 / 97 \\
16: 20\end{array}$ & $\begin{array}{c}5 / 22 / 97 \\
11: 50 \\
\end{array}$ & $\begin{array}{c}5 / 28 / 97 \\
13: 30 \\
\end{array}$ & $\begin{array}{l}6 / 4 / 97 \\
16: 05 \\
\end{array}$ & $\begin{array}{c}6 / 17 / 97 \\
11: 15 \\
\end{array}$ & $\begin{array}{c}6 / 30 / 97 \\
13: 18 \\
\end{array}$ & $\begin{array}{c}7 / 16 / 97 \\
16: 00 \\
\end{array}$ & $\begin{array}{c}12 / 16 / 97 \\
12: 54 \\
\end{array}$ & $\begin{array}{c}12 / 16 / 97 \\
12: 54 \\
\end{array}$ \\
\hline Carbazole & 112.7 & 172.5 & 188.9 & 768.8 & 753.3 & 374.4 & 235.6 & ND & ND \\
\hline Naphthalene & 382.2 & 839.4 & 1082.6 & 1849.1 & 4585.4 & 11391.2 & 1768.0 & 248.5 & 226.2 \\
\hline 2-Methyinaphthalene & 250.3 & 872.8 & 1226.3 & 1620.6 & 2819.2 & 19318.7 & 1694.3 & 126.3 & 118.7 \\
\hline Acenaphthylene & 6.3 & 9.7 & 9.0 & 11.1 & 6.2 & 71.2 & 16.6 & 3.6 & 3.1 \\
\hline Acenaphthene & 391.6 & 750.8 & 1114.0 & 696.6 & 712.2 & 11515.5 & 1391.2 & 52.8 & 48.5 \\
\hline Dibenzofuran & 303.5 & 517.4 & 731.8 & 477.0 & 482.1 & 8799.2 & 1086.2 & 45.1 & 40.4 \\
\hline Fluorene & 162.5 & 473.3 & 712.3 & 318.5 & 291.7 & 6641.2 & 771.5 & 15.8 & 13.8 \\
\hline Phenanthrene & 307.3 & 982.2 & 1362.9 & 614.8 & 592.6 & 6818.7 & 1595.2 & 27.6 & 23.5 \\
\hline Anthracene & 39.7 & 174.5 & 267.4 & 105.4 & 98.6 & 1329.0 & 122.4 & 3.2 & 3.0 \\
\hline Fluoranthene & 55.8 & 422.5 & 726.7 & 127.3 & 117.2 & 559.6 & 495.6 & 3.7 & 2.7 \\
\hline Pyrene & 44.4 & 408.0 & 719.8 & 112.7 & 87.4 & 344.6 & 391.8 & 3.5 & 2.3 \\
\hline Chrysene & 5.3 & 84.8 & 164.6 & 21.5 & 16.6 & ND & 83.0 & ND & 0.5 \\
\hline Benzo[b]fluoranthene & ND & 17.8 & 38.5 & 4.6 & 4.4 & ND & 35.6 & ND & 0.1 \\
\hline Benzo[k]fluoranthene & ND & 23.2 & 44.3 & 5.3 & 4.6 & ND & 27.8 & ND & 0.1 \\
\hline Benzo[a]pyrene & ND & 19.9 & 42.5 & 4.8 & 4.9 & ND & 32.9 & ND & 0.2 \\
\hline Indeno[1,2,3-cd\}pyrene & ND & ND & 10.7 & ND & ND & ND & 23.7 & ND & ND \\
\hline Dibenz[ah]anthracene & ND & ND & ND & ND & ND & ND & ND & ND & ND \\
\hline Benzo[ghi]perylene & ND & ND & 7.0 & ND & ND & ND & 17.5 & ND & ND \\
\hline 2,3,5,6-Tetrachlorophenol & ND & ND & ND & 19.5 & 46.4 & ND & 12.0 & 7.4 & 7.5 \\
\hline 2,3,4,5-Tetrachlorophenol & ND & ND & ND & ND & ND & ND & ND & 0.5 & ND \\
\hline 2,3,4,6-Tetrachlorophenol & ND & ND & ND & 8.8 & 11.6 & ND & 9.9 & 2.1 & 1.9 \\
\hline Pentachlorophenol & 1.1 & 23.5 & 11.2 & 201.4 & 300.4 & 84.2 & 72.3 & 33.3 & 31.2 \\
\hline Total Oxygenates $(\mu \mathrm{g} / \mathrm{L})$ & 12 & 36 & 53 & 117 & 139 & 152 & 270 & 98 & 101 \\
\hline Total PAH $(\mu \mathrm{g} / L)$ & 2074 & 5795 & 8482 & 6797 & 10651 & 67163 & 9875 & 530 & 483 \\
\hline Total CI-Phenols $(\mu \mathrm{g} / \mathrm{L})$ & 1 & 24 & 11 & 230 & 359 & 84 & 94 & 43 & 41 \\
\hline Total GC-MS $(\mu \mathrm{g} / \mathrm{L})$ & 2087 & 5854 & 8546 & 7144 & 11148 & 67399 & 10240 & 672 & 625 \\
\hline$\%$ Oxygenates & 0.6 & 0.6 & 0.6 & 1.6 & 1.2 & 0.2 & 2.6 & 14.6 & 16.2 \\
\hline
\end{tabular}


Table 5. Results of groundwater chemical analyses for Well S-15

\begin{tabular}{|c|c|c|c|c|c|c|}
\hline Sample Name & $\begin{array}{l}S-15 \\
(5 / 28 \\
1630)\end{array}$ & $\begin{array}{l}\text { S-15 } \\
(6 / 19 \\
1210)\end{array}$ & $\begin{array}{l}S-15 \\
(6 / 30 \\
1615)\end{array}$ & $\begin{array}{l}S-15 \\
(7 / 16 \\
1520)\end{array}$ & $\begin{array}{c}\text { S-15 } \\
(12 / 16 \\
1310)\end{array}$ & $\begin{array}{c}S-15 \\
(12 / 16 \\
1310)\end{array}$ \\
\hline Date/Time Sampled & $\begin{array}{c}5 / 28 / 97 \\
16: 30\end{array}$ & $\begin{array}{c}6 / 19 / 97 \\
12: 10\end{array}$ & $\begin{array}{c}6 / 30 / 97 \\
16: 15\end{array}$ & $\begin{array}{c}7 / 16 / 97 \\
15: 20\end{array}$ & $\begin{array}{c}12 / 16 / 97 \\
13: 10\end{array}$ & $\begin{array}{c}12 / 16 / 97 \\
13: 10\end{array}$ \\
\hline$\overline{\mathrm{pH}}$ & 7.0 & 6.9 & 6.7 & 6.6 & 6.8 & NA \\
\hline $\mathrm{TIC}(\mu \mathrm{g} \mathrm{C} / \mathrm{g})$ & 57.3 & 57.1 & 56.7 & 55.6 & 41.1 & NA \\
\hline \multicolumn{7}{|l|}{ Cations $(\mu \mathrm{g} / \mathrm{g})$} \\
\hline $\mathrm{Al}$ & ND & NA & ND & NA & NA & NA \\
\hline$B$ & ND & NA & ND & NA & NA & NA \\
\hline $\mathrm{Ca}$ & 75.76 & NA & 77.81 & NA & NA & NA \\
\hline $\mathrm{Cr}$ & 0.05 & NA & 0.07 & NA & NA & NA \\
\hline $\mathrm{Cu}$ & 0.04 & NA & 0.13 & NA & NA & NA \\
\hline $\mathrm{Fe}$ & 0.22 & NA & 0.25 & NA & NA & NA \\
\hline K & 2.11 & NA & 3.82 & NA & NA & NA \\
\hline $\mathrm{Mg}$ & 13.58 & NA & 12.69 & NA & NA & NA \\
\hline $\mathrm{Mn}$ & 0.08 & NA & 0.05 & NA & NA & NA \\
\hline $\mathrm{Na}$ & 17.74 & NA & 30.91 & NA & NA & NA \\
\hline s & 1.71 & NA & 3.18 & NA & NA & NA \\
\hline $\mathrm{Si}$ & 13.21 & NA & 33.50 & NA & NA & NA \\
\hline $\mathrm{Sr}$ & 0.04 & NA & 0.04 & NA & NA & NA \\
\hline $\mathrm{Zn}$ & 1.30 & NA & 3.03 & NA & NA & NA \\
\hline \multicolumn{7}{|l|}{ Anions $(\mu \mathbf{g} / \mathbf{g})$} \\
\hline Fluoride & NA & NA & ND & ND & ND & NA \\
\hline Chloride & NA & NA & 30.4 & 17.9 & 14.5 & NA \\
\hline Nitrite & NA & NA & ND & ND & ND & NA \\
\hline Bromide & NA & NA & ND & ND & ND & NA \\
\hline Nitrate & NA & NA & 14.5 & 7.6 & 16.2 & NA \\
\hline Phosphate & NA & NA & ND & ND & ND & NA \\
\hline Sulfate & NA & NA & 69.8 & $29.5^{\prime}$ & 50.6 & NA \\
\hline \multicolumn{7}{|c|}{ Semivolatile Organics $(\mu \mathrm{g} / \mathrm{L})$} \\
\hline Phenol & 0.7 & NA & ND & 14.5 & 0.4 & 3.7 \\
\hline 2-Methylphenol & ND & NA & ND & 7.4 & 0.1 & 0.4 \\
\hline 3- and 4-Methylphenol & ND & NA & ND & 22.1 & 0.8 & 1.8 \\
\hline 2,4-Dimethylphenol & ND & NA & ND & ND & ND & ND \\
\hline Benzoic acid & ND & NA & ND & 84.9 & 7.8 & 16.1 \\
\hline Fluorenone & 26.2 & NA & 68.8 & 318.0 & 102.6 & 100.8 \\
\hline Anthrone & ND & NA & ND & 9.6 & 8.1 & 7.5 \\
\hline
\end{tabular}

\begin{tabular}{|c|c|c|c|c|c|c|}
\hline Sample Name & $\begin{array}{c}\text { S-15 } \\
(5 / 28 \\
1630)\end{array}$ & $\begin{array}{r}\text { S-15 } \\
(6 / 19 \\
1210)\end{array}$ & $\begin{array}{r}S-15 \\
(6 / 30 \\
1615)\end{array}$ & $\begin{array}{c}S-15 \\
(7 / 16 \\
1520)\end{array}$ & $\begin{array}{c}\text { S-15 } \\
(12 / 16 \\
1310)\end{array}$ & $\begin{array}{c}\text { S-15 } \\
(12 / 16 \\
1310)\end{array}$ \\
\hline Date/Time Sampled & $\begin{array}{c}5 / 28 / 97 \\
16: 30\end{array}$ & $\begin{array}{c}6 / 19 / 97 \\
12: 10\end{array}$ & $\begin{array}{c}6 / 30 / 97 \\
16: 15\end{array}$ & $\begin{array}{c}7 / 16 / 97 \\
15: 20\end{array}$ & $\begin{array}{c}12 / 16 / 97 \\
13: 10\end{array}$ & $\begin{array}{c}12 / 46 / 97 \\
13: 10\end{array}$ \\
\hline 9,10 -Anthracenedione & 6.2 & NA & ND & 57.8 & 52.2 & 55.7 \\
\hline 7,8-Benzoquinoline & 25.0 & NA & ND & 72.5 & ND & ND \\
\hline Carbazole & 150.7 & NA & 232.5 & 347.6 & ND & ND \\
\hline Naphthalene & 457.5 & NA & 5471.3 & 3974.2 & 160.3 & 172.6 \\
\hline 2-Methy|naphthalene & 578.4 & NA & 907.5 & 1919.4 & 149.0 & 151.7 \\
\hline Acenaphthylene & 4.2 & NA & ND & 36.4 & 16.8 & 25.3 \\
\hline Acenaphthene & 621.9 & NA & 543.8 & 865.5 & 359.1 & 343.6 \\
\hline Dibenzofuran & 385.2 & NA & 627.5 & 937.4 & 409.6 & 403.0 \\
\hline Fluorene & 358.3 & NA & 151.3 & 464.5 & 137.2 & 133.9 \\
\hline Phenanthrene & 745.4 & NA & 1078.8 & 1426.8 & 975.7 & 912.9 \\
\hline Anthracene & 136.8 & NA & 206.3 & 275.4 & 15.0 & 16.6 \\
\hline Fluoranthene & 337.0 & NA & 145.0 & 424.4 & 366.6 & 379.2 \\
\hline Pyrene & 310.4 & NA & 111.3 & 348.0 & 293.0 & 286.8 \\
\hline Chrysene & 69.5 & NA & ND & 30.0 & 41.2 & 40.2 \\
\hline Benzo[b]fluoranthene & 14.2 & $\mathrm{NA}$ & ND & 11.9 & 3.9 & 4.0 \\
\hline Benzo[k]fluoranthene & 18.1 & NA & ND & 9.0 & 4.6 & 4.1 \\
\hline Benzo[a]pyrene & 16.7 & NA & ND & 5.7 & 2.8 & 2.4 \\
\hline Indeno[1,2,3-cd]pyrene & ND & NA & ND & ND & ND & ND \\
\hline Dibenz[ah]anthracene & ND & NA & ND & ND & ND & ND \\
\hline Benzo[ghi]perylene & ND & NA & ND & ND & ND & ND \\
\hline 2,3,5,6-Tetrachlorophenol & ND & NA & 48.8 & 141.9 & 75.0 & 65.7 \\
\hline 2,3,4,5-Tetrachlorophenol & ND & NA & ND & ND & ND & ND \\
\hline 2,3,4,6-Tetrachlorophenol & ND & NA & 92.5 & 160.4 & 11.9 & 10.8 \\
\hline Pentachlorophenol & 18.3 & NA & 2111.3 & 3388.4 & 576.8 & 575.7 \\
\hline Total Oxygenates $(\mu g / L)$ & 33 & - & 69 & 514 & 172 & 186 \\
\hline Total PAH $(\mu \mathrm{g} / L)$ & 4229 & - & 9475 & 11149 & 2935 & 2876 \\
\hline Total Cl-Phenols $(\mu \mathrm{g} / \mathrm{L})$ & 18 & - & 2253 & 3691 & 664 & 652 \\
\hline Total GC-MS $(\mu \mathrm{g} / \mathrm{L})$ & 4281 & - & 11796 & 15354 & 3771 & 3715 \\
\hline$\%$ Oxygenates & 0.8 & - & 0.6 & 3.3 & 4.6 & 5.0 \\
\hline
\end{tabular}


Table 6. Results of groundwater chemical analyses for Wells MW-41, MW-44, EW-1, EW-2, EW-3 and EW-5

\begin{tabular}{|c|c|c|c|c|c|c|c|c|c|c|}
\hline Sample Name & $\begin{array}{c}M W-41 \\
(5 / 6 \\
1540)\end{array}$ & $\begin{array}{c}M W-41 \\
(6 / 18 \\
1100)\end{array}$ & $\begin{array}{c}M-41 \\
(7 / 16 \\
1820)\end{array}$ & $\begin{array}{c}W-44 \\
(7 / 17 \\
0910)\end{array}$ & $\begin{array}{c}E W-1 \\
(5 / 8 \\
1000)\end{array}$ & $\begin{array}{l}E W-1 \\
(6 / 16 \\
1630)\end{array}$ & $\begin{array}{l}E W-2 \\
(6 / 19 \\
1240)\end{array}$ & $\begin{array}{c}E W-3 \\
(5 / 6 \\
1515)\end{array}$ & $\begin{array}{l}E W-3 \\
(6 / 16 \\
1530)\end{array}$ & $\begin{array}{l}E W-5 \\
(7 / 17 \\
1020)\end{array}$ \\
\hline Date/Time Sampled & $\begin{array}{l}5 / 6 / 97 \\
15: 40\end{array}$ & $\begin{array}{c}6 / 18 / 97 \\
11: 00\end{array}$ & $\begin{array}{c}7 / 16 / 97 \\
18: 20\end{array}$ & $\begin{array}{c}7 / 17 / 97 \\
9: 10\end{array}$ & $\begin{array}{l}5 / 8 / 97 \\
10: 00 \\
\end{array}$ & $\begin{array}{c}6 / 16 / 97 \\
16: 30\end{array}$ & $\begin{array}{c}6 / 19 / 97 \\
12: 40\end{array}$ & $\begin{array}{l}5 / 6 / 97 \\
15: 15\end{array}$ & $\begin{array}{c}6 / 16 / 97 \\
15: 30\end{array}$ & $\begin{array}{c}7 / 17 / 97 \\
10: 20\end{array}$ \\
\hline $\mathrm{pH}$ & 6.9 & 7.1 & 6.5 & 6.9 & 6.9 & 7.0 & 7.0 & 6.9 & 7.0 & 7.3 \\
\hline $\operatorname{TIC}(\mu \mathrm{g} C / g)$ & 44.7 & 45.9 & 72.8 & 66.7 & 56.8 & 50.5 & 66.0 & 47.8 & 43.9 & 35.5 \\
\hline \multicolumn{11}{|l|}{ Cations $(\mu g / g)$} \\
\hline Al & ND & NA & NA & NA & ND & NA & NA & ND & NA & NA \\
\hline$B$ & ND & NA & NA & NA & ND & NA & NA & ND & NA & NA \\
\hline $\mathrm{Ca}$ & 57.87 & NA & NA & NA & 79.90 & NA & NA & 62.61 & NA & NA \\
\hline $\mathrm{Cr}$ & ND & NA & NA & NA & ND & NA & NA & ND & NA & NA \\
\hline $\mathrm{Cu}$ & ND & NA & NA & NA & 0.02 & NA & NA & 0.02 & NA & NA \\
\hline $\mathrm{Fe}$ & ND & NA & NA & NA & 0.61 & NA & NA & 0.02 & NA & NA \\
\hline K & 1.11 & NA & NA & NA & 1.80 & NA & NA & 2.04 & NA & NA \\
\hline $\mathrm{Mg}$ & 10.80 & NA & NA & NA & 14.60 & NA & NA & 10.91 & NA & NA \\
\hline $\mathrm{Mn}$ & ND & NA & NA & NA & 0.21 & NA & NA & 0.03 & NA & NA \\
\hline $\mathrm{Na}$ & 17.17 & NA & NA & NA & 19.10 & NA & NA & 17.30 & NA & NA \\
\hline$s$ & 1.23 & NA & NA & NA & 11.40 & NA & NA & 1.32 & NA & NA \\
\hline Si & 17.20 & NA & NA & NA & 14.00 & NA & NA & 15.17 & NA & NA \\
\hline $\mathrm{Sr}$ & 0.02 & NA & NA & NA & 0.59 & NA & NA & 0.03 & NA & NA \\
\hline$\underline{Z n}$ & ND & NA & NA & NA & 0.08 & NA & NA & 0.03 & NA & NA \\
\hline \multicolumn{11}{|l|}{ Anions $(\mu g / g)$} \\
\hline Fluoride & ND & NA & ND & ND & ND & NA & NA & ND & NA & ND \\
\hline Chloride & 10.5 & NA & 19.7 & 22.2 & 17.4 & NA & NA & 11.1 & NA & 7.9 \\
\hline Nitrite & ND & NA & ND & ND & ND & NA & NA & ND & NA & ND \\
\hline Bromide & ND & NA & ND & ND & ND & NA & NA & ND & NA & ND \\
\hline Nitrate & 22.8 & NA & 23.8 & 35.5 & 32.5 & NA & NA & 13.6 & NA & 17.2 \\
\hline Phosphate & ND & NA & ND & ND & ND & NA. & NA & ND & NA & ND \\
\hline Sulfate & 21.2 & NA & $45.4 \quad 1$ & 38.8 & 34.4 & NA & NA & 21.0 & NA & 13.9 \\
\hline \multicolumn{11}{|c|}{ Semivolatile Organics ( $\mu \mathrm{g} / \mathrm{L})$} \\
\hline Phenol & ND & 1.6 & 1.0 & ND & ND & ND & 1.0 & ND & ND & ND \\
\hline 2-Methylphenol & ND & ND & ND & ND & ND & ND & ND & ND & ND & ND \\
\hline 3- and 4-Methylphenol & ND & ND & ND & ND & ND & ND & ND & ND & ND & ND \\
\hline 2,4-Dimethylphenol & ND & ND & ND & ND & ND & ND & ND & ND & ND & ND \\
\hline Benzoic acid & ND & ND & ND & ND & ND & ND & ND & ND & ND & ND \\
\hline Fluorenone & ND & 3.7 & 3.4 & ND & 1.7 & 9.4 & 57.6 & 2.1 & 30.4 & 1.8 \\
\hline Anthrone & ND & ND & ND & ND & ND & ND & 2.6 & ND & ND & ND \\
\hline 9,10-Anthracenedione & ND & ND & 1.1 & ND & ND & ND & 6.6 & ND & 4.0 & ND \\
\hline 7,8-Benzoquinoline & ND & ND & ND & ND & ND & ND & 3.3 & ND & ND & ND \\
\hline
\end{tabular}




\begin{tabular}{|c|c|c|c|c|c|c|c|c|c|c|}
\hline Carbazole & ND & ND & ND & ND & 6.1 & 28.9 & 42.4 & 20.2 & 29.1 & 0.9 \\
\hline Naphthalene & ND & 1.8 & 1.2 & ND & ND & 0.7 & 203.4 & ND & 12.5 & ND \\
\hline 2-Methylnaphthalene & ND & 2.1 & 2.5 & 0.5 & 22.2 & 2.9 & 287.8 & 6.4 & 23.7 & ND \\
\hline Acenaphthylene & ND & ND & ND & ND & 2.3 & 0.0 & 6.9 & 3.4 & 1.2 & ND \\
\hline Acenaphthene & ND & ND & 1.0 & 0.1 & 36.2 & 33.4 & 96.8 & 42.0 & 35.0 & 7.1 \\
\hline Dibenzofuran & ND & 1.6 & 1.6 & 0.4 & 37.1 & 12.1 & 222.8 & 36.5 & 39.2 & 5.9 \\
\hline Fluorene & ND & 0.1 & 0.9 & ND & 7.7 & 1.8 & 27.7 & 15.3 & 19.9 & 1.2 \\
\hline Phenanthrene & ND & 6.8 & 2.5 & 1.7 & 7.0 & 5.9 & 183.2 & 35.7 & 106.2 & 0.5 \\
\hline Anthracene & ND & 0.6 & 0.8 & 1.0 & 3.7 & 2.9 & 17.3 & 5.6 & 16.0 & 1.1 \\
\hline Fluoranthene & ND & 1.4 & 1.0 & 1.1 & 7.2 & 17.7 & 23.9 & 6.6 & 28.4 & 3.1 \\
\hline Pyrene & ND & 1.1 & 0.2 & 0.2 & 5.1 & 11.8 & 13.3 & 5.1 & 17.0 & 1.6 \\
\hline Chrysene & ND & ND & ND & ND & ND & 0.5 & ND & ND & 1.3 & ND \\
\hline Benzo[b]fluoranthene & ND & ND & ND & ND & ND & 0.2 & ND & ND & ND & ND \\
\hline Benzo[k]fluoranthene & ND & ND & ND & ND & ND & 0.3 & ND & ND & ND & ND \\
\hline Benzo[a]pyrene & ND & ND & ND & ND & ND & 0.3 & ND & ND & 0.3 & ND \\
\hline Indeno[1,2,3-cd]pyrene & ND & ND & ND & ND & ND & ND & ND & ND & ND & ND \\
\hline Dibenz[ah]anthracene & ND & ND & ND & ND & ND & ND & ND & ND & ND & ND \\
\hline Benzo[ghi]perylene & ND & ND & ND & ND & ND & ND & ND & ND & ND & ND \\
\hline 2,3,5,6-Tetrachlorophenol & ND & ND & 1.9 & ND & ND & ND & 2.0 & ND & 0.9 & ND \\
\hline 2,3,4,5-Tetrachlorophenol & ND & ND & ND & ND & ND & ND & ND & ND & ND & ND \\
\hline 2,3,4,6-Tetrachlorophenol & ND & ND & 2.0 & ND & ND & ND & 3.4 & ND & 0.8 & ND \\
\hline Pentachlorophenol & ND & 2.0 & 19.3 & ND & ND & 11.4 & 134.0 & ND & 21.0 & 4.5 \\
\hline Total Oxygenates $(\mu \mathrm{g} / \mathrm{L})$ & 0.0 & 5.4 & 5.5 & 0.0 & 1.7 & 9.4 & 67.7 & 2.1 & 34.4 & 1.8 \\
\hline Total PAH $(\mu \mathrm{g} / \mathrm{L})$ & 0.0 & 14.0 & 10.1 & 4.6 & 91.5 & 78.3 & 860.1 & 120.2 & 261.5 & 14.6 \\
\hline Total Ci-Phenols $(\mu \mathrm{g} / \mathrm{L})$ & 0.0 & 2.0 & 23.2 & 0.0 & 0.0 & 11.4 & 139.4 & 0.0 & 22.6 & 4.5 \\
\hline Total GC-MS $(\mu \mathrm{g} / \mathrm{L})$ & 0.0 & 23.0 & 40.4 & 5.0 & 136.3 & 140.1 & 1335.5 & 179.0 & 386.9 & 27.7 \\
\hline$\%$ Oxygenates & 0.0 & 23.3 & 13.6 & 0.0 & 1.2 & 6.7 & 5.1 & 1.2 & 8.9 & 6.4 \\
\hline
\end{tabular}


Table 7. Results of groundwater chemical analyses for Well S-4

\begin{tabular}{|c|c|c|c|}
\hline Sample Name & $\begin{array}{c}S-4(5 / 23 \\
1330)\end{array}$ & $\begin{array}{c}S-4(6 / 20 \\
1100)\end{array}$ & $\begin{array}{c}S-4(6 / 20 \\
1300)\end{array}$ \\
\hline Date/Time Sampled & $\begin{array}{c}5 / 23 / 97 \\
13: 30\end{array}$ & $\begin{array}{c}6 / 20 / 97 \\
11: 00\end{array}$ & $\begin{array}{c}6 / 20 / 97 \\
13: 00\end{array}$ \\
\hline$\overline{\mathrm{pH}}$ & NA & 4.6 & NA \\
\hline $\mathrm{TIC}(\mu \mathrm{g} \mathrm{C} / \mathrm{g})$ & NA & 75.9 & NA \\
\hline \multicolumn{4}{|l|}{ Cations $(\mu g / g)$} \\
\hline Al & NA & NA & NA \\
\hline$B$ & NA & NA & NA \\
\hline $\mathrm{Ca}$ & NA & NA & NA \\
\hline $\mathrm{Cr}$ & NA & NA & NA \\
\hline $\mathrm{Cu}$ & NA & NA & NA \\
\hline $\mathrm{Fe}$ & NA & NA & NA \\
\hline K & NA & NA & NA \\
\hline $\mathrm{Mg}$ & NA & NA & NA \\
\hline $\mathrm{Mn}$ & NA & NA & NA \\
\hline $\mathrm{Na}$ & NA & NA & NA \\
\hline S & NA & NA & NA \\
\hline Si & NA & NA & NA \\
\hline $\mathrm{Sr}$ & NA & NA & NA \\
\hline $\mathrm{Zn}$ & NA & NA & NA \\
\hline \multicolumn{4}{|l|}{ Anions $(\mu \mathrm{g} / \mathbf{g})$} \\
\hline Fluoride & NA & NA & NA \\
\hline Chloride & NA & NA & NA \\
\hline Nitrite & NA & NA & NA \\
\hline Bromide & NA & NA & NA \\
\hline Nitrate & NA & NA & NA \\
\hline Phosphate & NA & NA & NA \\
\hline Sulfate & NA & NA & NA \\
\hline \multicolumn{4}{|c|}{ Semivolatile Organics ( $\mu \mathrm{g} / \mathrm{L})$} \\
\hline Phenol & 2.4 & NA & 1.5 \\
\hline 2-Methylphenol & ND & NA & ND \\
\hline 3- and 4-Methylphenol & ND & NA & ND \\
\hline 2,4-Dimethylphenol & ND & NA & ND \\
\hline Benzoic acid & ND & NA & ND \\
\hline Fluorenone & ND & NA & ND \\
\hline Anthrone & ND & NA & ND \\
\hline
\end{tabular}

\begin{tabular}{|c|c|c|c|}
\hline Sample Name & $\begin{array}{c}S-4(5 / 23 \\
1330)\end{array}$ & $\begin{array}{c}S-4(6 / 20 \\
1100)\end{array}$ & $\begin{array}{c}S-4(6 / 20 \\
1300)\end{array}$ \\
\hline Date/Time Sampled & $\begin{array}{c}5 / 23 / 97 \\
13: 30 \\
\end{array}$ & $\begin{array}{c}6 / 20 / 97 \\
11: 00\end{array}$ & $\begin{array}{c}6 / 20 / 97 \\
13: 00\end{array}$ \\
\hline 9,10-Anthracenedione & ND & NA & ND \\
\hline 7,8-Benzoquinoline & ND & NA & ND \\
\hline Carbazole & ND & NA & ND \\
\hline Naphthalene & ND & NA & 6.9 \\
\hline 2-Methylnaphthalene & ND & NA & 1.4 \\
\hline Acenaphthylene & ND & NA & 0.6 \\
\hline Acenaphthene & ND & NA & ND \\
\hline Dibenzofuran & ND & NA & ND \\
\hline Fluorene & ND & NA & 3.0 \\
\hline Phenanthrene & 10.5 & NA & 88.6 \\
\hline Anthracene & 1.4 & NA & 9.9 \\
\hline Fluoranthene & ND & NA & 11.1 \\
\hline Pyrene & ND & NA & 22.5 \\
\hline Chrysene & ND & NA & 1.3 \\
\hline Benzo[b]fluoranthene & ND & NA & 0.7 \\
\hline Benzo[k]fluoranthene & ND & NA & 0.7 \\
\hline Benzo[a]pyrene & ND & NA & 0.7 \\
\hline Indeno[1,2,3-cd]pyrene & ND & NA & ND \\
\hline Dibenz[ah]anthracene & ND & NA & ND \\
\hline Benzo[ghi]perylene & ND & NA & ND \\
\hline 2,3,5,6-Tetrachlorophenol & ND & NA & ND \\
\hline 2,3,4,5-Tetrachlorophenol & ND & NA & ND \\
\hline 2,3,4,6-Tetrachlorophenol & ND & NA & ND \\
\hline Pentachlorophenol & ND & NA & ND \\
\hline Total Oxygenates $(\mu \mathrm{g} / \mathrm{L})$ & 2 & - & 1 \\
\hline Total PAH $(\mu \mathrm{g} / \mathrm{L})$ & 12 & - & 148 \\
\hline Total CI-Phenols $(\mu \mathrm{g} / L)$ & 0 & - & 0 \\
\hline Total GC-MS $(\mu \mathrm{g} / \mathrm{L})$ & 14 & - & 149 \\
\hline$\%$ Oxygenates & 17.0 & - & 1.0 \\
\hline
\end{tabular}


Table 8. Results of chemical analyses for miscellaneous water samples

\begin{tabular}{|c|c|c|c|c|c|c|c|}
\hline Sample Name & $\begin{array}{l}\text { S-13 } \\
\text { Cond. } \\
(6 / 20)\end{array}$ & $\begin{array}{l}\text { S-13 } \\
\text { Vapor } \\
(6 / 30)\end{array}$ & $\begin{array}{l}\text { S-13 } \\
\text { Vapor } \\
(6 / 30)\end{array}$ & $\begin{array}{c}\text { S-13 } \\
\text { Vapor } \\
\text { (6/30) }\end{array}$ & $\begin{array}{l}\text { Steam } \\
\text { Water } \\
(6 / 30)\end{array}$ & $\begin{array}{l}\text { Treat. } \\
\text { Fac. } \\
(6 / 30)\end{array}$ & $\begin{array}{l}\text { Top of } \\
\text { Sep. } \\
(6 / 30)\end{array}$ \\
\hline Date/Time Sampled & $\begin{array}{c}6 / 20 / 97 \\
13: 15\end{array}$ & $\begin{array}{c}6 / 30 / 97 \\
13: 15\end{array}$ & $\begin{array}{c}6 / 30 / 97 \\
13: 15\end{array}$ & $\begin{array}{c}6 / 30 / 97 \\
14: 20\end{array}$ & $\begin{array}{c}6 / 30 / 97 \\
17: 45\end{array}$ & $\begin{array}{c}6 / 30 / 97 \\
17: 15\end{array}$ & $6 / 30 / 97$ \\
\hline$\overline{\mathrm{pH}}$ & NA & NA & 4.4 & 4.4 & 7.0 & 7.0 & NA \\
\hline $\operatorname{TIC}(\mu \mathrm{g} \mathrm{C} / \mathrm{g})$ & NA & NA & 135.2 & 140.1 & 42.6 & 44.2 & NA \\
\hline \multicolumn{8}{|l|}{ Cations $(\mu g / g)$} \\
\hline Al & NA & NA & NA & NA & ND & ND & NA \\
\hline B & NA & NA & NA & NA & ND & ND & NA \\
\hline $\mathrm{Ca}$ & NA & NA & NA & NA & 0.07 & 63.80 & NA \\
\hline $\mathrm{Cr}$ & NA & NA & NA & NA & ND & ND & NA \\
\hline $\mathrm{Cu}$ & NA & NA & NA & NA & 0.02 & 0.03 & NA \\
\hline $\mathrm{Fe}$ & NA & NA & NA & NA & 0.02 & 0.03 & NA \\
\hline K & NA & NA & NA & NA & 1.78 & 2.98 & NA \\
\hline $\mathrm{Mg}$ & NA & NA & NA & NA & ND & 9.70 & NA \\
\hline $\mathrm{Mn}$ & NA & NA & NA & NA & ND & 0.02 & NA \\
\hline $\mathrm{Na}$ & NA & NA & NA & NA & 126.11 & 31.64 & NA \\
\hline s & NA & NA & NA & NA & 3.37 & 2.75 & NA \\
\hline $\mathrm{Si}$ & NA & NA & NA & NA & 25.31 & 26.94 & NA \\
\hline $\mathrm{Sr}$ & NA & NA & NA & NA & ND & 0.03 & NA \\
\hline $\mathrm{Zn}$ & NA & NA & NA & NA & 0.02 & 0.02 & NA \\
\hline \multicolumn{8}{|l|}{ Anions $(\mu g / g)$} \\
\hline Fluoride & NA & NA & ND & NA & ND & ND & NA \\
\hline Chloride & NA & NA & 5.2 & NA & 22.8 & 25.0 & NA \\
\hline Nitrite & NA & NA & ND & NA & ND & ND & NA \\
\hline Bromide & NA & NA & ND & NA & ND & ND & NA \\
\hline Nitrate & NA & NA & ND & NA & 14.3 & ND & NA \\
\hline Phosphate & NA & NA & ND & NA & ND & ND & NA \\
\hline Sulfate & NA & NA & ND & NA & 179.6 & 57.0 & NA \\
\hline \multicolumn{8}{|c|}{ Semivolatile Organics $(\mu g / L)$} \\
\hline Phenol & ND & ND & ND & NA & NA & 18 & ND \\
\hline 2-Methylphenol & ND & ND & ND & NA & NA & ND & ND \\
\hline 3- and 4-Methylphenol & ND & ND & ND & NA & NA & ND & ND \\
\hline 2,4-Dimethylphenol & ND & ND & ND & NA & NA & ND & ND \\
\hline Benzoic acid & ND & ND & ND & NA & NA & ND & ND \\
\hline Fluorenone & ND & 69 & 125 & NA & NA & 183 & 667 \\
\hline Anthrone & ND & ND & ND & NA & NA & ND & ND \\
\hline
\end{tabular}

\begin{tabular}{|c|c|c|c|c|c|c|c|}
\hline Sample Name & $\begin{array}{l}\text { S-13 } \\
\text { Cond. } \\
(6 / 20)\end{array}$ & $\begin{array}{l}\text { S-13 } \\
\text { Vapor } \\
(6 / 30)\end{array}$ & $\begin{array}{l}\text { S-13 } \\
\text { Vapor } \\
(6 / 30)\end{array}$ & $\begin{array}{c}\text { S-13 } \\
\text { Vapor } \\
(6 / 30)\end{array}$ & $\begin{array}{l}\text { Steam } \\
\text { Water } \\
\text { (6/30) }\end{array}$ & $\begin{array}{l}\text { Treat. } \\
\text { Fac. } \\
(6 / 30)\end{array}$ & $\begin{array}{l}\text { Top of } \\
\text { Sep. } \\
(6 / 30)\end{array}$ \\
\hline Date/Time Sampled & $\begin{array}{c}6 / 20 / 97 \\
13: 15 \\
\end{array}$ & $\begin{array}{c}6 / 30 / 97 \\
13: 15 \\
\end{array}$ & $\begin{array}{c}6 / 30 / 97 \\
13: 15 \\
\end{array}$ & $\begin{array}{c}6 / 30 / 97 \\
14: 20 \\
\end{array}$ & $\begin{array}{c}6 / 30 / 97 \\
17: 45 \\
\end{array}$ & $\begin{array}{c}6 / 30 / 97 \\
17: 15 \\
\end{array}$ & $6 / 30 / 97$ \\
\hline $9,10-$ Anthracenedione & ND & ND & ND & NA & NA & ND & 163 \\
\hline 7,8-Benzoquinoline & ND & ND & ND & NA & NA & ND & 170 \\
\hline Carbazole & ND & ND & ND & NA & NA & 166 & 451 \\
\hline Naphthalene & ND & 46 & 11 & NA & NA & 4188 & 13503 \\
\hline 2-Methylnaphthalene & ND & ND & 4 & NA & NA & 19119 & 50787 \\
\hline Acenaphthylene & ND & 34 & 36 & NA & NA & 45 & 166 \\
\hline Acenaphthene & 3332 & ND & 18 & NA & NA & 1955 & 7717 \\
\hline Dibenzofuran & 3358 & ND & 26 & NA & NA & 1758 & 6658 \\
\hline Fluorene & 2544 & 34 & 27 & NA & NA & 1241 & 4843 \\
\hline Phenanthrene & 19281 & 9281 & 5446 & NA & NA & 5077 & 17438 \\
\hline Anthracene & 2925 & 3189 & 1517 & NA & NA & 1039 & 4525 \\
\hline Fluoranthene & 1730 & 8868 & 4700 & NA & NA & 1640 & 6483 \\
\hline Pyrene & 1628 & 7158 & 3658 & NA & NA & 1153 & 4672 \\
\hline Chrysene & ND & 115 & 32 & NA & NA & ND & 64 \\
\hline Benzo[b]fluoranthene & ND & ND & ND & NA & NA & ND & ND \\
\hline Benzo[k]fluoranthene & ND & ND & ND & NA & NA & ND & ND \\
\hline Benzolaipyrene & ND & ND & ND & NA & NA & ND & 1 \\
\hline Indeno[1,2,3-cd]pyrene & ND & ND & ND & NA & NA & ND & ND \\
\hline Dibenz[ah]anthracene & ND & ND & ND & NA & NA & ND & ND \\
\hline Benzo[ghi]perylene & ND & ND & ND & NA & NA & ND & ND \\
\hline 2,3,5,6-Tetrachlorophenol & ND & ND & ND & NA & NA & 12 & ND \\
\hline $2,3,4,5$-Tetrachlorophenol & ND & ND & ND & NA & NA & ND & ND \\
\hline 2,3,4,6-Tetrachlorophenol & ND & ND & ND & NA & NA & 20 & ND \\
\hline Pentachlorophenol & ND & ND & ND & NA & NA & 612 & ND \\
\hline Total Oxygenates $(\mu g / L)$ & 0 & 69 & 125 & - & - & 201 & 830 \\
\hline Total PAH $(\mu \mathbf{g} / \mathbf{L})$ & 34797 & 28725 & 15475 & - & - & 37381 & 117479 \\
\hline Total Cl-Phenols $(\mu \mathrm{g} / \mathrm{L})$ & 0 & 0 & 0 & - & - & 644 & 0 \\
\hline Total GC-MS $(\mu \mathrm{g} / \mathrm{L})$ & 34797 & 28794 & 15601 & - & - & 38226 & 118309 \\
\hline$\%$ Oxygenates & 0.0 & 0.2 & 0.8 & - & - & 0.5 & 0.7 \\
\hline
\end{tabular}


Table 9. Results of chemical analyses (semivolatile organics, $\mu \mathrm{g} / \mathrm{g}$ ) for miscellaneous free product samples

\begin{tabular}{|c|c|c|c|c|c|c|c|c|c|c|c|c|c|c|c|}
\hline Sample Name & $\begin{array}{c}\text { BYS } \\
\text { (Filtered) }\end{array}$ & $\begin{array}{c}\text { Gravity } \\
\text { Separator }\end{array}$ & DAFT & $\begin{array}{c}\text { Grav. Sep. } \\
\text { (Sludge) }\end{array}$ & $\begin{array}{c}\text { S-13- } \\
\text { Crystals }\end{array}$ & $\begin{array}{c}\text { S-13- } \\
\text { Crystals }\end{array}$ & DAFT & $\overline{\text { DAFT }}$ & $\begin{array}{c}\text { S-12 } \\
\text { Scale }\end{array}$ & $\begin{array}{c}\text { S-13 } \\
\text { Scale } \\
\text { (High) }\end{array}$ & $\begin{array}{c}\text { S-13 } \\
\text { Scale } \\
\text { (Low) }\end{array}$ & $\begin{array}{l}\text { S-15 } \\
\text { Scale }\end{array}$ & $\begin{array}{l}\text { EW-2 } \\
\text { Scale }\end{array}$ & $\begin{array}{c}\text { Tank \#2 } \\
\text { (Top) }\end{array}$ & $\begin{array}{c}\text { Tank \#2 } \\
\text { (Bottom - } \\
\text { Emuision) }\end{array}$ \\
\hline Date Sampled & & $6 / 19 / 97$ & $6 / 19 / 97$ & $6 / 19 / 97$ & $6 / 30 / 97$ & $6 / 30 / 97$ & $7 / 16 / 97$ & $7 / 15-7 / 16$ & $10 / 17 / 97$ & $10 / 17 / 97$ & $10 / 17 / 97$ & $10 / 17 / 97$ & $10 / 17 / 97$ & $10 / 26 / 97$ & $10 / 26 / 97$ \\
\hline Phenol & ND & ND & ND & ND & ND & ND & ND & ND & ND & ND & ND & ND & ND & ND & ND \\
\hline 2-Methylphenol & ND & ND & ND & ND & ND & ND & ND & ND & ND & ND & ND & ND & ND & ND & ND \\
\hline 3- and 4-Methylphenol & ND & ND & ND & ND & ND & ND & ND & ND & ND & ND & ND & ND & ND & ND & ND \\
\hline 2,4-Dimethylphenol & ND & ND & ND & ND & ND & ND & ND & ND & ND & ND & ND & ND & ND & ND & ND \\
\hline Benzoic acid & ND & ND & ND & ND & ND & ND & ND & ND & ND & ND & ND & ND & ND & ND & ND \\
\hline Fluorenone & 804 & 586 & ND & ND & ND & ND & ND & ND & ND & ND & ND & ND & ND & ND & ND \\
\hline Anthrone & 115 & ND & ND & ND & 125 & ND & ND & ND & ND & ND & ND & ND & ND & ND & ND \\
\hline 9,10 -Anthracenedione & 105 & ND & ND & ND & 629 & ND & ND & ND & ND & ND & ND & ND & ND & ND & ND \\
\hline 7,8-Benzoquinoline & 891 & 374 & ND & ND & 214 & ND & ND & ND & ND & ND & ND & ND & ND & ND & ND \\
\hline Carbazole & 2271 & 727 & ND & ND & 244 & ND & ND & ND & ND & ND & ND & ND & ND & ND & ND \\
\hline Naphthalene & 23026 & 32768 & 667 & 3 & 4 & 79 & 22818 & 23051 & ND & ND & 82 & 3 & ND & 41500 & 17177 \\
\hline 2-Methylnaphthalene & 32501 & 56434 & 1879 & 5 & ND & ND & 95566 & 95859 & ND & ND & 267 & 21 & ND & 94280 & 63398 \\
\hline Acenaphthylene & 244 & 273 & ND & 3 & 6 & ND & ND & ND & ND & ND & ND & ND & ND & ND & 149 \\
\hline Acenaphthene & 24240 & 30303 & 3980 & 22 & ND & ND & 8556 & 8626 & ND & ND & 961 & 262 & ND & 10600 & 6391 \\
\hline Dibenzofuran & 15010 & 18586 & 2788 & 12 & 123 & ND & 7030 & 7010 & ND & ND & 728 & 228 & ND & 7520 & 5021 \\
\hline Fluorene & 17814 & 21848 & 3717 & 28 & 633 & 556 & 4848 & 4798 & ND & ND & 908 & 360 & ND & 5610 & 3574 \\
\hline Phenanthrene & 29097 & 56838 & 17505 & 234 & 32149 & 87143 & 12899 & 13232 & 10 & 3 & 8700 & 4616 & 3 & 14020 & 10490 \\
\hline Anthracene & 6875 & 12333 & 2576 & 93 & 44167 & 292857 & 3343 & 3455 & 4 & 2 & 3907 & 987 & 1 & 3750 & 2973 \\
\hline Fluoranthene & 20840 & 30737 & 10040 & 355 & 27149 & 40675 & 2475 & 2525 & 64 & 5 & 10603 & 5714 & 4 & 2080 & 1623 \\
\hline Pyrene & 21804 & 25061 & 8576 & 341 & 22038 & 32222 & 2091 & 2091 & 90 & 5 & 8880 & 4888 & 4 & 1530 & 1132 \\
\hline Chrysene & 6200 & 6253 & 1909 & 142 & 476 & 437 & ND & ND & 336 & 9 & 871 & 578 & 2 & ND & 94 \\
\hline Benzo[b]fluoranthene & 1638 & 2192 & 1313 & 58 & ND & ND & ND & ND & 25 & 3 & 70 & 92 & ND & ND & ND \\
\hline Benzo[k]fluoranthene & 1461 & 2030 & 1222 & 51 & ND & ND & ND & ND & 30 & 5 & 107 & 127 & ND & ND & ND \\
\hline Benzo[a]pyrene & 1675 & 2051 & ND & 63 & ND & ND & ND & ND & 7 & 2 & 73 & 79 & ND & ND & ND \\
\hline Indeno[1,2,3-cd]pyrene & 469 & ND & ND & 19 & ND & ND & ND & ND & 1 & ND & ND & ND & ND & ND & ND \\
\hline Dibenz[ah]anthracene & 263 & ND & ND & 51 & ND & ND & ND & ND & ND & ND & ND & ND & ND & ND & ND \\
\hline Benzo[ghi]perylene & 313 & ND & ND & 15 & ND & ND & ND & ND & ND & ND & ND & ND & ND & ND & ND \\
\hline 2,3,5,6-Tetrachlorophenol & ND & ND & ND & ND & ND & ND & ND & ND & ND & ND & ND & ND & ND & ND & ND \\
\hline 2,3,4,5-Tetrachlorophenol & ND & ND & ND & ND & ND & ND & ND & ND & ND & ND & ND & ND & ND & ND & ND \\
\hline 2,3,4,6-Tetrachlorophenol & ND & ND & ND & ND & ND & ND & ND & ND & ND & ND & ND & ND & ND & ND & ND \\
\hline Pentachlorophenol & 267 & ND & ND & ND & ND & ND & ND & ND & ND & ND & ND & ND & ND & ND & ND \\
\hline Total Oxygenates $(\mu \mathrm{g} / \mathrm{g})$ & 1024 & 586 & 0 & 0 & 754 & 0 & 0 & 0 & 0 & 0 & 0 & 0 & 0 & 0 & 0 \\
\hline Total PAH $(\mu \mathbf{g} / \mathbf{g})$ & 206632 & 298808 & 56172 & 1449 & 127202 & 453968 & 159626 & 160646 & 568 & 34 & 36156 & 17953 & 13 & 180890 & 112022 \\
\hline Total Cl-Phenols $(\mu \mathrm{g} / \mathrm{g})$ & 267 & 0 & 0 & 0 & 0 & 0 & 0 & 0 & 0 & 0 & 0 & 0 & 0 & 0 & 0 \\
\hline Total GC-MS & 207923 & 299394 & 56172 & 1449 & 127956 & 453968 & 159626 & 160646 & 568 & 34 & 36156 & 17953 & 13 & 180890 & 112022 \\
\hline$\%$ Oxygenates & 0 & 0 & 0 & 0 & 1 & 0 & 0 & 0 & 0 & 0 & 0 & 0 & 0 & 0 & 0 \\
\hline
\end{tabular}

